UNIVERSIDADE DE SÃO PAULO

FFCLRP - DEPARTAMENTO DE PSICOLOGIA E EDUCAÇÃO

PROGRAMA DE PÓS-GRADUAÇÃO DE PSICOLOGIA

\title{
Comparação da Escala CR10 de Borg com a Escala Analógica Visual (VAS) na avaliação da dor em pacientes com Disfunções Temporomandibulares
}

Adriana do Vale Ferreira Bacci

Dissertação apresentada à Faculdade de Filosofia, Ciências e Letras de Ribeirão Preto da USP, como parte das exigências para a obtenção do título de Mestre em Ciências. Área: Psicologia

Ribeirão Preto - SP

2004 
UNIVERSIDADE DE SÃO PAULO

FFCLRP - DEPARTAMENTO DE PSICOLOGIA E EDUCAÇÃO

PROGRAMA DE PÓS-GRADUAÇÃO DE PSICOLOGIA

\section{Comparação da Escala CR10 de Borg com a Escala Analógica Visual (VAS) na avaliação da dor em pacientes com Disfunções Temporomandibulares}

Adriana do Vale Ferreira Bacci

Orientador: Prof. Dr. Sérgio Sheiji Fukusima

Dissertação apresentada à Faculdade de Filosofia, Ciências e Letras de Ribeirão Preto da USP, como parte das exigências para a obtenção do título de Mestre em Ciências. Área: Psicologia

Ribeirão Preto - SP

2004 


\section{Ferreira - Bacci, Adriana do Vale}

Comparação da escala CR10 de Borg com a Escala Analógica Visual (VAS) na avaliação da dor em pacientes com Disfunções Temporomandibulares. Ribeirão Preto, 2004.

11 p. : il.; $30 \mathrm{~cm}$

Dissertação, apresentada à Faculdade de Filosofia, Ciências e Letras de Ribeirão Preto / USP - Dep. De Psicologia e Educação.

Orientador: Fukusima, Sérgio Sheiji

1. Dor. 2. Escala de Categorias e Razão (CR10). 3. Escala Analógica Visual (VAS) 
À Minha filha Giovana, quem dividiu comigo em meu ventre grande parte da elaboração desse trabalho. 


\section{AGRADECIMENTOS}

Ao meu marido, pelo companheirismo e grande incentivo;

Aos meus pais, pela força que me deram para enfrentar mais uma etapa de minha formação;

Ao Prof. Dr. Sérgio Sheiji Fukusima, pela orientação e desenvolvimento do verdadeiro espírito de pesquisadora;

Ao Prof, Dr Marcelo de Oliveira Mazzetto, pelas sugestões, correções e orientações;

Ao técnico de laboratório, Igor, pela sua boa vontade e disponibilidade em ajudar;

Aos colegas de laboratório, Ana Irene, Luciana e Nelson pelas precisas ajudas;

Ao amigo Murilo, pela solicitude;

Aos pacientes, pela confiança em compartilhar comigo sua "queixas" e suas "dores";

À FAPESP, pelo apoio financeiro. 


\section{ÍNDICE}

\section{INTRODUÇÃO}

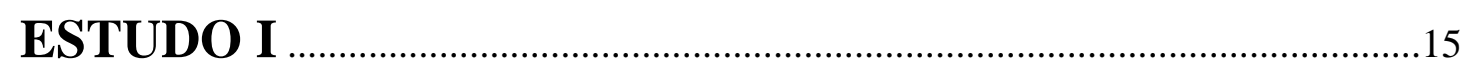

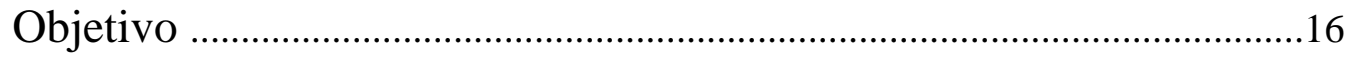

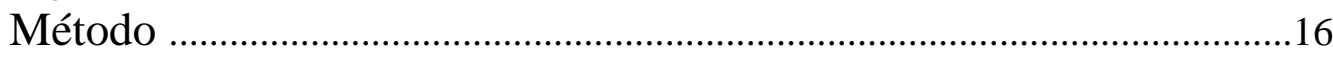

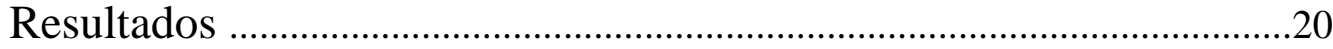

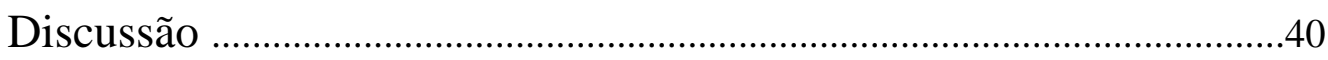

ESTUDO II.

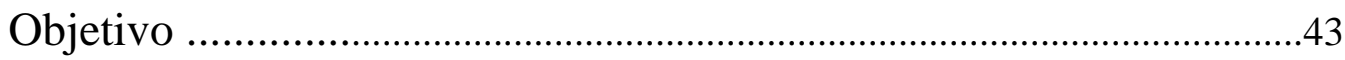

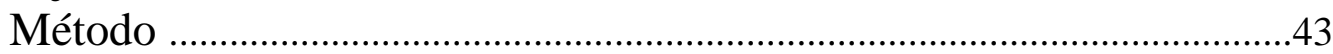

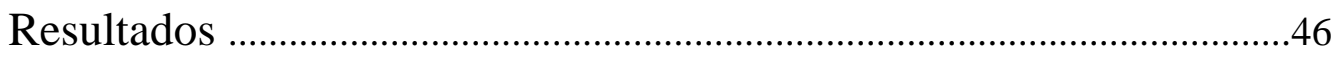

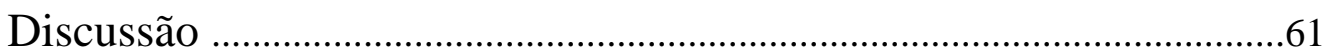

DISCUSSÃO GERAL …………………………………………………...64

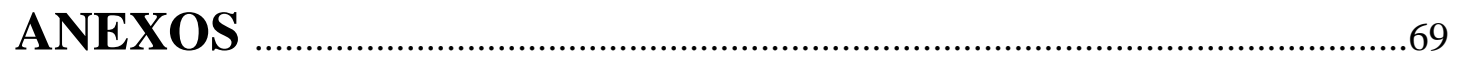

REFERÊNCIAS BIBLIOGÁFICAS.................................................105 
Ferreira-Bacci, A.V. Comparação da escala CR10 de Borg com a Escala Analógica Visual na avaliação da dor em pacientes com Disfunções Temporomandibulares. 2004. 111p. Dissertação de Mestrado. Faculdade de Filosofia, Ciências e Letras de Ribeirão Preto, Universidade de São Paulo, Ribeirão Preto.

\section{Resumo}

A Visual Analogue Scale (VAS) e a escala Category-Ratio (CR10) foram aplicadas para mensurar a dor em pacientes com Disfunções Temporomandibulares (DTMs) em dois estudos. No primeiro estudo, em 35 pacientes (Grupo I) foram aplicadas uma versão modificada da escala CR10 em português e a VAS para mensurar a dor espontânea, durante função orofacial e durante palpação antes e após tratamento odontológico. A modificação na CR10 consistiu em um desmembramento das categorias verbais e da escala numérica apresentadas cada uma delas em única coluna em mesma folha. Os coeficientes de correlação de Pearson entre as pontuações da VAS e da CR10 foram 0,85 antes do tratamento odontológico e 0,9 após o tratamento, indicando alta validade de critério. A associação entre os valores numéricos e as categorias verbais da Escala CR10 Modificada mostrou diferenças em relação ao que é proposto na escala original. As categorias: "Moderado", "Forte” e "Muito Forte” foram associadas a valores superiores aos originais. O segundo estudo foi planejado para investigar se essas discrepâncias nas associações das categorias com os seus valores numéricos eram replicáveis e verificar se não dependiam da forma de apresentação da escala CR10 modificada. Para isso, as escalas foram aplicadas para medir dor em duas novas amostras de pacientes com DTMs antes do tratamento odontológico. A CR10 com nova modificação e a VAS foram aplicadas à primeira amostra (Grupo II , n=23 pacientes). A 
modificação na CR10 consistiu na apresentação primeiro da escala numérica em uma coluna seguida pela apresentação das categorias verbais em três colunas. A CR10 original e a VAS foram aplicadas à segunda amostra (Grupo III, n=17 pacientes). Os coeficientes de correlação de Pearson foram 0,9 para o Grupo II e 0,8 para o Grupo III, indicando também alta validade de critério. Assim como no primeiro estudo, na escala CR10, as categorias verbais: "Moderado”, "Forte” e "Muito Forte” foram associadas na escala numérica a valores superiores aos propostos na escala original Em ambos estudos, a escala CR10 foi a mais bem avaliada pelos pacientes, segundo a facilidade de compreensão das instruções e a adequação para o registro da dor. Evidencia-se a necessidade de mais estudos para validar a escala CR10 para a língua portuguesa para determinar com precisão a associação das categorias verbais aos valores numéricos.

Palavras-chave: Dor, Escala de Categoria e Razão (CR10), Escala Analógica Visual (VAS) 
Ferreira-Bacci, A.V. Comparison of CR10 Borg's Scale with Visual Analogue Scale (VAS) to assess pain in patients with Temporomandibular Disorders. 2004. 111p. Academic Dissertation. Faculdade de Filosofia, Ciências e Letras de Ribeirão Preto, Universidade de São Paulo, Ribeirão Preto.

\begin{abstract}
Visual Analogue Scale (VAS) and Category-Ratio Scale (CR10) were applied to measure pain in patients with Temporomandibular Disorders (TMDs). In the first study, a modified version of CR10 translated to Portuguese and VAS were applied to measure spontaneous pain, functional pain and pain by touch after and before dentistry treatment in 35 patients (Group I). The CR10 modification consisted of presenting the verbal categories and the numerical scale in separated columns in a sheet. Coefficients of Pearson's correlation between VAS and CR10 scores were .85 and .90 respectively before and after treatment, indicating a high criterion validation. The association of numerical values and verbal categories of Modified CR10 scale were different from the original CR10. The verbal expressions “moderate”, "strong” and "very strong” were attached to higher values. In the second study we investigated if these discrepancies in attaching the verbal categories to the numerical scale were replicable and if they were not an artifact of the way of presenting the modified CR10 scale. To check these topics, the scales were applied to measure pain in two new samples of patients with TMD before dentistry treatment. A new modified version of the CR10 scale and the VAS were applied to the first sample (Group II, n=23 patients). This modification in CR10 scale consisted of presenting first the numerical scale in separate column, and then the verbal categories distributed in three columns. The original CR10 and VAS were applied to the
\end{abstract}


second sample (Group III, n=17 patients). Coefficients of Pearsons correlation between CR10 and VAS were .9 for Group II and .8 for Group III, indicating also high criterion validation. As indicated in the first study, some verbal categories were attached to the numerical scale at higher values than those ones in the original scale. In both studies,, most patients judged the CR10 easier to be understood and more adequate to measure pain than VAS. There is evidence of the necessity of more studies to validate CR10 to Portuguese to determine with precision the association of the verbal categories to the numeric values.

Key-words: Pain, Category Ratio Scale (CR10), Visual Analogue Scale (VAS). 


\section{Introdução}

Diversas definições têm sido empregadas para o conceito “dor”. Uma definição adequada é apontada pela Associação Internacional para o Estudo da Dor como “uma experiência sensória e emocional desagradável associada à lesão tecidual real ou potencial, ou descrita em termos dessa lesão”.

O reconhecimento do caráter emocional da dor implica na possibilidade de interpretações múltiplas oriundas da experiência pessoal e da cultura de cada indivíduo (BORG, 1998). Para Conti et al (2001) nem sempre é possível determinar o quanto a percepção de dor resulta de estímulo externo ou das emoções do sujeito, o que torna essa experiência um fenômeno puramente subjetivo. Essa subjetividade pode dificultar a comunicação e como conseqüência o estudo da dor. Entretanto, sendo uma experiência comum em seres humanos, faz-se necessário o uso de uma linguagem inteligível que facilite o diagnóstico e a despensa de cuidados com relação à dor (MOLINA, 1999; BORG, 1998; LE RESCHE ET AL, 1988 E MAGNUSSON et al, 1995).

Dentro desse contexto, a dor facial parece ter grande importância em vários estudos clínicos e científicos. (READING \& RAW, 1976; SEYMOUR et al, 1985; LE RESCHE et al, 1988; SOUZA, 1990; LE RESCHE et al, 1992; FELICIO \& MAZZETTO, 1994; WILSON et al, 1994; MAGNUSSON et al, 1995; KROGSTAD et al, 1996; KROGSTAD et al, 1998; GIL et al, 1998; RAUHALA et al, 1999).

Um elevado número de pessoas procura alívio da dor facial através de tratamentos especializados conforme demonstraram Felicio \& Mazzetto (1994), Magnusson et al (1995), Krogstad et al (1996), Rauhala et al (1999), Molina (1999) e 
Carniel (2001). Saber diagnosticar e tratar a dor corretamente torna-se então uma exigência para o profissional da saúde.

Para Harness et al (1990) apud Rauhala et al (1999) a dor facial pode ser dividida em dois grandes grupos: Grupo de dor miogênica facial (quando somente os músculos da face estão envolvidos) e Grupo de Desordem Temporomandibular (quando há o envolvimento também da Articulação Temporomandibular). Carniel (1997) e Rauhala et al (1999) mostraram que a maior parte dos pacientes está incluída nesse segundo grupo. Para esses pacientes, o tratamento odontológico conservador (aconselhamento, placa terapêutica oclusal e ajuste oclusal) tem-se mostrado eficaz na diminuição da dor.

As Disfunções Temporomandibulares (DTMs) ou Disfunções Craniomandibulares (DCMs) constituem uma alteração musculoesquelética de origem multifatorial que pode compreender tanto componentes miogênicos quanto artrálgicos (RAUHALA et al, 1999). Outras denominações, menos comuns, também podem ser atribuídas a essas alterações como Síndrome de Costen, Disfunção Mandibular, Síndrome da Dor e Disfunção Miofascial, Síndrome da Articulação Temporomandibular (SIQUEIRA \& TEIXEIRA, 2001). Essa diversidade conceitual reflete a complexidade dessa alteração.

Diversos sinais e sintomas fazem parte das DTMs: dores, ruídos, zumbidos e estalos localizados na Articulação Temporomandibular (LE RESCHE, et al, 1992; CARVALHO, 2000 e SIPILÄ, 2002); sensibilidade espontânea e avaliada pela palpação dos músculos da mastigação (LE RESCHE, et al, 1992; MOLINA, 1999; CARVALHO et al, 2000), da cabeça (CARNIEL, 1997; MOLINA, 1999; KAUKALA et al, 1999 e CARNIEL, 2001) e do pescoço (MOLINA, 1999). Os transtornos internos das 
Articulações Temporomandibulares (ATMs), como deslocamento de disco, e doenças degenerativas, como artralgias, osteoartrites e osteoartroses, também podem ser associados às DTMs (HENRIKSON \& NILNER, 2000).

Dentre os sintomas, a dor parece preponderar e, muitas vezes, com a intenção de aliviá-la o paciente procura por um tratamento especializado (SOUZA, 1990; FELICIO \& MAZZETTO, 1994, CARNIEL, 2001 e SIQUEIRA \& TEIXEIRA, 2001). No estudo de Souza (1990), os resultados mostraram que a dor facial, considerada presente quando confirmada subjetiva e objetivamente (através da pesquisa de reflexos álgicos como taquicardia e hipertensão arterial), prevaleceu em 95\% dos pacientes.

A dor nas DTMs, apesar de freqüente, muitas vezes, é negligenciada pelo paciente. Alguns deles desconhecem por completo o diagnóstico provável e como resultado buscam ajuda de profissionais não especializados nesse distúrbio antes de iniciarem o tratamento adequado (CARNIEL, 2001). A intermitência (KOPP, 1977) e a recorrência da sintomatologia (SIQUEIRA \& TEIXEIRA, 2001), o desenvolvimento gradual da dor (KROGSTAD et al, 1996) e o seu agravamento pela movimentação mandibular, incluindo a mastigação (FELICIO \& MAZZETTO, 1994), podem sugerir que o paciente busque ajuda profissional especializada quando o sintoma já é intenso e a disfunção já se encontra em fase avançada.

Com relação à prevalência, estudos mostram que as DTMs são mais freqüentes em mulheres e adultos com idade inferior a 45 anos. (LE RESCHE, 1997; HENRIKSON \& NILNER, 2000; SIQUEIRA \& TEIXEIRA, 2001 e SIPILÄ, 2002).

Os fatores etiológicos das DTMs, segundo Caldana e Silva (2001), podem ser divididos em anatômicos (dentes, músculos, ligamentos e ATM), psicológicos (estresse, 
depressão) e neuromusculares. Quanto às disfunções neuromusculares, destacam-se como possíveis desencadeadores de DTMs: a hiperatividade muscular causada por hábitos parafuncionais (como apertar ou ranger dentes, mascar chicletes e morder objetos) e os distúrbios oclusais (perda da dimensão vertical, prematuridade oclusal e desequilíbrios oclusais).

Egermark et al.(2001) salientam que muitos portadores de DTMs possuem hábitos parafuncionais como o ranger de dentes ou bruxismo. No entanto, os autores afirmam que nem sempre é possível determinar a partir da observação clínica se esses hábitos participam como desencadeadores ou perpetuadores das DTMs.

Para Siqueira e Teixeira (2001) os aspectos emocionais e comportamentais dos pacientes têm forte influência tanto no prognóstico quanto na condução do tratamento. Esses autores apontam também outros fatores contribuintes para o aparecimento das DTMs tais como as variações ambientais como a diminuição da temperatura e o aumento da umidade do ar.

Conhecendo os possíveis fatores desencadeadores de DTMs o diagnóstico é realizado, inicialmente, a partir da anamnese e de exames que incluem as medidas da capacidade de movimento mandibular e a palpação dos músculos mastigatórios e das ATMs (KOPP, 1977). Com relação a esse último critério Le Resche et al (1988) salientam que medidas de dor obtidas pela palpação podem ser consideradas mais objetivas do que relatos de dor espontânea.

A Associação Internacional para o Estudo da Dor inclui, como critério diagnóstico, uma elevação da resposta psicofisiológica ao estresse. 
Caldana e Silva (2001) explicam que as respostas fisiológicas desencadeadas ao estresse podem provocar alterações fisiológicas como um aumento da atividade muscular e vascular da região facial com o conseqüente aparecimento da sintomatologia.

Damante (1990) acredita que a anamnese constitua uma importante etapa para a formulação do diagnóstico e mais especificamente para a identificação da dor. Com relação a esse sintoma o autor salienta que a anamnese deve se concentrar em torno de quatro perguntas fundamentais: Onde dói? Como dói? Quando dói? Há quanto tempo dói?

Alguns músculos mastigatórios como: masseter, pterigoideo medial e pterigoideo lateral podem apresentar-se, nas DTMs, com elevação da sensibilidade espontânea e à palpação (RAUHALA et al, 1999; MOLINA, 1999 e CARVALHO et al, 2000). Kaye et al, (1979) apud Rauhala et al (1999) chegam a afirmar que a elevação da sensibilidade no pterigoideo lateral pode representar um sinal patognomônico de DTM.

Um estudo realizado por Svensson et al (2001), comparando o limiar para dor avaliada durante exame de palpação no músculo masséter e no músculo da tíbia, demonstrou que pacientes com DTMs apresentam limiares menores de dor quando comparados a um grupo controle. Esses autores concluem que as DTMs desencadeiam um aumento da sensibilidade a qualquer estímulo doloroso.

Métodos psicofísicos podem ser utilizados como instrumentos auxiliares para avaliação da dor. Dentre eles, os métodos escalares diretos parecem ter um grande valor pela facilidade de aplicação e pela grande popularidade tanto no meio científico quanto clínico. Estes métodos podem gerar medidas da dor em nível de categorias (nominal ou ordinal), intervalos, razões e em razões ancoradas verbalmente. (BORG \& BORG, 2001) 
A Escala Analógica Visual (Visual Analogue Scale - VAS) tem sido amplamente utilizada como um método psicofísico produtor de escalas intervalares. O uso na Odontologia para a avaliação de intensidades de dor situadas na região da cabeça e do pescoço é difundido entre os profissionais e pesquisadores (WILSON et al, 1994; SEYMOUR et al, 1985; LE RESCHE et al, 1988; LE RESCHE et al, 1992; MAGNUSSON et al, 1995; KROGSTAD et al, 1998; ARIMA \& SVENSSON, 1999).

A grande utilização desse instrumento pode estar relacionada à facilidade de aplicação, alta precisão (HUSKISSON, 1983; PRICE et al, 1983, SEYMOUR et al, 1985; HARMS-RINGDAHL et al, 1986) e alta sensibilidade inclusive a pequenas variações de dor (LE RESCHE et al, 1988).

A escala VAS constitui-se de uma linha, freqüentemente de $10 \mathrm{~cm}$ de comprimento e extremidades com categorias verbais ou âncoras identificando um mínimo e um máximo (Anexo D). Ao examinando é pedido que faça um registro, ao longo da linha, representativo da variável estimada (HUSKISSON, 1983; SEYMOUR et al, 1985; BORG, 1998). A esse registro, posteriormente, é atribuído pelo pesquisador ou profissional, um valor numérico através da utilização de uma régua milimetrada. A identificação de valores absolutos, conseqüentemente, não é possível.

Huskisson (1983) afirma que essa escala pode ser utilizada de forma confiável tanto para comparar a intensidade da dor na mesma pessoa, ao longo do tempo, quanto em grupos que receberam diferentes tratamentos.

Le Resche et al (1988) apontaram limitações na VAS com relação à sua utilização para a quantificação da sensibilidade à palpação no diagnóstico das DTMs. Para esses autores, a validade da escala fica condicionada à confiabilidade das medidas 
consideradas nos resultados de pesquisa. Assim na clínica, os profissionais devem estar cientes de que suas próprias interpretações podem diferir da de outros profissionais da mesma área.

Outras limitações na utilização da VAS também têm sido apontadas por alguns autores como: a interrupção das respostas em intensidades pré-determinadas (BORG, 1998), dificuldades na compreensão e aplicação dessa escala (HUSKISSON, 1983; HARMS-RINGDAHL et al, 1986 e CARLSSON, 1983) e restrição da apresentação à forma verbal (JENSEN et al, 1986). Chapman e Syrjala (1991) e Gracely e Naliboff (1996) apontam como desvantagem da VAS o fato de que uma ampla gama de experiências psicológicas são comprimidas em uma única linha o que faz com que os sujeitos distribuam seus julgamentos independentemente da magnitude dos mesmos. Os autores consideram que esses aspectos possam constituir fatores limitantes na escolha dessa escala.

Linton e Götestam (1983) comparando a VAS com uma escala verbal de seis pontos para o registro de dor crônica atual e antiga mostraram que há discrepâncias entre os dois tipos de dor e que essas discrepâncias são maiores na VAS. Segundo os autores, isso se deve ao fato de que as avaliações ficam mais sujeitas a fatores subjetivos devido à falta de âncoras verbais ao longo da escala. Como conseqüência a escala VAS apresenta-se mais susceptível a erros de julgamento do que uma escala ancorada em expressões verbais. Além disso, Linton e Melin (1982) mostraram que pacientes com dores crônicas não se lembram acuradamente dos níveis de dor já experimentados o que torna os julgamentos menos precisos independentemente da escala utilizada. 
Huskisson (1983), no entanto, acredita que essa escala continua sendo muito útil na avaliação de medidas de dor a despeito das limitações apontadas.

Price et al (1983) realizaram um estudo onde comparam intensidades de diferentes temperaturas aplicadas sobre a pele de voluntários saudáveis e pacientes com relatos de dor crônica. O estudo permitiu a validação da escala VAS como uma escala de razão tanto para medidas clínicas quanto experimentais de dor. Para esses autores, escalas de razão são importantes porque permitem comparações de diferentes níveis de dor entre diferentes grupos e diferentes intensidades para o mesmo sujeito.

Uma outra escala mais recente e muito utilizada para avaliações de dor é a escala CR10 (Category-Ratio Scale) de Borg (Anexo I). Constitui-se de uma escala de razão e de categorias pareadas entre si de forma que para cada categoria existe um valor num contínuo numérico ( 0 - absolutamente nada; 0,5 - extremamente fraco; 1 - muito fraco; 2 - fraco; 3 - moderado; 5 - forte; 7 - muito forte e 10 extremamente forte). $O$ final da escala é deixado aberto e marcado apenas por um ponto, permitindo com isso a avaliação de medidas mais intensas. O sujeito deve procurar se lembrar da pior dor já experimentada. A essa experiência são atribuídos o valor máximo da escala (10) e a categoria "Extremamente Forte”. Essa classificação funcionará como uma âncora a partir da qual a experiência de dor atual deverá ser comparada. O sujeito deverá, então, associar o julgamento a uma categoria verbal (Absolutamente nada, extremamente fraco, muito fraco, fraco, moderado, forte e muito forte) e em seguida escolher o número correspondente. Nessa avaliação o uso de frações é permitido e incentivado.

A escala CR10 proporciona a determinação tanto de funções incrementais relativas quanto níveis absolutos da variável medida (através de uma função incremental 
positivamente acelerada). Essa escala apresenta boa validade confirmada pelas altas correlações obtidas em estudos comparativos com a VAS (aceita pela Associação Internacional para o Estudo da Dor) (WILSON \& JONES, 1989; HARMS-RINGDAHL et al, 1986 e NEELY, 1995). Há um alto índice de confiabilidade $(0,90)$ também determinado através de comparação com a VAS (BORG, 1998).

Os estudos da escala CR10, muitas vezes, são baseados em comparações com a escala VAS, devido ao fato dessa última já ser amplamente aceita nos meios científicos. Os resultados têm mostrado algumas vantagens da CR10 sobre a VAS: representa um método direto que não exige nenhum tipo de calibração especial, não limita as respostas (porque deixa o final da escala em aberto) e facilita a comunicação da variável avaliada pela presença de âncoras verbais ao longo de toda a escala (BORG, 1998).

Essas vantagens necessárias para uma escala para avaliar a dor são salientadas por Chapman e Syrjala, (1991). Para esses autores, a escala deve ser bem compreendida pelo paciente, ser capaz de registrar memória de dor e fornecer ao examinador uma ampla série de pontuações, além de ser sensível a intervenções analgésicas.

Magnusson et al (1995) realizaram um estudo comparativo entre diferentes escalas (VAS, escala numérica - Numerical Scale, escala de avaliação de comportamentos - Behaviour Rating Scale, escala verbal-Verbal Scale e escala combinada com uma grande parte de valores numéricos acompanhados de frases Combined Scale) para a avaliação de dor e desconforto nas DTMs. As escalas foram aplicadas em quatro momentos diferentes do tratamento odontológico. Na primeira e na quarta aplicação, foi pedido aos pacientes que avaliassem qual delas era a mais fácil de compreender e qual era a mais relevante para a avaliação da dor nas DTMs. Os 
resultados mostraram que a escala de avaliação de comportamentos foi considerada a mais simples na primeira aplicação seguida pela escala combinada. Na última aplicação essa ordem se inverteu. A escala VAS nas duas aplicações foi considerada menos fácil de entender e menos relevante que as duas escalas citadas.

Conti et al (2001) estudando a precisão e a sensibilidade das escalas VAS, Escala Numérica, Escala de Avaliação de Comportamento e Escala Verbal, em pacientes com DTMs, encontraram uma melhora geral nos sintomas, de aproximadamente 30-50\%, com o tratamento sendo que as mudanças mais significativas acontecem nos dois primeiros meses após o início do tratamento. De todas as escalas, a que apresentou melhor precisão foi a Escala Numérica. Todas as outras escalas registraram uma mudança nos sintomas antes da aplicação de qualquer tratamento. Para os autores, essa mudança pode ser explicada pela flutuação natural dos sintomas (KOPP, 1977, EGERMARK et al, 2001) e por uma acomodação geral dos mesmos. Segundo Linton e Gotestam, (1983) os pacientes, geralmente, tendem a superestimar os sintomas no primeiro contato com o profissional como forma de impressionar e se assegurar de que serão adequadamente tratados.

Harms-Ringdahl et al (1986) discutindo a comparação da escala CR10 com a VAS para a avaliação da dor mostraram que alguns pacientes apontam dificuldades em compreender a escala numérica. No entanto, a maior parte consegue entender uma escala verbal. Com relação à preferência entre elas os pacientes, geralmente, apontam a escala verbal.

Gracely et al (1980) relatam que as escalas de dor que utilizam descritores verbais apresentam vantagens como a facilidade de compreensão das palavras (ao 
contrário dos números, não exigem detalhadas explicações ou mesmo a prática), a identificação de diferentes dimensões da experiência da dor e a possibilidade de comparação inter e intra grupos. Além dessas vantagens, Gescheider (1997) aponta que a utilização de descritores verbais aumenta a possibilidade de concordância entre os avaliadores.

Na construção de escalas psicofísicas que utilizam expressões verbais, Borg e Borg (1994) salientam a importância da seleção de uma expressão verbal que funcione como um padrão fixo que permita a comparação e a calibração das outras expressões. Segundo Borg e Lindblad (1976), as expressões utilizadas influenciam o julgamento da dor e podem revelar uma realidade perceptiva específica. Ainda com relação à utilização de expressões verbais em escalas psicofísicas, esses autores, em um estudo de 2001, apontam que adjetivos e advérbios podem ser usados como constantes multiplicativas obtendo relações congruentes entre palavras e números.

Para Waddie (1996) é inevitável que a linguagem influencie a expressão da dor porque a linguagem não é utilizada somente para descrever a dor, mas faz parte dela. Assim, sabemos que estamos com dor quando podemos de alguma forma expressá-la. E o autor salienta que a expressão da dor pela linguagem verbal é fortemente influenciada pelo contexto cultural. Quanto a esse aspecto, Pereira e Sousa (1998) chamam a atenção para a importância de se verificar a adequação na tradução de termos utilizados em uma escala psicofísica. Pimenta e Teixeira (1997) questionam se a utilização da palavra “Moderada” bastante utilizada em escalas de categoria é adequada para essa finalidade na língua portuguesa. 
Wilson e Jones (1989) compararam a utilização da escala CR10 de Borg (modificada para o esforço percebido) com a VAS para medidas de dispnéia durante exercícios físicos. A escala CR10 obteve maior reprodutibilidade que a VAS e, além disso, correlacionou-se com uma das variáveis analisadas (ventilação pulmonar por minuto) melhor. Os autores concluíram, por isso, que a escala CR10 parece ser melhor para avaliar dispnéia do que a VAS.

Jensen et al (1986) propuseram cinco critérios segundo os quais as escalas de dor deveriam ser avaliadas: facilidade de administração e pontuação, possibilidade de julgamentos corretos, sensibilidade relativa definida como o número de categorias de respostas possíveis, sensibilidade para detectar efeitos do tratamento e relação entre a escala e a medida mais fiel da intensidade subjetiva de dor. Considerando esses aspectos o critério de facilidade de administração e pontuação torna-se imprescindível uma vez que, geralmente, na clínica dispõe-se de pouco tempo e recursos para a avaliação da dor. (MAGNUSSON et al, 1995).

A escolha de uma escala para avaliação da intensidade da dor presente nas DTMs deve considerar além dos critérios citados, o relato da dor como o ponto principal e não simplesmente a dor per si. Assim, a dor deve sempre ser contextualizada dentro do meio sócio-cultural do paciente e relacionada às expectativas, ao humor, e a experiências prévias de dor de cada pessoa. (BORG, 1998 e MOLINA, 1999).

Felício e Mazzetto (1994) relatam que, geralmente, a dor é identificada pelo indivíduo com base nas próprias experiências prévias e nas experiências de outros conhecidos. Essas experiências são utilizadas como parâmetros para o reconhecimento da magnitude da dor atual vivenciada. (GRACELY et al, 1980) 
Portanto, a identificação da dor como ponto importante no diagnóstico das DTMs deve ser feita levando-se em conta o contexto psico-sócio-cultural em que está inserido o paciente.

Considerando-se o estresse como um dos fatores, comumente, apontado como desencadeador das DTMs as diversas culturas podem enfrentar diferentes fontes de estresse. Por exemplo, a convivência, em grandes centros urbanos, acrescida de alta competitividade no mundo do trabalho pode ser fonte permanente de estresse. Concomitantemente, situações de crise pessoal (como perda de um ente querido, desemprego, doenças prolongadas, mudanças de cidade e de casa) podem configurar situações estressantes e como conseqüência podem levar ao aparecimento de diferentes desadaptações sociais e fisiológicas.

Dentro desse contexto, o aparecimento de sintomas, como a dor, pode ser influenciado por fatores emocionais, cognitivos e motivacionais. (BORG, 1998 e SIQUEIRA \& TEIXEIRA, 2001). Wolf (1973) apud Felício e Mazzetto (1994) “explica que a percepção da dor depende da integridade de conexões nervosas. Porém, a reação à dor está vinculada a funções cognitivas e dependentes em parte da maneira como o indivíduo a significa, de acordo com a experiência vivida. Variando por isso, de indivíduo para indivíduo e no mesmo indivíduo em circunstâncias diferentes”. (p. 193).

A ansiedade pode contribuir como fator agravante na percepção dolorosa, conseqüentemente, mecanismos, que possam ajudar a controlá-la, favorecem a diminuição da dor. O aconselhamento possibilita ao paciente uma compreensão e controle da situação que possa desencadear uma experiência de dor. Para Kopp (1977) o aconselhamento tem um efeito positivo na percepção dos pacientes e pode contribuir 
para a redução dos sintomas mesmo antes de qualquer intervenção profissional. Nesse sentido, Camparis e Cardoso Jr (2002) explicam que a falta de informação contribui para a formação de medos exagerados que aumentam a ansiedade e com isso a sensibilidade ao estímulo doloroso.

Os tratamentos para as DTMs, geralmente, incluem terapias oclusais, comportamentais, físicas e farmacológicas (OKESON, 1998). O principal objetivo é, geralmente, o controle da dor (LE RESCHE et al , 1992).

Gaudet e Brown (2000) comparando, em um período de seis meses, pacientes que receberam algum tipo de tratamento para as DTMs com outros que não receberam nenhum tratamento concluíram que a melhora dos sintomas não é espontânea e por isso é beneficiada pelo tratamento.

O registro adequado das intensidades de dor por meio de métodos psicofísicos escalares possibilita a eleição do melhor tratamento para às DTMs e conseqüente redução do sofrimento associado a esse distúrbio. Para Conti et al (2001) a redução da dor crônica contribui para uma melhora na qualidade de vida de maneira geral.

\section{Justificativa:}

A complexidade da mensuração da dor pode ser um fator de dificuldade para o profissional da saúde interessado na caracterização das DTMs e na elaboração de um diagnóstico e plano de tratamento adequados. Portanto, o estudo de escalas psicofísicas para mensurar a dor, visando a seu aprimoramento e adequação a condições diversas poderia facilitar o trabalho dos profissionais da saúde e conseqüentemente a obtenção de resultados mais favoráveis ao tratamento clínico. 
ESTUDO I 


\section{OBJETIVO:}

O objetivo desse estudo foi comparar as escalas CR10 e VAS para mensurar a dor (espontânea, durante função orofacial e durante palpação) nas Disfunções Temporomandibulares antes e após tratamento odontológico conservador (aconselhamento, placa mio-relaxante e ajuste oclusal).

\section{MÉTODO}

Participantes: Participaram voluntariamente, no primeiro semestre de 2002, 35 pacientes (seis do sexo masculino e 29 do sexo feminino) com idades entre 13 e 54 anos (média=31,7 anos) e nível de instrução de primário a terceiro grau (Primeiro Grau: 54,28 \%; Segundo Grau: 40 \%; Terceiro Grau: 5,71 \%). Do total de 35 pacientes, três (todos do sexo feminino) foram eliminados na segunda fase desse estudo por abandono do tratamento odontológico. Todos os pacientes foram encaminhados à clínica de Oclusão da Faculdade de Odontologia de Ribeirão Preto - USP com o diagnóstico de Disfunções Temporomandibulares. O encaminhamento foi feito a partir de uma triagem realizada pelos professores responsáveis pela disciplina de Oclusão II ministrada ao terceiro ano do curso de Odontologia da FORP - USP. A inclusão do paciente no estudo dependeu do preenchimento do Termo de Consentimento (Anexo A) aprovado pelo Comitê de Ética da FORP-USP, protocolo de no. 2001.1.982.58.2.

Material: A aplicação das escalas CR10 Modificada e Escala Analógica Visual, foi feita em duas fases: antes e após tratamento odontológico. O intervalo entre a primeira e a segunda fase compreendeu uma média de dois meses. As aplicações foram 
precedidas por uma anamnese adaptada do roteiro, atualmente, aplicado na clínica psicológica da Universidade de Ribeirão Preto (UNAERP) e do Centro de Psicologia Aplicada da Faculdade de Filosofia, Ciências e Letras de Ribeirão Preto (F.F.C.L.R.P.) para triagem de pacientes adolescentes e adultos (Anexo B). Somente após o tratamento odontológico (segunda fase) realizou-se uma anamnese simplificada (Anexo C)

As aplicações das escalas foram antecedidas por instruções padronizadas para cada uma delas (Anexo D - Escala VAS e Anexo E - Escala CR10). Foram utilizados diagramas específicos para o registro visual das regiões / pontos de dor (Anexo F) e protocolos para a VAS (Anexo D) e para CR10 (Anexo E) para se registrar as avaliações de dor de cada paciente.

A modificação realizada na CR10 consistiu de um desmembramento da parte verbal e numérica sendo as categorias verbais e os valores numéricos ordenados cada um em uma única coluna em uma mesma folha A4. Somente os valores numéricos zero e 10 foram associados às categorias verbais: Absolutamente Nada e Extremamente Forte, respectivamente, como na escala original. A instrução para essa escala foi mantida como na original apenas retirada a parte que ensinava ao sujeito a associação automática entre as categorias verbais e os valores numéricos (Segundo as instruções originais: "Se a sua percepção é ‘Muito Fraca”, escolha 1; se “Moderada, escolha 3, etc.”) (Anexo E).

Procedimento: As escalas foram aplicadas pela própria pesquisadora, na Clínica de Oclusão da FORP-USP. Aleatoriamente, foram distribuídas e aplicadas em um mesmo dia para cada paciente. A obtenção da anamnese e a aplicação das escalas duraram aproximadamente 30 (trinta) minutos. 
Interferências na percepção da dor, como medicação analgésica e doença aguda, registradas na anamnese, não foram consideradas fatores excludentes da aplicação das escalas. Optou-se por considerar essas interferências como possíveis fatores adicionais para a análise e compreensão dos resultados.

Antes da aplicação das escalas, explicou-se o procedimento por meio da leitura, pela pesquisadora, de instruções padronizadas, seguido pelo esclarecimento de dúvidas do paciente. Compreendendo as escalas, cada paciente passou por um processo de “calibração”. Exemplos de pelo menos uma e no máximo três experiências prévias de dor (dor durante parto, angina, queimaduras, etc.) foram apontados pelo paciente no sentido de situar nas escalas a intensidade da dor avaliada.

A aplicação das escalas envolveu a identificação da dor, pelo paciente, por meio de três variáveis avaliadas distintamente: dor espontânea, durante função orofacial e ao exame de palpação.

Para avaliação da dor espontânea o paciente foi questionado: “Tem sentido dor espontânea na região da cabeça ou pescoço durante a última semana?” Respostas positivas implicavam na indicação do local da dor. A partir dessa informação, o diagrama (Anexo F) para a localização visual de dor foi preenchido pela pesquisadora. Em seguida, o paciente marcou manualmente o protocolo das escalas para a específica dor espontânea. No caso de mais de uma região com presença de dor foi considerada somente a região de maior intensidade. Dessa forma, mesmo quando o paciente indicou mais de um local doloroso, ou mesmo identificou diferença entre os dois lados da face e pescoço, as escalas para avaliação da dor espontânea foram aplicadas uma única vez apenas para o local de maior intensidade de dor. 
Em seqüência, por meio de questões diretas, avaliou-se a presença de dor durante a função, nesta ordem: mastigação, fonação e deglutição. As perguntas, fundamentalmente, foram as seguintes: “Sente dor quando mastiga?”. Se a resposta fosse afirmativa o protocolo das escalas era fornecido para marcação da intensidade de dor. O mesmo procedimento foi aplicado para avaliar a fonação e a deglutição, com as questões: “Sente dor ao falar?” "Sente dor quando engole?”.

Finalmente, a pesquisadora realizou o exame de palpação. A apresentação da dor nos seguintes elementos faciais foi avaliada durante o exame: músculos (temporal, masseter, pterigoideo medial e lateral, esternocleidomastoideo, trapézio, supra-hioideos e infra-hioideos nesta ordem) e ATM (polo lateral e posterior) (Anexo G). A identificação de dor imediatamente à palpação de cada elemento facial implicou no fornecimento das escalas para que o paciente registrasse a dor avaliada. Para cada um desses elementos quando houve diferenciação entre os lados da face e pescoço duas medidas de dor foram registradas, uma para o lado direito e outra para o lado esquerdo.

Considerando as três avaliações (dor espontânea, durante a função e à palpação), para cada sujeito foi possível até um total de 48 medidas de dor (uma para dor espontânea, três para dor durante a função e 20 para dor à palpação sendo um total de 24 medidas na CR10 e 24 na VAS).

Após o preenchimento de todos os protocolos com as escalas CR10 de Borg e VAS para os três tipos de dor (espontânea, durante a função e à palpação) questionouse como cada paciente avaliou as escalas. Para isso foram aplicadas as questões padronizadas: “Qual das duas escalas você considera mais fácil de entender?” “Qual das duas escalas você considera a mais correta para melhor representar os diversos tipos de 
dor que você identificou?” As respostas foram anotadas em uma folha arquivada juntamente com os protocolos do paciente.

É importante alertar para o fato de que a aplicação das escalas (VAS e CR10) dependeu da presença de dor, sendo assim nos casos onde não houve identificação de dor pelo paciente, para as três formas de avaliação (espontânea, durante função e ao exame de palpação) somente o processo de "calibração" foi registrado em ambas as escalas.

Tratamento dos dados: Os resultados foram submetidos a ANOVAs: para a dor espontânea compararam-se dois lados da face com duas sessões: antes e após tratamento (2 lados x 2 sessões); para a dor durante função orofacial compararam-se três tipos de função com duas sessões (3 funções x 2 sessões) e para a dor durante palpação compararam-se 10 regiões faciais com dois lados da face e pescoço e duas sessões (10 regiões x 2 lados x 2 sessões).

Foram calculados os coeficientes de correlação de Pearson entre as pontuações obtidas com as escalas VAS e CR10 Modificada I com a finalidade de verificar a validade concorrente dessas escalas para mensurar dor nas DTMs.

\section{RESULTADOS}

O Grupo I foi formado por 35 pacientes sendo que três foram eliminados da segunda avaliação (após tratamento) porque desistiram do tratamento odontológico. Para esses três pacientes as escalas VAS e CR10 Modificada I foram aplicadas em uma só etapa. Para os outros 32 pacientes, as escalas VAS e CR10 Modificada I foram 
apresentadas em duas fases ou etapas: antes do tratamento odontológico realizado pelos alunos de graduação na Clínica de Oclusão da FORP - USP e após a realização desse tratamento.

O tempo médio de apresentação dos sinais e sintomas foi 5,67 anos. Para 29 pacientes $(82,86 \%)$ a dor apareceu como principal queixa isolada ou associada à outra queixa. Trinta pacientes (85,7\%) relataram possuir hábito parafuncional (Bruxismo e/ou Briquismo). Quando questionados sobre as possíveis causas do problema que apresentam $13(37,14 \%)$ apontaram mais de uma causa, sendo que entre os 35 pacientes, 17 (48,6\%) pacientes apontaram o estresse, 14 (40\%) apontaram a má oclusão/ausência e/ou desgaste de alguns dentes, três (8,6\%) apontaram a mastigação e cinco (14,3\%) não souberam indicar o que poderia estar causando as DTMs. Treze $(37,14 \%)$ pacientes apontaram mais de uma situação que poderia estar relacionada à DTM, entre os 35 as situações apontadas foram: mastigação (dez pacientes - 28,6\%), estresse (oito pacientes - 22,8\%), movimentação mandibular (apontada como "final do dia" - sete pacientes 20\%), o período da manhã (sete pacientes - 20\%), contato com alimento e/ou líquido gelado (quatro pacientes - 11,4 \%), abertura de boca e/ou fala (quatro pacientes - 11,4\% ), a rotina diária (três - 8,6\%) e o período menstrual (dois - 5,7\%). Antes de iniciar o atendimento na clínica de oclusão, 28 pacientes (80\%) já haviam consultado outros profissionais da saúde: cirurgiões-dentistas, fisioterapeutas e médicos (clínico-geral, neurologista, oftalmologista, otorrinolaringologista e psiquiatra).Os dados completos obtidos com as anamneses são apresentados nos anexos (Anexo J). 
As queixas principais que levaram os pacientes a buscar o tratamento odontológico foram analisadas e organizadas em categorias comuns apresentadas na Tabela 1.

Tabela 1 - Número e porcentagem de pacientes em relação à queixa principal.

\begin{tabular}{|c|c|}
\hline Queixa Principal & Número e Porcentagem de Pacientes \\
\hline Dor orofacial & $10(28,57 \%)$ \\
\hline Dor e Estalos nas ATMs & $3(8,57 \%)$ \\
\hline Dor e Encaminhamento de outro profissional & $4(11,43 \%)$ \\
\hline $\begin{array}{l}\text { Dor e Dificuldade de abertura de boca e } \\
\text { mastigação / Hábito Parafuncional / Má } \\
\text { oclusão }\end{array}$ & $11(31,43 \%)$ \\
\hline $\begin{array}{c}\text { Dor e Dificuldade de abertura de boca e } \\
\text { mastigação / Hábito Parafuncional / Má } \\
\text { oclusão e Encaminhamento de outro } \\
\text { profissional }\end{array}$ & $1(2,86 \%)$ \\
\hline $\begin{array}{c}\text { Dificuldade de abertura de boca e mastigação / } \\
\text { Hábito Parafuncional / Má oclusão }\end{array}$ & $1(2,86 \%)$ \\
\hline $\begin{array}{l}\text { Dificuldade de abertura de boca e mastigação / } \\
\text { Hábito Parafuncional / Má oclusão e Tensão / } \\
\text { insônia }\end{array}$ & $2(5,71 \%)$ \\
\hline Estalos nas ATMs & $1(2,86 \%)$ \\
\hline $\begin{array}{l}\text { Estalos nas ATMs e Encaminhamento de outro } \\
\text { profissional }\end{array}$ & $1(2,86 \%)$ \\
\hline Encaminhamento de outro profissional & $1(2,86 \%)$ \\
\hline
\end{tabular}


Quanto à apresentação da dor, antes do tratamento odontológico, a maior incidência foi de dor à mastigação (65,71\% dos pacientes) (Tabela 3). Em segundo lugar ficou a dor espontânea no lado esquerdo da face (60\%) e em terceiro lugar a dor espontânea no lado direito da face (57,14\%) (Tabela 2).

Observa-se que a soma das porcentagens para cada tipo de dor excede $100 \%$ porque cada paciente poderia apresentar mais de um tipo de dor. 
Tabela 2 - Caracterização da Dor Espontânea, no Grupo I, anterior ao tratamento odontológico segundo a localização (Direita ou Esquerda), o número de pacientes, as médias e desvios padrão nas escalas VAS e CR10 de Borg

\begin{tabular}{|c|c|c|c|c|c|}
\hline \multirow{2}{*}{ Localização } & \multirow{2}{*}{$\begin{array}{c}\mathrm{N}^{0} \text { Sujeitos } \\
(\%)\end{array}$} & \multicolumn{2}{|c|}{ VAS } & \multicolumn{2}{|c|}{ CR10 Modificada I } \\
\hline & & Média & DP & Média & DP \\
\hline Direito & $\begin{array}{c}20 \\
(57,14 \%)\end{array}$ & 2,92 & 2,70 & 3,83 & 3,70 \\
\hline Esquerdo & $\begin{array}{c}21 \\
(60 \%)\end{array}$ & 3,47 & 2,62 & 4,33 & 3,53 \\
\hline
\end{tabular}

Tabela 3 - Caracterização da Dor à Função Orofacial, no Grupo I, anterior ao tratamento segundo a função (Mastigação, Fonação, Deglutição), o número de pacientes, as médias e desvios padrão nas escalas VAS e CR10 de Borg

\begin{tabular}{|c|c|cc|cc|}
\hline $\begin{array}{c}\text { Função } \\
\text { Orofacial }\end{array}$ & $\begin{array}{c}\text { No Sujeitos } \\
(\%)\end{array}$ & \multicolumn{2}{|c|}{ VAS } & \multicolumn{2}{|c|}{ CR10 Modificada I } \\
\hline Mastigação & $\begin{array}{c}23 \\
(65,71 \%)\end{array}$ & 3,33 & 2,27 & 4,04 & Média \\
Fonação & $\begin{array}{c}13 \\
(37,14 \%)\end{array}$ & 1,61 & 1,96 & 2,18 & 3,04 \\
Deglutição & $\begin{array}{c}6 \\
(17,14 \%)\end{array}$ & 0,27 & 0,63 & 0,46 & 1,27 \\
\hline
\end{tabular}


Tabela 4 - Caracterização da Dor à Palpação no lado Direito, no Grupo I, anterior ao tratamento segundo a localização (músculos e ATM), o número de pacientes, as médias e desvios padrão nas escalas VAS e CR10 de Borg

\begin{tabular}{|c|c|c|c|c|c|}
\hline Localização & $\begin{array}{c}\text { № Sujeitos } \\
(\%)\end{array}$ & Média & $\mathrm{DP}$ & $\begin{array}{l}\text { CR10 N } \\
\text { Média }\end{array}$ & cada I \\
\hline Temporal & $\begin{array}{c}11 \\
(31,43 \%)\end{array}$ & 0,65 & 1,42 & 1,03 & 2,40 \\
\hline Masséter & $\begin{array}{c}12 \\
(34,28 \%)\end{array}$ & 0,79 & 1,20 & 1,05 & 1,94 \\
\hline Pterigoideo Medial & $\begin{array}{c}7 \\
(20 \%)\end{array}$ & 0,69 & 1,73 & 0,84 & 2,31 \\
\hline Pterigoideo Lateral & $\begin{array}{c}19 \\
(54,28 \%)\end{array}$ & 1,73 & 2,27 & 1,72 & 2,86 \\
\hline Esternocleidom. & $\begin{array}{c}11 \\
(31,42 \%)\end{array}$ & 1,06 & 2,07 & 1,30 & 2,76 \\
\hline Trapézio & $\begin{array}{c}8 \\
(22,86 \%)\end{array}$ & 1,04 & 2,07 & 1,10 & 2,40 \\
\hline Supra-Hioideos & $\begin{array}{c}5 \\
(14,28 \%)\end{array}$ & 0,49 & 1,51 & 0,50 & 1,82 \\
\hline Infra- Hioideos & $\begin{array}{c}4 \\
(11,43 \%)\end{array}$ & 0,35 & 0,90 & 0,32 & 1,33 \\
\hline ATM- Polo Lateral & $\begin{array}{c}16 \\
(45,71 \%)\end{array}$ & 1,35 & 2,05 & 1,46 & 2,45 \\
\hline ATM- Polo Posterior & $\begin{array}{c}5 \\
(14,28 \%)\end{array}$ & 0,18 & 0,67 & 0,10 & 0,40 \\
\hline
\end{tabular}


Tabela 5 - Caracterização da Dor à Palpação no lado Esquerdo, no Grupo I, anterior ao tratamento segundo a localização (músculos e ATM), o número de pacientes e as médias nas escalas VAS e CR10 de Borg

\begin{tabular}{|c|c|c|c|c|c|}
\hline Localização & $\begin{array}{c}\mathrm{N}^{0} \text { Sujeitos } \\
(\%)\end{array}$ & Média & $\mathrm{DP}$ & $\begin{array}{l}\text { CR10 M } \\
\text { Média }\end{array}$ & cada I \\
\hline Temporal & $\begin{array}{c}10 \\
(28,57 \%)\end{array}$ & 0,68 & 1,28 & 1,00 & 2,33 \\
\hline Masséter & $\begin{array}{c}12 \\
(34,28 \%)\end{array}$ & 1,22 & 1,85 & 1,71 & 2,84 \\
\hline Pterigoideo Medial & $\begin{array}{c}4 \\
(11,43 \%)\end{array}$ & 0,59 & 1,80 & 0,76 & 2,32 \\
\hline Pterigoideo Lateral & $\begin{array}{c}18 \\
(51,43 \%)\end{array}$ & 1,68 & 2,03 & 1,90 & 2,80 \\
\hline Esternocleidom. & $\begin{array}{c}12 \\
(34,28 \%)\end{array}$ & 0,47 & 0,88 & 1,50 & 2,77 \\
\hline Trapézio & $\begin{array}{c}10 \\
(28,57 \%)\end{array}$ & 1,07 & 2,00 & 1,31 & 2,60 \\
\hline Supra-Hioideos & $\begin{array}{c}4 \\
(11,43 \%)\end{array}$ & 0,49 & 1,51 & 0,50 & 1,82 \\
\hline Infra- Hioideos & $\begin{array}{c}5 \\
(14,28 \%)\end{array}$ & 0,41 & 0,93 & 0,33 & 1,33 \\
\hline ATM- Polo Lateral & $\begin{array}{c}15 \\
(42,86 \%)\end{array}$ & 1,09 & 2,02 & 1,28 & 2,22 \\
\hline ATM- Polo Posterior & $\begin{array}{c}8 \\
(22,86 \%)\end{array}$ & 0,72 & 1,81 & 0,65 & 1,79 \\
\hline
\end{tabular}


Entre os 35 pacientes avaliados na primeira fase, 33 (94,3\%) apresentaram dor em pelo menos uma das 24 condições de medidas possíveis (dor espontânea: uma condição, dor durante função: três condições, dor à palpação: vinte condições, sendo dez para cada lado da face e/ou pescoço). Esses 33 sujeitos produziram um total de 279 medidas de dor, sendo 41 para dor espontânea, 42 para dor durante função orofacial e 196 para dor à palpação.

Antes do tratamento, as associações entre os valores numéricos e as âncoras verbais, como propostas na escala CR10 original em inglês, diferiram das associações encontradas em português. As categorias: "moderado", "forte” e "muito forte” foram associadas respectivamente aos valores médios de 4,63, 7,41, e 9,63 diferentes significativamente $(\mathrm{p}<0,001)$ dos valores “3”, “5” e “7” propostos na versão original. (Tabela 6). 
Tabela 6 - Categorias verbais em Inglês e em Português (Brasil) usadas como âncoras da escala CR10, no Grupo I, na primeira fase (anterior ao tratamento odontológico)

\begin{tabular}{|c|c|c|c|c|c|c|c|}
\hline \multirow[t]{3}{*}{ Categoria Ve } & \multirow{3}{*}{ Português } & \multirow{3}{*}{ Inglês } & \multirow{2}{*}{\multicolumn{2}{|c|}{$\begin{array}{c}\text { CR10 } \\
\text { Português }\end{array}$}} & \multirow[b]{3}{*}{ Média } & \multicolumn{2}{|c|}{ VAS } \\
\hline & & & & & & & \\
\hline & & & Média & DP & & DP & $\mathbf{N}$ \\
\hline Absolute nothing & absolutamente nada & 0 & 0,01 & 0,05 & 0,85 & 0,53 & 18 \\
\hline Extremely weak & extremamente fraco & 0,5 & 1,01 & 1,09 & 1,09 & 0,57 & 22 \\
\hline Very weak & muito fraco & 1 & 0,86 & 0,48 & 1,89 & 0,90 & 15 \\
\hline Weak & fraco & 2 & 2,25 & 1,89 & 1,93 & 1,16 & 77 \\
\hline Moderate & moderado & 3 & $4,60 *$ & 1,86 & 3,53 & 1,14 & 79 \\
\hline Strong & forte & 5 & $7,41^{*}$ & 1,69 & 5,42 & 1,43 & 42 \\
\hline Very Strong & muito forte & 7 & $9,63^{*}$ & 0,58 & 7,85 & 0,99 & 12 \\
\hline Extremely strong & extremamente forte & 10 & 9,33 & 1,03 & 6,67 & 2,52 & 6 \\
\hline More than extremely strong & maior que extrem. forte & $>10$ & 12 & 1,07 & 8,58 & 2,15 & 8 \\
\hline
\end{tabular}

O coeficiente de correlação de Pearson entre todas as pontuações da VAS e da CR10 foi de 0,83. Os coeficientes de correlação para cada avaliação de dor separadamente foram: 0,68 para dor espontânea; 0,73 para dor durante função e 0,86 para dor durante palpação (Figura 1). Todos esses coeficientes indicam um alto grau de validade de critério por concorrência. 
1a Fase

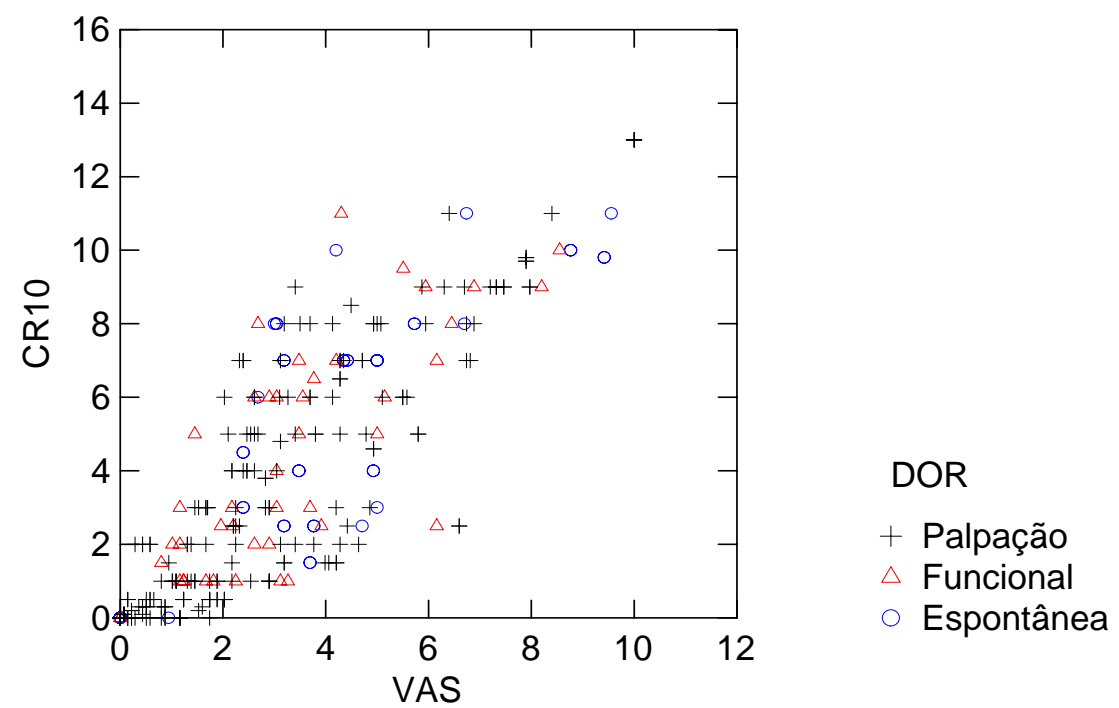

Figura 1: Relação entre os valores numéricos, segundo os três tipos de dor (à palpação, funcional e espontânea), apresentados na VAS e na CR10, no Grupo I (CR10 Modificada I) antes do tratamento (primeira fase).

Após o tratamento odontológico houve, de forma geral, uma redução da intensidade dos três tipos de dor (Tabelas 7, 8, 9 e 10). Quanto à freqüência de apresentação observa-se uma mudança: nessa fase a dor mais freqüente foi a espontânea (lado direito - 50\% dos pacientes e lado esquerdo - 40,62\%) seguida pela dor à mastigação (25\%) (Tabelas 7 e 8). 
Tabela 7 - Caracterização da Dor Espontânea, no Grupo I, posterior ao tratamento odontológico segundo a localização (Direita ou Esquerda), o número de pacientes, as médias e desvios padrão nas escalas VAS e CR10 de Borg

\begin{tabular}{|c|c|cc|cc|}
\hline & \multicolumn{2}{|c|}{ VAS } & \multicolumn{2}{|c|}{ CR10 Modificada I } \\
Localização & $\begin{array}{c}\text { No Sujeitos } \\
(\%)\end{array}$ & Média & DP & Média & DP \\
\hline Direito & $\begin{array}{c}16 \\
(50 \%)\end{array}$ & 2,56 & 2,63 & 2,84 & 3,21 \\
Esquerdo & $\begin{array}{c}13 \\
(40,62 \%)\end{array}$ & 2,02 & 2,48 & 1,96 & 2,69 \\
\hline
\end{tabular}

Tabela 8 - Caracterização da Dor à Função Orofacial, no Grupo I, posterior ao tratamento segundo a função (Mastigação, Fonação, Deglutição), o número de pacientes, as médias e desvios padrão nas escalas VAS e CR10 de Borg

\begin{tabular}{|c|c|cc|cc|}
\hline $\begin{array}{c}\text { Função } \\
\text { Orofacial }\end{array}$ & $\begin{array}{c}\text { No Sujeitos } \\
(\%)\end{array}$ & \multicolumn{2}{|c|}{ VAS } & \multicolumn{2}{|c|}{ CR10 Modificada I } \\
\hline Mastigação & $\begin{array}{c}8 \\
(25 \%)\end{array}$ & 0,86 & 1,52 & 0,80 & 1,48 \\
Fonação & $\begin{array}{c}1 \\
(3,12 \%)\end{array}$ & 0,09 & 0,46 & 0,16 & 0,16 \\
Deglutição & $\begin{array}{c}1 \\
(3,12 \%)\end{array}$ & 0,17 & 0,86 & 0,16 & 0,80 \\
\hline
\end{tabular}


Tabela 9 - Caracterização da Dor à Palpação no lado Direito, no Grupo I, posterior ao tratamento segundo a localização (músculos e ATM), o número de pacientes e as médias nas escalas VAS e CR10 de Borg

\begin{tabular}{|c|c|c|c|c|c|}
\hline \multirow{2}{*}{ Localização } & \multirow{2}{*}{$\begin{array}{c}\text { № Sujeitos } \\
(\%)\end{array}$} & \multicolumn{2}{|c|}{ VAS } & \multicolumn{2}{|c|}{ CR10 Modificada I } \\
\hline & & Média & DP & Média & DP \\
\hline Temporal & $\begin{array}{c}5 \\
(15,62 \%)\end{array}$ & 0,37 & 1,13 & 0,52 & 1,49 \\
\hline Masséter & $\begin{array}{c}4 \\
(12,5 \%)\end{array}$ & 0,30 & 0,77 & 0,26 & 0,79 \\
\hline $\begin{array}{c}\text { Pterigoideo } \\
\text { Medial }\end{array}$ & $\begin{array}{c}3 \\
(9,37 \%)\end{array}$ & 0,11 & 0,31 & 0,14 & 0,57 \\
\hline $\begin{array}{c}\text { Pterigoideo } \\
\text { Lateral }\end{array}$ & $\begin{array}{c}7 \\
(21,87 \%)\end{array}$ & 0,53 & 1,23 & 0,70 & 1,64 \\
\hline Esternocleidom. & $\begin{array}{c}6 \\
(18,75 \%)\end{array}$ & 0,39 & 0,95 & 0,60 & 1,50 \\
\hline Trapézio & $\begin{array}{c}6 \\
(18,75 \%)\end{array}$ & 0,27 & 0,62 & 0,24 & 0,66 \\
\hline Supra-Hioideos & $\begin{array}{c}6 \\
(18,75 \%)\end{array}$ & 0,38 & 0,89 & 0,46 & 1,10 \\
\hline Infra- Hioideos & $\begin{array}{c}4 \\
(12,5 \%)\end{array}$ & 0,21 & 0,83 & 0,32 & 1,09 \\
\hline $\begin{array}{c}\text { ATM- Polo } \\
\text { Lateral }\end{array}$ & $\begin{array}{c}5 \\
(15,62 \%)\end{array}$ & 0,35 & 0,96 & 0,34 & 1,05 \\
\hline $\begin{array}{l}\text { ATM- Polo } \\
\text { Posterior }\end{array}$ & $\begin{array}{c}11 \\
(34,37 \%)\end{array}$ & 0,68 & 1,16 & 0,75 & 1,45 \\
\hline
\end{tabular}


Tabela 10 - Caracterização da Dor à Palpação no lado Esquerdo, no Grupo I, posterior ao tratamento segundo a localização (músculos e ATM), o número de pacientes e as médias nas escalas VAS e CR10 de Borg

\begin{tabular}{|c|c|c|c|c|c|}
\hline Localização & $\begin{array}{c}\mathrm{N}^{0} \text { Sujeitos } \\
(\%)\end{array}$ & Média & DP & $\begin{array}{l}\text { CR10 M } \\
\text { Média }\end{array}$ & cada I \\
\hline Temporal & $\begin{array}{c}6 \\
(18,7 \%)\end{array}$ & 0,27 & 0,62 & 0,36 & 1,03 \\
\hline Masséter & $\begin{array}{c}5 \\
(15,62 \%)\end{array}$ & 0,31 & 0,78 & 0,30 & 0,86 \\
\hline Pterigoideo Medial & $\begin{array}{c}5 \\
(15,62 \%)\end{array}$ & 0,41 & 1,01 & 0,43 & 1,11 \\
\hline Pterigoideo Lateral & $\begin{array}{c}7 \\
(21,87 \%)\end{array}$ & 0,35 & 0,81 & 0,51 & 1,24 \\
\hline Esternocleidom. & $\begin{array}{c}7 \\
(21,87 \%)\end{array}$ & 0,47 & 0,88 & 0,64 & 1,30 \\
\hline Trapézio & $\begin{array}{c}8 \\
(25 \%)\end{array}$ & 0,50 & 1,00 & 0,57 & 1,04 \\
\hline Supra-Hioideos & $\begin{array}{c}4 \\
(12,5 \%)\end{array}$ & 0,31 & 0,84 & 0,40 & 1,07 \\
\hline Infra- Hioideos & $\begin{array}{c}3 \\
(9,37 \%)\end{array}$ & 0,21 & 0,83 & 0,32 & 1,09 \\
\hline ATM- Polo Lateral & $\begin{array}{c}5 \\
(15,62 \%)\end{array}$ & 0,40 & 1,00 & 0,54 & 1,48 \\
\hline ATM- Polo Posterior & $\begin{array}{c}7 \\
(21,87 \%)\end{array}$ & 0,61 & 1,32 & 0,50 & 1,29 \\
\hline
\end{tabular}


Na segunda fase, entre os 32 sujeitos avaliados, 27 (84,4\%) apresentaram algum tipo de dor, produzindo um total de 147 medidas de dor sendo 27 para dor espontânea, dez para dor durante função e 110 para dor à palpação. Na segunda fase da pesquisa somente a âncora "muito forte" associada ao valor numérico médio de 8,5 diferiu significativamente $(\mathrm{p}<0,001)$ do valor “7” proposto na escala original (Tabela 11).

Tabela 11 - Categorias verbais em Inglês e em Português (Brasil) usadas como âncoras da escala CR10, no Grupo I, na segunda fase (após tratamento odontológico)

\begin{tabular}{|c|c|c|c|c|c|c|c|}
\hline \multicolumn{2}{|l|}{ Categoria Verbal } & \multicolumn{3}{|c|}{ CR10 } & \multicolumn{3}{|c|}{ VAS } \\
\hline \multirow[t]{2}{*}{ Inglês } & \multirow[t]{2}{*}{ Português } & \multirow[t]{2}{*}{ Inglês } & \multicolumn{2}{|c|}{ Português } & & & \\
\hline & & & Média & DP & Média & DP & $\mathbf{N}$ \\
\hline Absolute nothing & absolutamente nada & 0 & 0,21 & 0,57 & 1,36 & 1,51 & 7 \\
\hline Extremely weak & extremamente fraco & 0,5 & 0,87 & 0,60 & 1,20 & 0,80 & 26 \\
\hline Very weak & muito fraco & 1 & 1,60 & 0,82 & 1,47 & 0,71 & 23 \\
\hline Weak & fraco & 2 & 2,62 & 1,28 & 1,90 & 0,79 & 40 \\
\hline Moderate & moderado & 3 & 3,64 & 1,24 & 3,06 & 1,30 & 33 \\
\hline Strong & forte & 5 & 5,08 & 1,71 & 4,61 & 1,43 & 13 \\
\hline Very Strong & muito forte & 7 & $8,5^{*}$ & 0,58 & 6,27 & 1,80 & 4 \\
\hline Extremely strong & extremamente forte & 10 & 10 & --- & 8,27 & --- & 1 \\
\hline More than extremely strong & maior que extrem. forte & $>10$ & ----- & ----- & ---- & ---- & ---- \\
\hline
\end{tabular}

O coeficiente de correlação de Pearson entre todas as pontuações da VAS e da CR10 foi de 0,8. Considerando cada avaliação de dor separadamente foi encontrado o coeficiente de 0,9 para os três tipos de dor (espontânea, durante função e à palpação). (Figura 2) Todos esses coeficientes indicam um alto grau de validade de critério por concorrência. 


\section{2.a Fase}

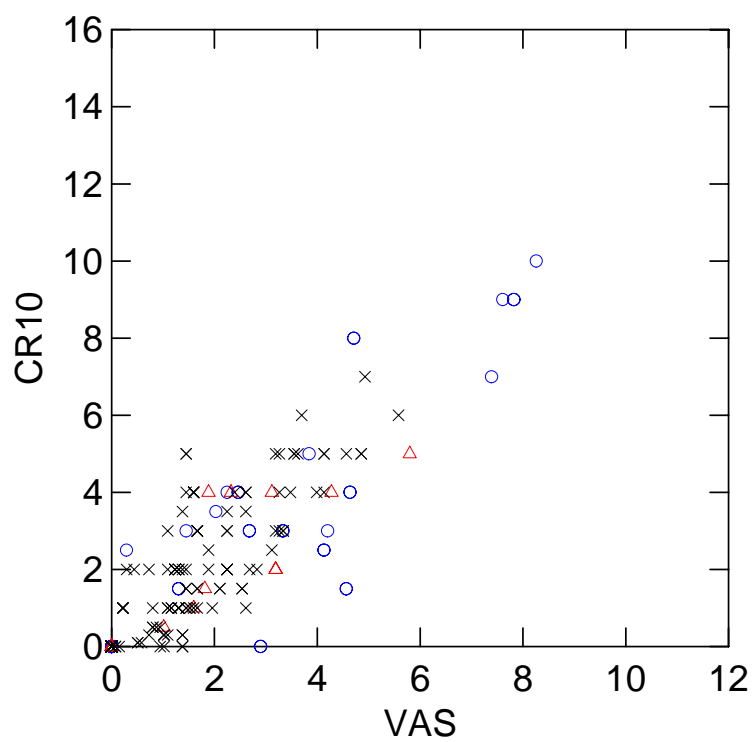

DOR

Palpação

Funcional

Espontânea

Figura 2: Relação entre os valores numéricos, segundo os três tipos de dor (à palpação, funcional e espontânea), apresentados na VAS e na CR10, no Grupo I (CR10 Modificada I) após o tratamento (segunda fase).

\section{Comparação entre a Primeira e a Segunda Fase de Aplicação das escalas}

\section{para o Grupo I:}

A redução da porcentagem de pacientes que apresentou dor na primeira fase $(94,3 \%)$ para a segunda fase $(84,4 \%)$ sugere a efetividade do tratamento odontológico para aliviar a dor associada às DTMs. Entretanto, na análise separada de cada tipo de dor, observa-se que a redução nas porcentagens não foi homogênea. Em alguns casos como na Dor à Palpação no Pólo Posterior da ATM lado direito houve elevação da porcentagem de pacientes que apresentou dor após tratamento odontológico. (Figuras 3, 4, 5 e 6). Vale ressaltar nas diferenças das porcentagens de dor antes e após tratamento odontológico que a maior redução foi para Dor à Mastigação. 


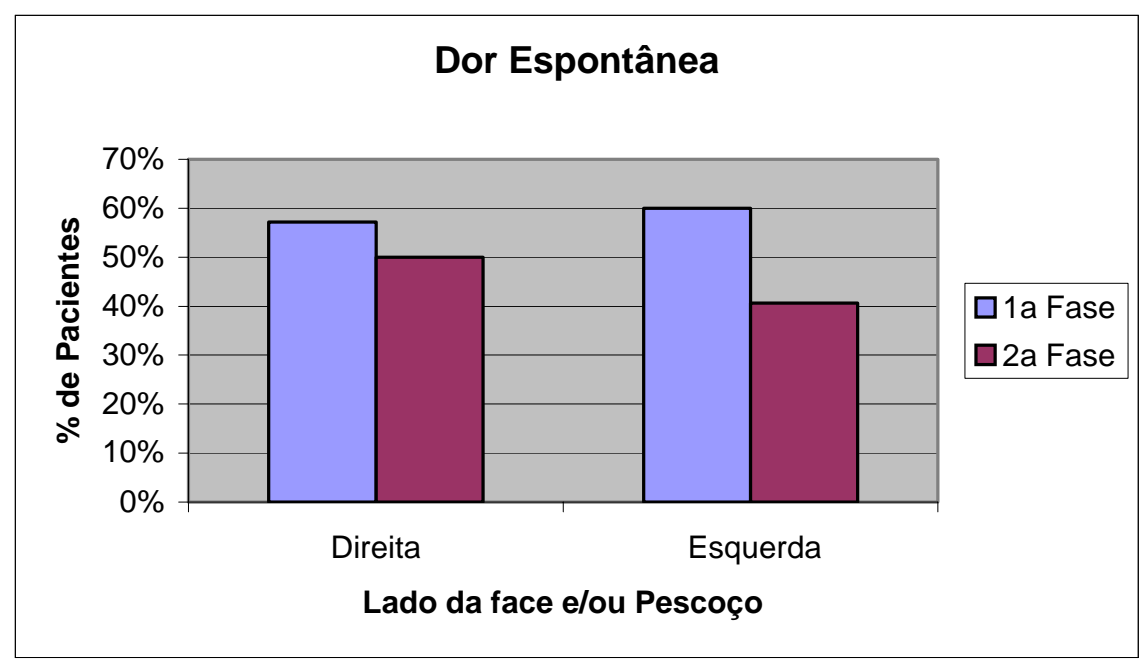

Figura 3: Pacientes do Grupo I que apresentou Dor Espontânea em cada um dos lados da face e/ou pescoço (Direita ou Esquerda) na $1^{\mathrm{a}}$ e $2^{\mathrm{a}}$ Fase (Antes e Após tratamento).

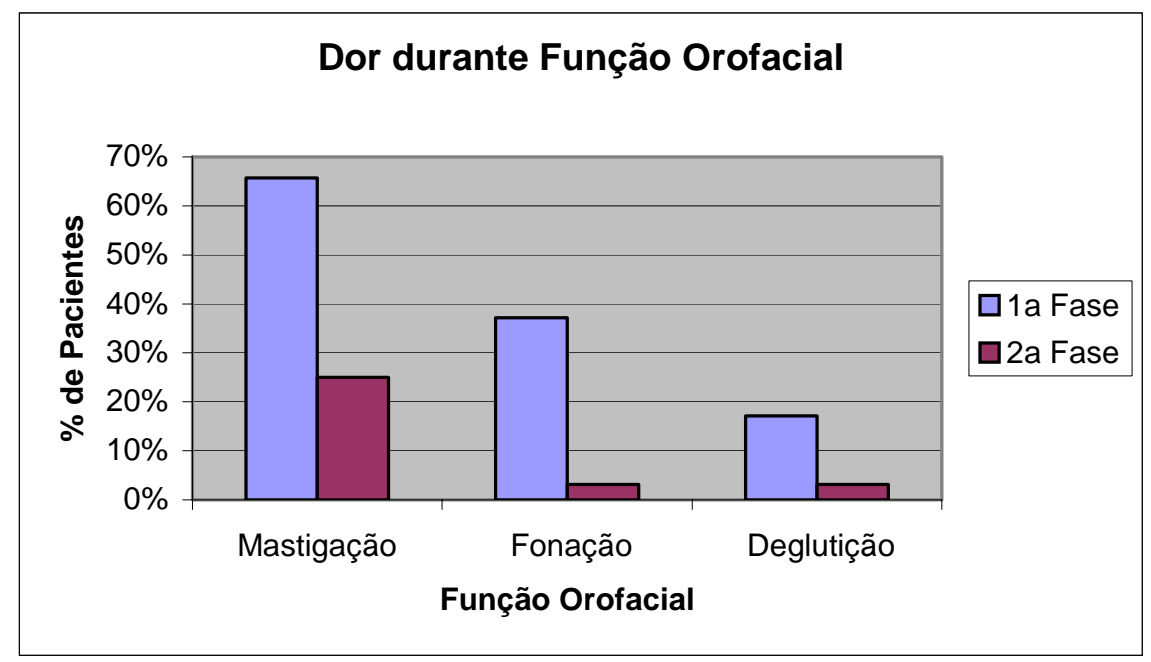

Figura 4: Pacientes do Grupo I que apresentou Dor Durante Função Orofacial (Mastigação, Fonação e Deglutição) na $1^{\mathrm{a}}$ e $2^{\mathrm{a}}$ Fase (Antes e Após tratamento). 


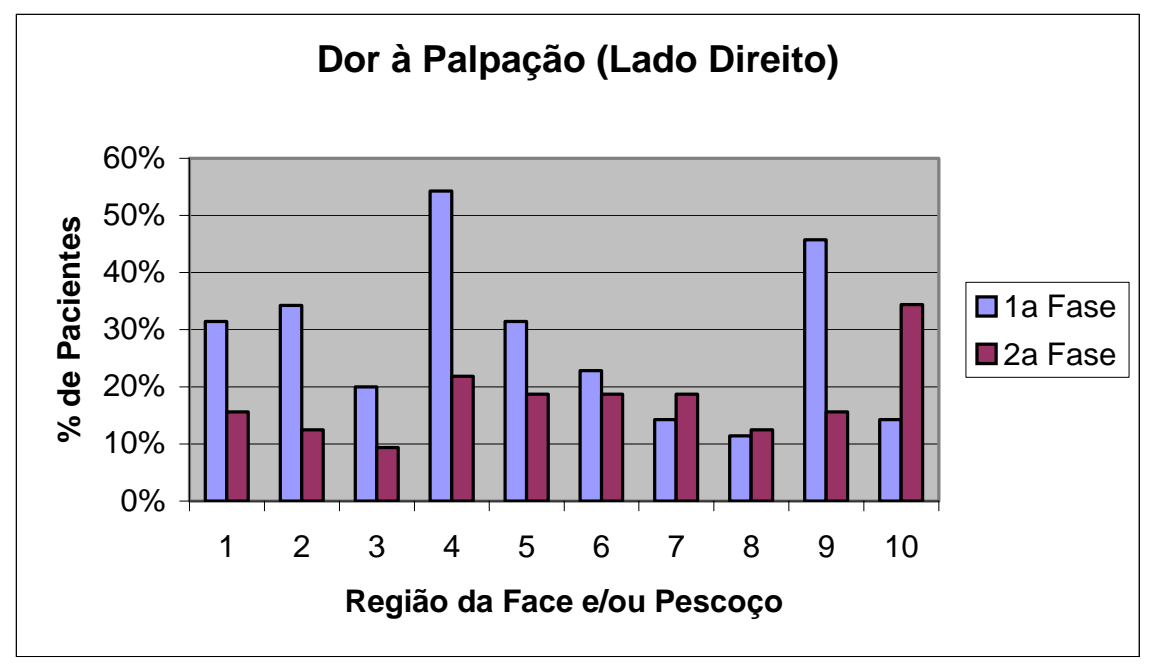

Figura 5: Pacientes do Grupo I, que apresentou Dor à Palpação, lado direito (1: Temporal; 2: Masseter; 3: Pterigóideo Medial; 4: Pterigóideo Lateral; 5: Esternocleidomastoideo; 6: Trapézio; 7: Suprahioideos; 8: Infrahioideos; 9: ATM Pólo Anterior e 10: ATM Pólo Posterior) na $1^{\mathrm{a}}$ e $2^{\mathrm{a}}$ Fase (Antes e Após tratamento).

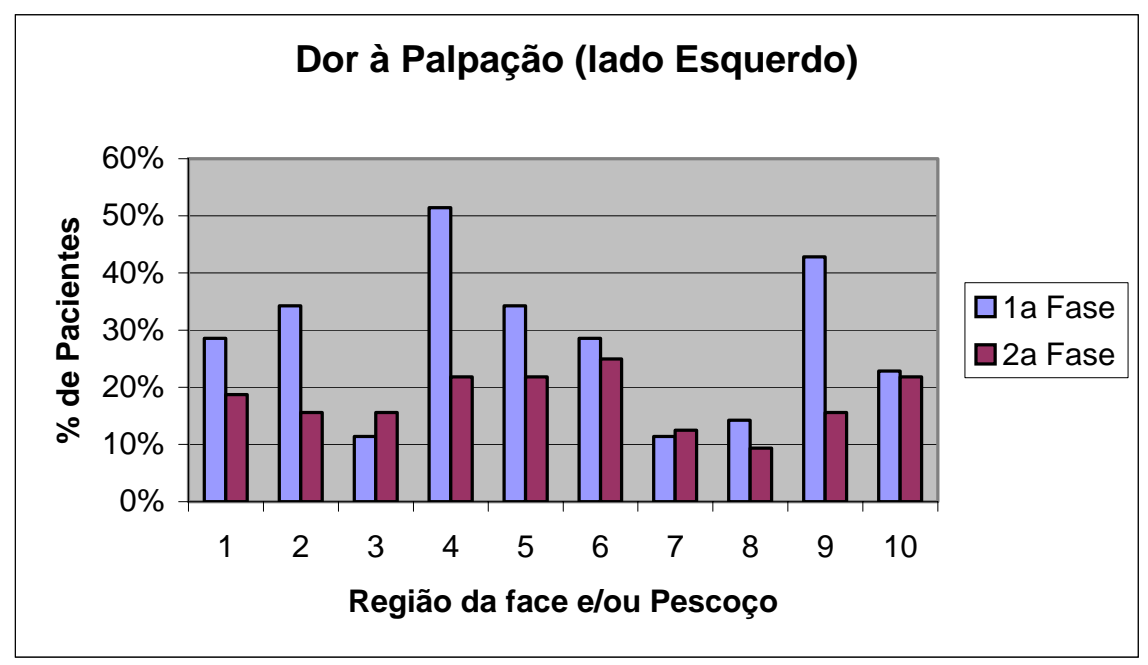

Figura 6: Pacientes do Grupo I, que apresentou Dor à Palpação, lado esquerdo (1: Temporal; 2: Masseter; 3: Pterigóideo Medial; 4: Pterigóideo Lateral; 5: Esternocleidomastoideo; 6: Trapézio; 7: Suprahioideos; 8: Infrahioideos; 9: ATM Pólo Anterior e 10: ATM Pólo Posterior) na $1^{\mathrm{a}}$ e $2^{\mathrm{a}}$ Fase (Antes e Após tratamento). 
Considerando o total de registros de dor nas escalas observa-se uma redução de 279 registros antes do tratamento para 147 registros após o tratamento. Esse fato sugere a sensibilidade das escalas para detectar alterações de dor.

Quanto às intensidades médias de todas as condições de dor em cada uma das escalas analisadas por meio de ANOVAs observa-se redução de dor após tratamento odontológico, exceto para as pontuações da VAS para dor espontânea $[\mathrm{F}(1,24)=2,35$; $\mathrm{p}$ $>0,05]$.

Na caracterização da dor, por meio de categorias verbais presentes na escala CR10, percebe-se que apesar da diminuição das intensidades médias da maioria das condições de dor ela foi classificada tanto antes como após o tratamento odontológico como “fraca” e “moderada” (Tabelas 6 e 11)

Para a dor espontânea, uma ANOVA para dois fatores (2 sessões x 2 lados da face) mostrou diferença entre as sessões somente na escala $\mathbf{C R 1 0}[F(1,24)=5,70$; $\mathrm{p}<0,05]$. Para os dois lados da face não houve diferença na CR10 $[\mathrm{F}(1,24)=0,13$; $\mathrm{p}>0,5]$ e nem na VAS $[F(1,24)=0,0 ; p>0,5]$.

Para a dor durante a função orofacial, uma ANOVA para dois fatores (2 sessões x 3 funções) mostrou diferença entre as sessões na $\mathbf{C R 1 0}[\mathrm{F}(1,24)=50,31 ; \mathrm{p}<0,005]$ e na VAS $[F(1,24)=46,35 ; p<0,001]$; entre as funções na $\mathbf{C R 1 0}[\mathrm{F}(2,48)=13,78 ; \mathrm{p}<0,005]$ e na VAS $[F(2,48)=23,76 ; p<0,001]$ e entre a interação função e sessão na CR10 $[F(2,48)=7,04 ; p<0,005]$ e na VAS $[F(2,48)=8,82 ; p=0,001]$. Comparando as três funções (mastigação, fonação e deglutição) antes e após tratamento houve diferença: 
para a dor à mastigação na $\mathbf{C R 1 0}[\mathrm{F}(1,24)=27,44 ; \mathrm{p}<0,001]$ e na VAS $[\mathrm{F}(1,24)=25,50$; $\mathrm{p}<0,001]$ e para a dor à fonação na $\mathbf{C R 1 0}[\mathrm{F}(1,24)=11,84 ; \mathrm{P}<0,005]$ e na VAS $[\mathrm{F}(1,24)=14,98 ; \mathrm{p}<0,005]$.

Para a dor à palpação, uma ANOVA para três fatores (2 sessões x 10 regiões x 2 lados ) mostrou diferença entre as sessões na CR10 $[\mathrm{F}(1,27)=4,75 ; \mathrm{p}<0,05]$ na VAS $[\mathrm{F}(1,27)=7,41 ; \mathrm{p}<0,05]$, entre as regiões na $\mathbf{C R 1 0}[\mathrm{F}(9,24)=2,8 ; \mathrm{p}<0,01]$ e na VAS $[F(9,243)=3,11 ; p<0,005]$ e entre a interação região e sessão na $\mathbf{C R 1 0}[\mathrm{F}(9,24)=2,84$; $\mathrm{p}<0,01]$ e $[\mathrm{F}(9,243)=3,3 ; \mathrm{p}<0,005]$. Devido a esta interação a análise foi desmembrada considerando cada sessão isoladamente. Neste caso a análise indicou diferença entre as regiões na CR10 $[\mathrm{F}(9,24)=3,48$; $\mathrm{p}<0,001]$ e na VAS $[\mathrm{F}(9,24)=$ 3,85; $\mathrm{p}<0,001$ ] somente antes do tratamento odontológico.

Quanto à percepção dos pacientes acerca da facilidade e adequação das escalas para o registro de dor, os dados antes e após o tratamento odontológico favoreceram a escala CR10 (Tabela 12). Os pacientes que preferiram a CR10, como a mais adequada para registrar a dor, apontaram como principal justificativa para essa escolha a presença de âncoras verbais e numéricas ao longo da escala. 
Tabela 12 - Número e Porcentagem de pacientes, no Grupo I, anterior e posterior ao tratamento odontológico, para cada escala segundo a facilidade de compreensão e adequação para registro de dor

ANTERIOR

POSTERIOR

\begin{tabular}{|c|cc|cc|}
\hline \multirow{2}{*}{ Escala } & $\begin{array}{c}\text { Facilidade de } \\
\text { compreensão }\end{array}$ & $\begin{array}{c}\text { Adequação para } \\
\text { registro de dor }\end{array}$ & $\begin{array}{c}\text { Facilidade de } \\
\text { compreensão }\end{array}$ & $\begin{array}{c}\text { Adequação para } \\
\text { registro de dor }\end{array}$ \\
\hline \multirow{2}{*}{ CR10 } & 19 & 27 & 19 & 27 \\
& $(59,37 \%)$ & $(84,37 \%)$ & $(59,37 \%)$ & $(84,37 \%)$ \\
VAS & 9 & 4 & 8 & 4 \\
& $(28,12 \%)$ & $(12,5 \%)$ & $(25 \%)$ & $(12,5 \%)$ \\
Ambas & 4 & 1 & 5 & $(3,12 \%)$ \\
& $(12,5 \%)$ & $(3,12 \%)$ & $(15,62 \%)$ & $(1$ \\
\hline
\end{tabular}




\section{DISCUSSÃO}

Após o tratamento odontológico conservador (placa mio relaxante, desgaste oclusal e aconselhamento) houve, de forma geral, uma diminuição das intensidades de dor. Essa diminuição foi assistemática considerando as regiões palpadas e as funções orofaciais avaliadas, e sistemática considerando os lados da face e pescoço.

A redução da dor sugere a efetividade do tratamento e a sensibilidade das escalas para registrar a dor (com exceção da VAS para dor espontânea em que não houve diferença entre antes e após o tratamento).

Como parte importante do tratamento deve-se considerar o aconselhamento (realizado durante todo o atendimento) que pode ter possibilitado ao paciente uma compreensão e controle da situação desencadeadora de dor (Kopp, 1977). Além disso, tem-se a influência da simples participação em um atendimento especializado. Isso porque a colaboração com o tratamento pode levar o paciente a retomar o problema a partir de uma postura mais cuidadosa e disposta a alterar a situação.

A alta correlação entre as duas escalas para todas as formas de dor sugere que a modificação realizada no formato da escala CR10 não inviabilizou ou prejudicou a capacidade da mesma para identificar intensidades de dor.

No entanto, a relação entre as categorias verbais e os valores numéricos como proposto na escala CR10 original em inglês diferente na escala modificada sugere que a adaptação de uma escala de razão ancorada em categorias verbais de um idioma para outro deva ser melhor investigado. Assim o Estudo II foi realizado com a aplicação de duas formas distintas da CR10: uma nova modificação (CR10 Modificada II) e a escala 
original (traduzida para o português) cada uma para um grupo de pacientes da clínica de Oclusão da FORP - USP atendidos no primeiro semestre do ano de 2003.

Supôs-se na elaboração desse novo estudo que a discordância encontrada na associação das partes verbal e numérica da Escala CR10 Modificada I e o que é proposto na Escala CR10 Original pudesse estar relacionada à forma como a escala modificada foi apresentada: primeiro as categorias verbais em uma única coluna e depois os valores numéricos, ambos apresentados em uma única folha. Considerou-se que a ordenação das expressões verbais em coluna, observada pelos pacientes, possa ter influenciado os julgamentos. A nova modificação proposta para o Estudo II para investigar a associação correta entre as categorias verbais e os valores numéricos consistiu em apresentar a parte numérica da escala antes da parte verbal. Esta última apresentada em três colunas, assim diminuindo a idéia de ordenação. Essa nova escala foi denominada de CR10 Modificada II. 


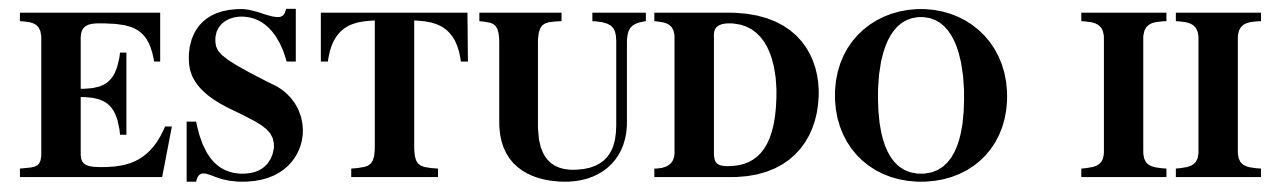




\section{OBJETIVO:}

O objetivo desse estudo foi investigar a discrepância dos resultados encontrados para o Grupo I na associação entre as categorias verbais e os valores numéricos da escala CR10 e o que é proposto originalmente por Borg. Para isso dois novos grupos foram formados no primeiro semestre de 2003: Grupo II para o qual foi aplicada a CR10 com uma nova modificação e Grupo III para o qual foi aplicada a CR10 original. Para os dois grupos foi aplicada a VAS.

\section{MÉTODO}

Participantes: Participaram voluntariamente, no primeiro semestre de 2003, 40 pacientes divididos em dois grupos segundo o tipo de apresentação da Escala CR10. Grupo II (CR10 Modificada II): 23 pacientes sendo M= 4 e F= 19 e Grupo III (CR10 Original): 17 pacientes femininos. As idades variaram entre 14 e 53 anos (média = 33,6 anos) e nível de instrução de primário a terceiro grau (Primeiro Grau: 50 \%; Segundo Grau: 37,5 \%; Terceiro Grau: 12,5 \%). Todos foram encaminhados à clínica de Oclusão da Faculdade de Odontologia de Ribeirão Preto - USP com o diagnóstico de Disfunções Temporomandibulares. O encaminhamento foi feito a partir de uma triagem realizada pelos professores responsáveis pela disciplina de Oclusão II ministrada ao terceiro ano do curso de Odontologia da FORP - USP. A inclusão do paciente no estudo dependeu do preenchimento do Termo de Consentimento (Anexo A) aprovado pelo Comitê de Ética da FORP-USP, protocolo de no. 2001.1.982.58.2.

Material: A aplicação das escalas: CR10 Modificada II, CR10 Original e VAS, foi feita em uma única fase: antes do tratamento odontológico. As aplicações foram 
precedidas por uma anamnese adaptada do roteiro, atualmente, aplicado na clínica psicológica da Universidade de Ribeirão Preto (UNAERP) e do Centro de Psicologia Aplicada da Faculdade de Filosofia, Ciências e Letras de Ribeirão Preto (F.F.C.L.R.P.) para triagem de pacientes adolescentes e adultos (Anexo B).

As aplicações das escalas foram antecedidas por instruções padronizadas para cada uma delas (Anexo D - Escala VAS, Anexo H - Escala CR10 Modificada II e Anexo I - Escala CR10 Original). Foram utilizados diagramas específicos para o registro visual das regiões / pontos de dor (Anexo F) e protocolos para a VAS (Anexo D) e para CR10 Modificada e Original (Anexo H e I respectivamente), onde foram registradas as avaliações de dor dadas por cada paciente.

A segunda modificação realizada na CR10 consistiu de um novo desmembramento da parte verbal e numérica. Nessa modificação os valores numéricos antecederam a apresentação em três colunas das categorias verbais, todos apresentados em uma mesma folha A4. Assim como na primeira modificação somente os valores zero e 10 foram associados às categorias verbais: Absolutamente Nada e Extremamente Forte, respectivamente, como na escala original. A instrução seguiu o mesmo modelo da CR10 Modificada I. (Anexo E).

Procedimento: As escalas foram aplicadas pela própria pesquisadora, na Clínica de Oclusão da FORP- USP. Aleatoriamente, foram distribuídas e aplicadas em um mesmo dia para cada paciente. A obtenção da anamnese e a aplicação das escalas duraram aproximadamente 30 (trinta) minutos.

Assim como para o Grupo I, antes da aplicação das escalas explicou-se o procedimento por meio da leitura, pela pesquisadora, de instruções padronizadas, 
seguido pelo esclarecimento de dúvidas do paciente. Compreendendo as escalas, cada paciente passou por um processo de “calibração”.

A aplicação das escalas, assim como no Grupo I, envolveu a identificação da dor, pelo paciente, por meio de três variáveis avaliadas distintamente: dor espontânea, durante função orofacial e ao exame de palpação . O procedimento de avaliação para cada uma dessas condições de dor foi feito da mesma forma que para o Grupo I.

\section{Tratamento dos dados:}

Os resultados da CR10 Modificada II (Grupo II), relativos a cada categoria verbal foram submetidos ao Teste $t$ - Student para checar se as respectivas médias correspondiam aos valores estabelecidos a elas como na escala original.

Foram calculados os coeficientes de correlação de Pearson entre as pontuações obtidas com as escalas VAS e CR10 Modificada II e VAS e CR10 Original com a finalidade de verificar a validade concorrente dessas escalas para mensurar dor nas DTMs. 


\section{RESULTADOS}

Considerando os Grupos II e III como uma única amostra, o tempo médio de apresentação dos sinais e sintomas foi 6,9 anos. Para 36 pacientes (90\%) a dor apareceu como principal queixa isolada ou associada à outra queixa. Trinta e cinco pacientes (88,37\%) relataram possuir hábitos parafuncionais (bruxismo e/ou briquismo). Quando questionados sobre as possíveis causas do problema que apresentam 10 (25\%) apontaram mais de uma causa, sendo que entre os 40 pacientes, 13 (32,5\%) pacientes apontaram o estresse, 14 (35 \%) apontaram a má oclusão/ausência e/ou desgaste de alguns dentes, três (7,5\%) apontaram o sofrimento de traumas na cabeça, dois (5\%) apontaram a mastigação e nove (22,5\%) não souberam indicar o que poderia estar causando as DTMs. Dentre os 40 pacientes avaliados, onze (27,5 \%) apontaram mais de uma situação que poderia estar relacionada às DTMs. As situações relacionadas foram: tensão emocional (30\%), mastigação/movimentação mandibular (27,5\%), rotina diária (7,5\%), barulho (5\%) e mudança de temperatura (5\%). Doze pacientes (30\%) não relacionaram às DTMs a quaisquer fatos externos e/ou internos. Antes de iniciar o atendimento na clínica de oclusão, trinta pacientes (75\%) já haviam consultado outros profissionais da saúde: cirurgiões-dentistas, fisioterapeutas e médicos (clínico-geral, neurologista, oftalmologista, otorrinolaringologista e psiquiatra). Os dados obtidos com as anamneses são apresentados nos anexos (Anexo L).

As queixas principais que levaram os pacientes a buscar o tratamento odontológico foram analisadas e organizadas em categorias comuns apresentadas na Tabela 13. 
Tabela 13 - Número e porcentagem de pacientes em relação à queixa principal

\begin{tabular}{|c|c|}
\hline Queixa Principal & Número e Porcentagem de Pacientes \\
\hline Dor orofacial & $24(60 \%)$ \\
\hline Dor e Cãibras no pescoço & $1(2,5 \%)$ \\
\hline Dor e Estalos nas ATMs & $5(12,5 \%)$ \\
\hline $\begin{array}{c}\text { Dor e Encaminhamento de outro } \\
\text { profissional }\end{array}$ & $1(2,5 \%)$ \\
\hline $\begin{array}{c}\text { Dor e Dificuldade de abertura de boca e } \\
\text { mastigação / Hábito Parafuncional / Má } \\
\text { oclusão }\end{array}$ & $4(10 \%)$ \\
\hline $\begin{array}{l}\text { Dor e Dificuldade de abertura de boca e } \\
\text { mastigação / Hábito Parafuncional / Má } \\
\text { oclusão e Estalos nas ATMs }\end{array}$ & $1(2,5 \%)$ \\
\hline $\begin{array}{l}\text { Dificuldade de abertura de boca e } \\
\text { mastigação / Hábito Parafuncional / Má } \\
\text { oclusão e Encaminhamento profissional }\end{array}$ & $1(2,5 \%)$ \\
\hline Estalos nas ATMs & $2(5 \%)$ \\
\hline Encaminhamento de outro profissional & $1(2,5 \%)$ \\
\hline
\end{tabular}

\section{GRUPO II}

Quanto à incidência da dor, a maior porcentagem foi de Dor Espontânea (78,26\% e 69,56\% no lado direito e esquerdo, respectivamente) seguida pela Dor à Mastigação (65,21\%). (Tabelas 14 e 15). 
Tabela 14 - Caracterização da Dor Espontânea, no Grupo II, segundo a localização (Direita ou Esquerda), o número de pacientes, as médias e desvios padrão nas escalas VAS e CR10 de Borg

\begin{tabular}{|c|c|c|c|c|c|}
\hline \multirow{2}{*}{ Localização } & $\begin{array}{c}\text { No Sujeitos } \\
(\%)\end{array}$ & \multicolumn{2}{|c|}{ VAS } & \multicolumn{2}{c|}{ CR10 } \\
\hline Direito & $\begin{array}{c}18 \\
(78,26 \%)\end{array}$ & 5,66 & 2,18 & 6,28 & 2,16 \\
Esquerdo & $\begin{array}{c}16 \\
(69,56 \%)\end{array}$ & 6,08 & 2,13 & 6,63 & 2,16 \\
\hline
\end{tabular}

Tabela 15 - Caracterização da Dor à Função Orofacial, no Grupo II, segundo à função (Mastigação, Fonação, Deglutição), o número de pacientes, as médias e desvios padrão nas escalas VAS e CR10 de Borg

\begin{tabular}{|c|c|c|c|c|c|}
\hline \multirow{2}{*}{$\begin{array}{c}\text { Função } \\
\text { Orofacial }\end{array}$} & $\begin{array}{c}\text { No Sujeitos } \\
(\%)\end{array}$ & \multicolumn{3}{|c|}{ VAS } & \multicolumn{3}{c|}{ CR10 } \\
\hline Mastigação & $\begin{array}{c}\text { Média } \\
(65,21 \%)\end{array}$ & 6,19 & 2,36 & 6,47 & 2,00 \\
Fonação & $\begin{array}{c}13 \\
(56,52 \%)\end{array}$ & 6,66 & 2,08 & 6,60 & 1,71 \\
Deglutição & 6 & 6,08 & 3,76 & 5,70 & 4,00 \\
\hline
\end{tabular}


Tabela 16 - Caracterização da Dor à Palpação no lado Direito, no Grupo II, segundo a localização (músculos e ATM), o número de pacientes, as médias e desvios padrão nas escalas VAS e CR10 de Borg

\begin{tabular}{|c|c|c|c|c|c|}
\hline Localização & $\begin{array}{c}\text { No } \\
\text { Pacientes } \\
\text { (\%) }\end{array}$ & Média & DP & Média & DP \\
\hline Temporal & $\begin{array}{c}9 \\
(39,13 \%)\end{array}$ & 4,17 & 2,49 & 4,03 & 2,71 \\
\hline Masséter & $\begin{array}{c}9 \\
(39,13 \%)\end{array}$ & 4,46 & 2,61 & 4,02 & 2,82 \\
\hline Pterigoideo Medial & $\begin{array}{c}7 \\
(30,43 \%)\end{array}$ & 2,79 & 1,45 & 3,00 & 1,85 \\
\hline Pterigoideo Lateral & $\begin{array}{c}10 \\
(43,48 \%)\end{array}$ & 3,60 & 2,48 & 3,35 & 2,71 \\
\hline Esternocleidom. & $\begin{array}{c}9 \\
(39,13 \%)\end{array}$ & 3,81 & 1,28 & 3,33 & 1,60 \\
\hline Trapézio & $\begin{array}{c}7 \\
(30,43 \%)\end{array}$ & 4,69 & 2,56 & 4,21 & 2,94 \\
\hline Supra-Hioideos & $\begin{array}{c}7 \\
(30,43 \%)\end{array}$ & 1,77 & 1,31 & 1,97 & 1,51 \\
\hline Infra- Hioideos & $\begin{array}{c}2 \\
(8,70 \%)\end{array}$ & 2,90 & 1,13 & 3,25 & 2,47 \\
\hline ATM- Polo Lateral & $\begin{array}{c}10 \\
(43,48 \%)\end{array}$ & 6,26 & 2,69 & 5,70 & 2,28 \\
\hline ATM- Polo Posterior & $\begin{array}{c}12 \\
(52,17 \%)\end{array}$ & 4,49 & 3,02 & 4,21 & 2,62 \\
\hline
\end{tabular}


Tabela 17 - Caracterização da Dor à Palpação no lado Esquerdo, no Grupo II, segundo a localização (músculos e ATM), o número de pacientes e as médias nas escalas VAS e CR10 de Borg

\begin{tabular}{|c|c|c|c|c|c|}
\hline Localização & $\begin{array}{c}\text { No } \\
\text { Pacientes } \\
\text { (\%) }\end{array}$ & Média & DP & Média & DP \\
\hline Temporal & $\begin{array}{c}9 \\
(39,13 \%)\end{array}$ & 3,54 & 2,62 & 3,44 & 3,00 \\
\hline Masséter & $\begin{array}{c}8 \\
(34,78 \%)\end{array}$ & 5,14 & 2,41 & 4,75 & 2,45 \\
\hline Pterigoideo Medial & $\begin{array}{c}7 \\
(30,43 \%)\end{array}$ & 2,71 & 1,17 & 2,79 & 0,99 \\
\hline Pterigoideo Lateral & $\begin{array}{c}7 \\
(30,43 \%)\end{array}$ & 4,43 & 2,23 & 3,57 & 2,82 \\
\hline Esternocleidom. & $\begin{array}{c}9 \\
(39,13 \%)\end{array}$ & 2,92 & 1,50 & 3,33 & 1,56 \\
\hline Trapézio & $\begin{array}{c}10 \\
(43,48 \%)\end{array}$ & 4,59 & 2,14 & 4,30 & 2,31 \\
\hline Supra-Hioideos & $\begin{array}{c}7 \\
(30,43 \%)\end{array}$ & 1,77 & 1,31 & 1,97 & 1,51 \\
\hline Infra- Hioideos & $\begin{array}{c}2 \\
(8,70 \%)\end{array}$ & 2,90 & 1,13 & 3,25 & 2,47 \\
\hline ATM- Polo Lateral & $\begin{array}{c}9 \\
(39,13 \%)\end{array}$ & 6,23 & 2,95 & 5,94 & 2,72 \\
\hline ATM- Polo Posterior & $\begin{array}{c}8 \\
(34,78 \%)\end{array}$ & 4,46 & 3,15 & 4,38 & 2,81 \\
\hline
\end{tabular}


Entre os 23 pacientes avaliados no Grupo II, 22 (95,65\%) apresentaram dor em pelo menos uma das 24 condições de medidas possíveis (dor espontânea: uma condição, dor durante função: três condições, dor à palpação: vinte condições, sendo dez para cada lado da face e/ou pescoço). Esses 22 sujeitos produziram um total de 217 medidas de dor em cada uma das escalas, sendo 34 para dor espontânea, 25 para dor durante função orofacial e 158 para dor à palpação.

Pode-se observar que, nesse grupo, as associações entre os valores numéricos e as âncoras verbais, como proposto na escala CR10 original em inglês, diferem das associações encontradas em português. As categorias: "fraco", "moderado", "forte” e “muito forte” foram associadas respectivamente aos valores médios de 2,97; 3,74; 6,10 e 7,75 diferentes significativamente $(\mathrm{p}<0,05)$ dos valores “2”, “3”, “5” e “7” como na versão original. A maior parte dos pacientes avaliou a dor em primeiro lugar como “Forte”; em segundo lugar como "Fraca” e em terceiro como “Moderada” (Tabela 18).

Tabela 18 - Categorias verbais em Inglês e em Português (Brasil) usadas como âncoras da escala CR10 no Grupo II (CR10 modificada para a língua portuguesa)

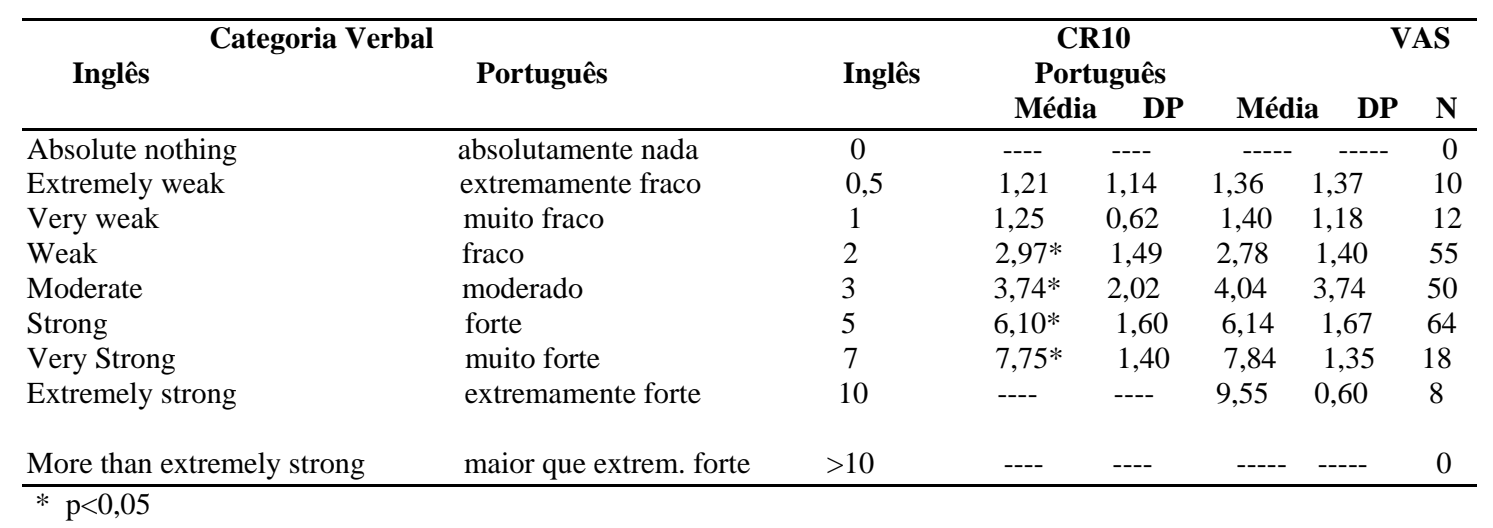


Os coeficientes da correlação de Pearson entre todas pontuações da VAS e da CR10 foi de 0,9 indicando um alto grau de validade de critério. Os coeficientes de correlação para cada avaliação de dor separadamente foram: 0,69 para dor espontânea; 0,82 para dor durante função e 0,91 para dor durante palpação (Figura 7).

\section{CR 10 Modificada}

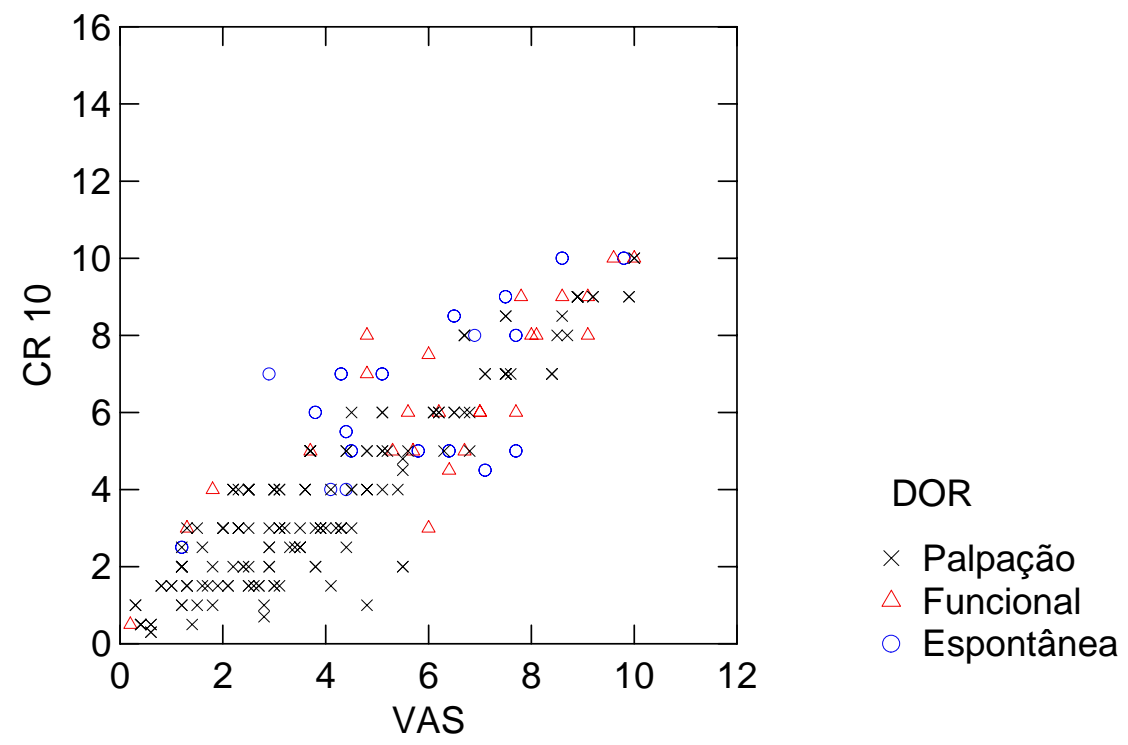

Figura 7: Relação entre os valores numéricos, segundo os três tipos de dor (à palpação, funcional e espontânea), apresentados na VAS e na CR10, no Grupo II (CR10 Modificada).

Quanto à percepção dos pacientes acerca da facilidade e adequação das escalas para o registro de dor, a maioria dos pacientes preferiu a Escala CR10 (Tabela 19). A principal justificativa para a escolha da CR10 como escala mais adequada, no Grupo II, foi a presença de valores numéricos (apontados por 47,83\% dos pacientes). (Figura 8) 
Tabela 19 - Número e Porcentagem de pacientes, no Grupo II, para cada escala segundo a facilidade de compreensão e adequação para registro de dor

\begin{tabular}{|c|cc|}
\hline Escala & $\begin{array}{c}\text { Facilidade de } \\
\text { compreensão }\end{array}$ & $\begin{array}{c}\text { Adequação para } \\
\text { registro de dor }\end{array}$ \\
\hline CR10 & 14 & 18 \\
& $(60,90 \%)$ & $(78,26 \%)$ \\
VAS & 4 & 2 \\
& $(17,40 \%)$ & $(8,70 \%)$ \\
Ambas & 5 & 3 \\
& $(21,74 \%)$ & $(13,04 \%)$ \\
\hline
\end{tabular}

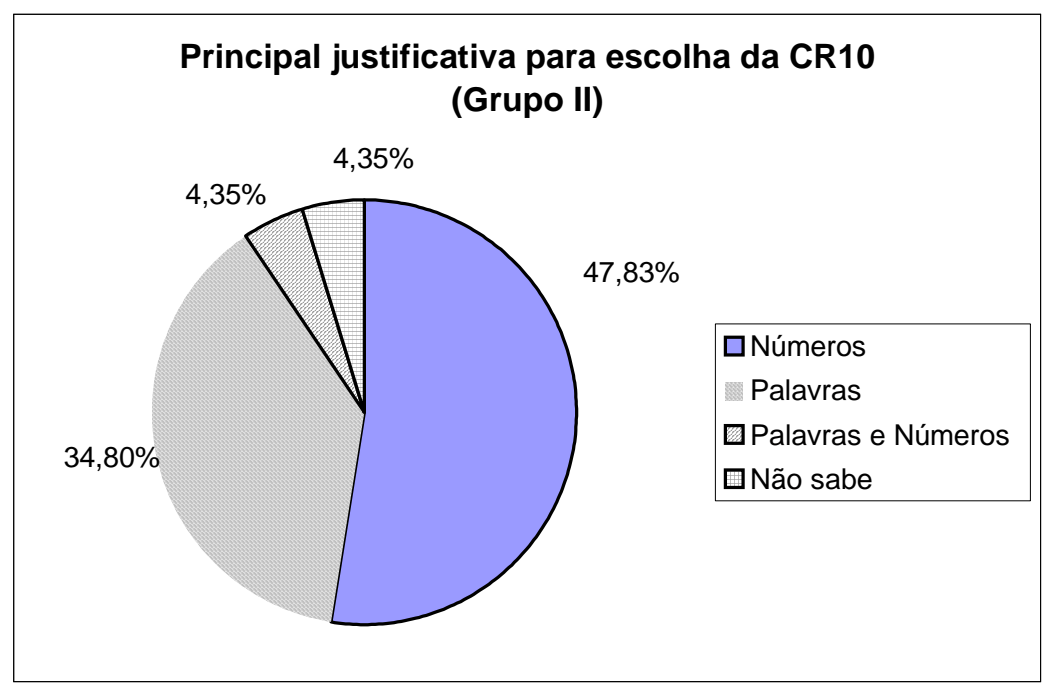

Figura 8: Principal justificativa apontada pelos 23 pacientes do Grupo II (CR10 Original) para escolha da CR10 como escala mais adequada para mensurar dor. 


\section{GRUPO III}

Quanto à incidência da dor, a maior porcentagem foi de Dor Espontânea (ambos os lados, direito e esquerdo da face em 76,47\% dos pacientes) seguida pela Dor à Mastigação (52,94\% dos pacientes) (Tabelas 20 e 21).

Tabela 20 - Caracterização de Dor Espontânea, no Grupo III, segundo a localização (Direita ou Esquerda), o número de pacientes, as médias e desvios padrão nas escalas VAS e CR10 de Borg

\begin{tabular}{|c|c|cc|cc|}
\hline & \multicolumn{2}{|c|}{ VAS } & \multicolumn{3}{c|}{ CR10 } \\
Localização & $\begin{array}{c}\text { No Sujeitos } \\
(\%)\end{array}$ & Média & DP & Média & DP \\
\hline Direito & $\begin{array}{c}13 \\
(76,47 \%)\end{array}$ & 5,25 & 3,80 & 4,27 & 3,43 \\
Esquerdo & $\begin{array}{c}13 \\
(76,47 \%)\end{array}$ & 5,72 & 4,05 & 5,12 & 4,50 \\
\hline
\end{tabular}


Tabela 21 - Caracterização da Dor à Função Orofacial, no Grupo III, segundo à função (Mastigação, Fonação, Deglutição), o número de pacientes, as médias e desvios padrão nas escalas VAS e CR10 de Borg

\begin{tabular}{|c|c|cc|cc|}
\hline \multirow{2}{*}{$\begin{array}{c}\text { Função } \\
\text { Orofacial }\end{array}$} & $\begin{array}{c}\text { No Sujeitos } \\
(\%)\end{array}$ & \multicolumn{2}{|c|}{ VAS } & \multicolumn{3}{c|}{ CR10 } \\
\hline Mastigação & $\begin{array}{c}\text { Média } \\
(52,94 \%)\end{array}$ & DP & Média & DP \\
Fonação & $\begin{array}{c}4,59 \\
(23,53 \%)\end{array}$ & 4,23 & 2,80 & 2,90 & 1,55 \\
Deglutição & $\begin{array}{c}3 \\
(17,65 \%)\end{array}$ & 4,10 & 3,52 & 1,83 & 1,61 \\
\hline
\end{tabular}


Tabela 22 - Caracterização da Dor à Palpação no lado Direito, no Grupo III, segundo a localização (músculos e ATM), o número de pacientes e as médias nas escalas VAS e CR10 de Borg

\begin{tabular}{|c|c|c|c|c|c|}
\hline \multirow{2}{*}{ Localização } & \multirow{2}{*}{$\begin{array}{c}\text { No Pacientes } \\
\text { (\%) }\end{array}$} & \multicolumn{2}{|c|}{ VAS } & \multicolumn{2}{|c|}{ CR10 } \\
\hline & & Média & $\mathrm{DP}$ & Média & DP \\
\hline Temporal & $\begin{array}{c}8 \\
(47,06 \%)\end{array}$ & 2,45 & 2,02 & 2,31 & 1,44 \\
\hline Masséter & $\begin{array}{c}5 \\
(29,41 \%)\end{array}$ & 2,40 & 2,69 & 2,28 & 1,94 \\
\hline $\begin{array}{c}\text { Pterigoideo } \\
\text { Medial }\end{array}$ & $\begin{array}{c}5 \\
(29,41 \%)\end{array}$ & 5,28 & 3,61 & 3,46 & 2,56 \\
\hline $\begin{array}{c}\text { Pterigoideo } \\
\text { Lateral }\end{array}$ & $\begin{array}{c}4 \\
(23,53 \%)\end{array}$ & 2,75 & 2,32 & 1,83 & 1,89 \\
\hline Esternocleidom. & $\begin{array}{c}6 \\
(35,30 \%)\end{array}$ & 3,87 & 2,40 & 3,38 & 1,36 \\
\hline Trapézio & $\begin{array}{c}6 \\
(35,30 \%)\end{array}$ & 2,22 & 2,20 & 3,67 & 1,86 \\
\hline Supra-Hioideos & $\begin{array}{c}5 \\
(29,41 \%)\end{array}$ & 3,52 & 2,78 & 2,88 & 1,40 \\
\hline Infra- Hioideos & $\begin{array}{c}2 \\
(11,76 \%)\end{array}$ & 4,45 & 3,18 & 4,00 & 2,83 \\
\hline $\begin{array}{c}\text { ATM- Polo } \\
\text { Lateral }\end{array}$ & $\begin{array}{c}9 \\
(52,94 \%)\end{array}$ & 5,83 & 3,00 & 5,16 & 2,80 \\
\hline $\begin{array}{l}\text { ATM- Polo } \\
\text { Posterior }\end{array}$ & $\begin{array}{c}8 \\
(47,06 \%)\end{array}$ & 3,83 & 3,24 & 3,80 & 2,48 \\
\hline
\end{tabular}


Tabela 23 - Caracterização da Dor à Palpação no lado Esquerdo, no Grupo III, segundo a localização (músculos e ATM), o número de pacientes e as médias nas escalas VAS e CR10 de Borg

\begin{tabular}{|c|c|c|c|c|c|}
\hline Localização & $\begin{array}{c}\text { No } \\
\text { Pacientes } \\
\text { (\%) }\end{array}$ & Média & DP & Média & DP \\
\hline Temporal & $\begin{array}{c}8 \\
(47,06 \%)\end{array}$ & 3,17 & 2,11 & 2,54 & 1,54 \\
\hline Masséter & $\begin{array}{c}8 \\
(47,06 \%)\end{array}$ & 2,11 & 2,18 & 2,30 & 1,45 \\
\hline Pterigoideo Medial & $\begin{array}{c}5 \\
(29,41 \%)\end{array}$ & 4,62 & 2,80 & 2,70 & 1,60 \\
\hline Pterigoideo Lateral & $\begin{array}{c}5 \\
(29,41 \%)\end{array}$ & 3,40 & 1,51 & 2,00 & 1,27 \\
\hline Esternocleidom. & $\begin{array}{c}8 \\
(47,06 \%)\end{array}$ & 2,84 & 2,45 & 2,26 & 1,70 \\
\hline Trapézio & $\begin{array}{c}8 \\
(47,06 \%)\end{array}$ & 3,33 & 2,80 & 2,75 & 1,60 \\
\hline Supra-Hioideos & $\begin{array}{c}5 \\
(29,41 \%)\end{array}$ & 3,52 & 2,80 & 2,90 & 1,40 \\
\hline Infra- Hioideos & $\begin{array}{c}2 \\
(11,76 \%)\end{array}$ & 4,45 & 3,18 & 4,00 & 2,83 \\
\hline ATM- Polo Lateral & $\begin{array}{c}9 \\
(52,94 \%)\end{array}$ & 4,32 & 1,90 & 4,00 & 1,65 \\
\hline ATM- Polo Posterior & $\begin{array}{c}11 \\
(64,70 \%)\end{array}$ & 4,51 & 2,85 & 4,09 & 2,60 \\
\hline
\end{tabular}


No Grupo III, entre os 17 sujeitos avaliados, 16 (94,12\%) apresentaram algum tipo de dor, produzindo um total de 169 medidas de dor sendo 26 para dor espontânea; 16 para dor durante função e 127 para dor à palpação. Nesse grupo, as âncoras “absolutamente nada”, "muito fraco", “moderado", "forte” e "muito forte” foram associadas a valores numéricos médios de 0,30; 1,30; 3,40; 5,45 e 8,03 significativamente diferentes dos valores “0”, “1”, “3”, “5” е “7” propostos na escala original (Tabela 24). Pode-se observar que no Grupo III a maior parte dos pacientes avaliou a dor na seguinte ordem: "Moderada”, “Fraca” e "Forte”.

Tabela 24 - Categorias verbais em Inglês e em Português (Brasil) usadas como âncoras da escala CR10 no Grupo III (CR10 Original)

\begin{tabular}{|c|c|c|c|c|c|c|c|}
\hline \multicolumn{2}{|c|}{ Categoria Verbal } & \multicolumn{6}{|c|}{ CR10 } \\
\hline \multirow{2}{*}{ Inglês } & \multirow[t]{2}{*}{ Português } & \multirow[t]{2}{*}{ Inglês } & \multicolumn{2}{|c|}{ Português } & \multirow[b]{2}{*}{ Média } & \\
\hline & & & Média & DP & & DP & \\
\hline & 7 & & 07 & 8 & $\overline{00}$ & $0 \div 2$ & \\
\hline & & & & 0,30 & 0,01 & 0,כ3 & 11 \\
\hline Extremely weak & extremamente fraco & 0,5 & 0,53 & 0,19 & 1,03 & 0,66 & 18 \\
\hline Very weak & muito fraco & 1 & $1,30 *$ & 0,26 & 1,17 & 0,64 & 10 \\
\hline Weak & fraco & 2 & 2,03 & 0,38 & 3,35 & 2,50 & 34 \\
\hline Moderate & moderado & 3 & $3,40 *$ & 0,61 & 3,92 & 1,91 & 52 \\
\hline Strong & forte & 5 & $5,45^{*}$ & 0,50 & 6,38 & 1,56 & 26 \\
\hline Very Strong & muito forte & 7 & $8,03 *$ & 1,01 & 9,01 & 1,14 & 15 \\
\hline Extremely strong & extremamente forte & 10 & 10,00 & ---- & 10,00 & ---- & 2 \\
\hline More than extremely strong & maior que extrem. forte & $>10$ & 15,00 & ---- & 10,00 & ---- & 1 \\
\hline
\end{tabular}

No Grupo III, o coeficiente da correlação de Pearson foi 0,8 indicando um alto grau de validade de critério. Considerando cada avaliação de dor separadamente os coeficientes foram: 0,80 para dor espontânea; 0,90 para dor durante função e 0,78 para dor durante palpação (Figura 9). 
CR 10 Original

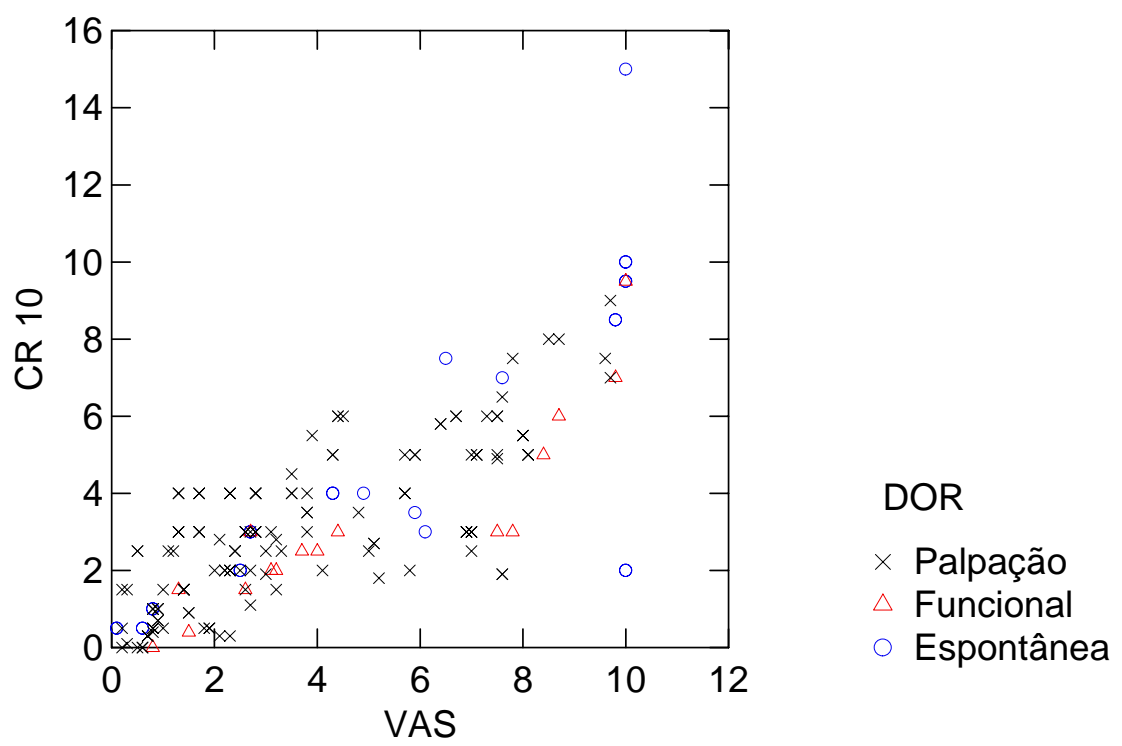

Figura 9: Relação entre os valores numéricos, segundo os três tipos de dor (à palpação, funcional e espontânea), apresentados na VAS e na CR10, no Grupo III (CR10 Original traduzida para o português).

Quanto à percepção dos pacientes acerca da facilidade e adequação das escalas para o registro de dor, a maioria dos pacientes do Grupo III preferiu a Escala CR10 (Tabela 25). A principal justificativa para a escolha da CR10 como escala mais adequada foi, com igual porcentagem, a presença de âncoras verbais e valores numéricos ao longo da escala (ambos apontados por 35,3\% dos pacientes) (Figura 10). 
Tabela 25. Número e Porcentagem de pacientes, no Grupo III, para cada escala segundo a facilidade de compreensão e adequação para registro de dor

\begin{tabular}{|c|cc|}
\hline Escala & $\begin{array}{c}\text { Facilidade de } \\
\text { compreensão }\end{array}$ & $\begin{array}{c}\text { Adequação para } \\
\text { registro de dor }\end{array}$ \\
\hline CR10 & 10 & 16 \\
& $(58,82 \%)$ & $(94,12 \%)$ \\
VAS & 2 & 1 \\
& $(11,76 \%)$ & $(5,88 \%)$ \\
Ambas & 5 & 0 \\
& $(29,41 \%)$ & $(0,00 \%)$ \\
\hline
\end{tabular}

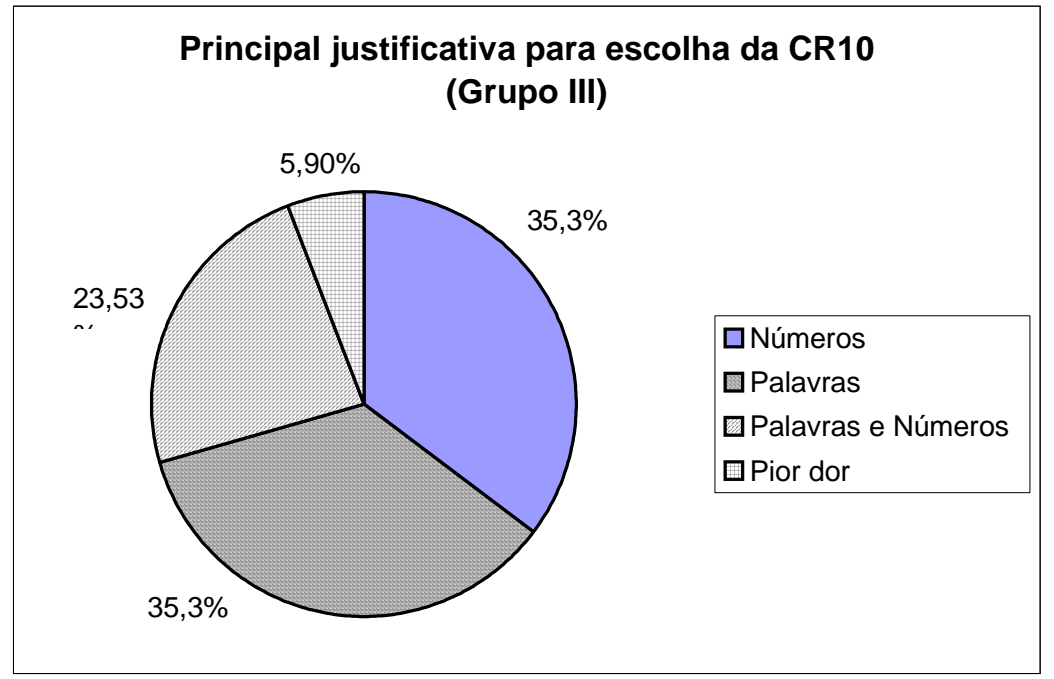

Figura 10: Principal justificativa apontada pelos 17 pacientes do Grupo III (CR10 Original) para escolha da CR10 como escala mais adequada para mensurar dor. 


\section{DISCUSSÃO}

Nesse segundo estudo a dor mais freqüente foi a dor Espontânea em ambos os lados da cabeça e pescoço. Quanto à intensidade, as escalas CR10 e VAS demonstraram pontuações para a dor Espontânea e para a dor Durante Função mais intensas do que para dor Durante Palpação. Destaca-se que para a avaliação da dor Espontânea e da dor Durante Função a dor poderia não estar presente no momento do registro das escalas. Sendo assim esperar-se-ia nesses casos a influência direta do “fator memória” nos julgamentos. De fato, segundo Linton e Götestam (1983), poderiam ser esperadas discrepâncias para o registro de dor Espontânea e Durante Função em relação à dor Durante Palpação.

No Grupo II, onde foi apresentada a CR10 Modificada II houve um menor coeficiente de correlação para os registros da Dor Espontânea e da Dor Durante Função nas escalas CR10 e VAS comparado ao coeficiente de correlação para Dor à Palpação. Esses dados apóiam os resultados de Linton e Melin (1982) que mostram que pacientes com dores crônicas não se lembram acuradamente dos níveis de dor já vivenciados.

Inversamente, no Grupo III (para o qual foi apresentada a escala CR10 Original) a correlação entre os registros da CR10 e da VAS para a dor Durante Palpação foi menor do que para A Dor Espontânea e para a Dor Durante Função. Segundo Le Resche et al (1988) a dor Durante palpação pode ser considerada como a mais objetiva. Levando isso em consideração, a redução do coeficiente de correlação entre os registros da VAS e da Cr10 para Dor à Palpação, no Grupo III, pode indicar discordância entre o que foi encontrado e o que seria esperado nas pontuações da CR10. 
De forma geral, houve alta correlação entre os registros da CR10 Modificada II e VAS (Grupo II) e CR10 original e VAS (Grupo III) o que sugere que todas essas escalas sejam eficazes na identificação e mensuração da dor (Coeficiente de Correlação de Pearson = 0,9 no Grupo II e 0,8 no Grupo III).

As justificativas para a escolha da CR10 como escala mais adequada foram a presença ou de números ou de palavras. A associação dos dois fatores foi apontada por um número maior de pacientes na Escala CR10 Original (23,53\% - Grupo III) do que na Escala CR10 Modificada (4,35\% - Grupo II). Esse fato pode ser decorrente da forma de apresentação das escalas: enquanto para o Grupo II as palavras foram apresentadas dissociadas dos números para o Grupo III ambos eram pareados.

A presença de números como justificativa para a escolha da CR10, por uma grande porcentagem de pacientes de ambos os grupos, contradiz os resultados de HarmsRingdahl et al (1986) de que a maior parte dos pacientes prefere a escala verbal à numérica.

Com relação à associação entre a escala verbal e a numérica, presentes na CR10, os resultados mostraram discrepâncias significativas $(\mathrm{p}<0,01)$ entre os valores numéricos apresentados para algumas categorias e os que são propostos na escala CR10 original em inglês. Nos Grupos II e III, as categorias “moderado”, “forte” e “muito forte” foram associadas a valores superiores aos valores 3, 5 e 7, propostos na versão original para cada uma daquelas categorias. Nesse estudo, os valores encontrados foram respectivamente 3,74; 6,10 e 7,75 no Grupo II e 3,40; 5,45 e 8,03 no Grupo III. Além disso, em cada um dos grupos existiram outras associações entre categoria e valor numérico significativamente diferentes dos propostos na escala CR10 original. 
Esses resultados corroboram os encontrados no Grupo I na primeira fase de coleta de dados (Antes do tratamento odontológico) em que as categorias: “moderado”, “forte” e "muito forte” foram associadas aos valores numéricos respectivamente 4,60; 7,41 e 9,63 significativamente superiores aos propostos na versão original. Evidencia-se assim que as categorias verbais traduzidas para o português utilizadas na escala CR10 tenham valores quantitativos diferentes associados aos seus significados semânticos comparadas às mesmas categorias na língua inglesa. Sugere-se a partir disso que seja feita uma modificação adequada da Escala CR10 para a população brasileira, ao menos para mensurar especificamente a dor em DTMs. 
DISCUSSÃO

GERAL 
A percepção dos pacientes acerca das DTMs mostra que fatores psicológicos como estresse e fatores neuromusculares como distúrbios oclusais têm grande importância nessas Disfunções (CALDANA \& SILVA, 2001).

A forte relação entre DTMs e hábitos parafuncionais está de acordo com os resultados encontrados por Egermark et al, (2001). No entanto, assim como apontado na literatura, o presente estudo não permite a distinção desses hábitos como etiologia e/ou conseqüência das DTMs.

O grande número de pacientes que procurou por profissionais não especializados no tratamento das DTMs antes de iniciar o atendimento na clínica de oclusão da FORPUSP pode ser sugestiva de que exista falta de conhecimento por parte dos portadores dessas disfunções do que seja e/ou como se tratam as DTMs como apontado na literatura por Carniel (2001). Concomitante a esse fato, o baixo percentual de pacientes que chegou ao serviço por encaminhamento de outro profissional da saúde indica que persiste entre os profissionais uma dificuldade em se diagnosticar corretamente as DTMs e conseqüentemente encaminhar o paciente para um atendimento adequado.

A presença de dor como principal queixa de pacientes com DTMs como é sugerido pela literatura específica da área (FELÍCIO \& MAZZETTO, 1994, KROGSTAD et al, 1996 e CARNIEL, 2001) é confirmado no presente estudo, onde 82,86\% dos pacientes no Estudo I e 90\% dos pacientes no Estudo II apontaram a presença desse sintoma como um fator mobilizador para a busca de atendimento especializado. A dor avaliada, principalmente, como "Fraca” e "Moderada" e com duração média de 5,67 anos no Estudo I e 6,9 anos no Estudo II indica o caráter crônico dessas Disfunções. O paciente sente-se incomodado com a dor, mas convive 
com ela por vários anos antes de procurar ajuda profissional, sugerindo que, de fato, esse sintoma seja intermitente (KOPP, 1977), recorrente (SIQUEIRA \& TEIXEIRA, 2001) e tenha desenvolvimento gradual (KROGSTAD et al, 1996). No entanto, a pressuposição de que o paciente busque ajuda profissional especializada somente quando o sintoma encontra-se intenso, não se confirmou nesse estudo.

A grande incidência de DTMs entre mulheres e adultos jovens (LE RESCHE, 1997; HENRIKSON \& NILNER, 2000; SIQUEIRA \& TEIXEIRA, 2001 E SIPILÄ, 2002) é confirmada, cuja maioria dos pacientes é do sexo feminino (82,86\% no Estudo I e 90\% no Estudo II) e com idade média de 31,7 anos no Estudo I e 33,6 anos no

\section{Estudo II}

As altas correlações obtidas com as três formas de apresentação da CR10 e a VAS evidenciam que essas escalas sejam eficazes na identificação e mensuração da dor. Deve-se considerar que a dor nas DTMs aparece principalmente caracterizada por valores entre 2 e 6 . Sendo assim a VAS representada por uma linha de $10 \mathrm{~cm}$ possibilita a avaliação da dor de forma mais fiel e concordante com a escala CR10. Observa-se também que a baixa escolaridade não se mostra como fator limitante para a aplicação dessas escalas.

Quanto à preferência, a maioria dos pacientes de todos os grupos apontou a Escala CR10 (tanto a modificada quanto a original) como mais fácil de compreender e mais adequada para mensurar dor. Esse resultado pode sugerir que a presença de referências para a dor como as âncoras verbais e numéricas presentes na CR10 representam uma vantagem sobre a VAS (que não dispõe de referências internas). A comparação com vivências passadas de dor pode também facilitar ao paciente a 
avaliação da dor atual. A partir disso, pode-se privilegiar a CR10 como instrumento de escolha segundo os critérios de seleção de escalas propostos por Chapman e Syrjala, (1991): facilidade de compreensão pelo paciente, capacidade de registrar memória de dor e fornecimento ao examinador de uma ampla série de pontuações, além de sensibilidade a intervenções analgésicas.

A utilização da escala CR10 pelo cirurgião-dentista pode representar um ganho na medida em que possibilita ao paciente melhor compreender as instruções quando comparada à escala VAS, tradicionalmente usada, aumentando assim as chances de obtenção de respostas mais precisas para a avaliação de dor. Ao mesmo tempo, a utilização da CR10 permite a comparação não somente intra, mas, também interindividual, possibilitando com isso estudos populacionais que visem uma compreensão mais ampla para as DTMs. A utilização da CR10 pode por fim, repercutir em diagnósticos mais precisos e planos de tratamento melhor elaborados.

No entanto, considerando os resultados dos Estudos I e II evidencia-se que as categorias verbais: “moderado”, “forte” e “muito forte”, utilizadas na CR10, quando traduzidas para o português possuem significados semânticos diferentes do que as mesmas categorias em inglês propostas na versão original da escala. Deve-se considerar no uso da palavra "moderado" presente na CR10 que essa palavra não faz parte usualmente da classificação da dor na língua portuguesa. A palavra "moderado” vem do latim e significa "medíocre em quantidade ou qualidade”. Dessa forma, o uso dessa palavra pode gerar interpretações pouco específicas na quantificação da dor dificultando a associação com valores numéricos. Outro problema observado na tradução literal das categorias verbais da CR10 para o português está relacionado ao significado que a 
palavra “forte” e "muito forte” podem adquirir na classificação da dor. A palavra "forte” advém do latim e significa "enérgico, poderoso, substancioso”. Em uma classificação de dor esse significado conduz à idéia de “intensidade acima da média”, que numa escala de zero a dez ficaria acima do valor cinco. A palavra "muito" também advém do latim e significa “que é em grande número ou em abundância ou em grande intensidade”. Por conseguinte o pronome indefinido "muito" associado à palavra "forte" em uma classificação de dor conduz à interpretação de "grande intensidade" o que ficaria próximo ao valor dez. Diante disso evidencia-se que as palavras “moderate”, "strong” e “very strong” quando traduzidas para a língua portuguesa parecem possuir significado semântico de quantidade ou intensidade diferente das mesmas palavras em inglês. De fato os resultados das pontuações da escala CR10 original e da escala CR10 Modificada I e II utilizadas no presente estudo revelaram essa diferença mostrando elevação dos valores numéricos associados a cada uma dessas categorias verbais.

Conclui-se que a aplicação da escala CR10 para a população brasileira requer um estudo adaptativo mais amplo para se determinar de maneira mais adequada e precisa as posições das expressões verbais em português sobre a escala numérica a partir da avaliação de uma amostra populacional maior do que a considerada nesse estudo. 
ANEXOS 


\section{ANEXO A: \\ TERMO DE CONSENTIMENTO LIVRE E ESCLARECIDO}

$\mathrm{Eu}$, informado (a) de que a pesquisa "Comparação da Escala CR10 de Borg com a Escala Analógica Visual (VAS) na Avaliação da Dor em Pacientes com Disfunções Temporomandibulares” a ser desenvolvida por Adriana do Vale Ferreira Bacci sob a orientação do Prof. Dr. Sérgio Sheiji Fukusima tem por objetivo saber se duas escalas específicas para a avaliação de dor são adequadas para identificar a intensidade da dor associada à Disfunção Temporomandibular. Todas as informações e dados obtidos nessa pesquisa poderão ser utilizados em reuniões e/ou em publicações científicas sem que minha identidade seja revelada.

Sei que para participar deverei responder a uma entrevista e a escalas de avaliação de dor. Nessas escalas, deverei tentar expressar a dor que tenho sentido espontaneamente, ao mastigar, ao falar e ao engolir e a dor que posso sentir ao exame de palpação realizado pela pesquisadora. A intensidade de minha dor será expressa através de números, palavras e marcações em uma linha que vai de uma Ausência de dor até um Máximo de dor.

Estou ciente de que a pesquisadora não irá me fornecer nenhum tipo de tratamento, independentemente da intensidade de minha dor.

Sei ainda que minha participação não oferecerá riscos à minha integridade física e mental e que posso não concordar em participar da pesquisa agora ou em qualquer outro momento, sem perder a possibilidade de receber o atendimento odontológico.

Estando ciente dessas informações, concordo em participar da pesquisa.

Ribeirão Preto, de de 200_.

Nome do participante:

Endereço:

Assinatura:

Pesquisadores responsáveis:

Adriana do Vale Ferreira Bacci Assinatura:

RG: 22597691-2

Sérgio Sheiji Fukusima

Assinatura:

RG: 8104069

Endereço: Av Bandeirantes, 3900. Tel: 6023729. Ribeirão Preto - SP 


\section{ANEXO B:}

\section{IDENTIFICAÇÃO}

Nome:

Idade:

Estado Civil:

Naturalidade:

Escolaridade:

Profissão:

\section{ANAMNESE}

Data de Nascimento:

Sexo: () Masc. () Fem.

Procedência:

\section{FONTE E MOTIVO DO ENCAMINHAMENTO}

- Queixa principal:

- Desde quando você nota essa problemática?

- Como se iniciou e foi se desenvolvendo essa problemática?

- Quais são, na sua opinião, as possíveis causas dessa problemática? (Investigar fatores pessoais, sociais ou ambientais que possam estar relacionados ao aparecimento e evolução dos sintomas)

- De que forma as dificuldades citadas afetaram suas atividades interpessoais? Como é a reação das pessoas do seu ambiente frente a sua problemática?

- Em quais situações essa problemática ocorre? (onde, quando, com quem)

\section{OUTRAS QUEIXAS:}

- Além do que você falou que o incomoda, você percebe que possui outras problemáticas?

\section{ATENDIMENTOS ANTERIORES}

- Já procurou algum tipo de ajuda para resolver o problema? (Especificar quais profissionais e em que ordem, que tipo de ajuda, por quanto tempo e em que esquema de trabalho)

\section{HISTÓRIAPESSOAL}

5.1 Saúde: Está ou esteve doente ultimamente?

Está tomando algum medicamento?

Já teve algum traumatismo na cabeça ou pescoço?

Aperta ou range os dentes?

Já passou por alguma cirurgia?

Teve algum processo infeccioso?

5.2 Alimentação/Nutrição: Sente alguma dificuldade para comer? Em caso positivo, qual?

Teve que mudar a alimentação por causa da problemática?

5.3 Sono: Toma medicamento para dormir?

Dorme em média quantas horas?

Como é o sono?

Como se sente ao acordar?

5.4 Socialização: Mora com quem?

Têm amigos? Com que freqüência os encontra?

Quais são suas atividades preferidas? E o que você faz para relaxar?

Pratica algum esporte? 


\begin{abstract}
ANEXO C:
Nome:

Está ou esteve doente ultimamente?

Está tomando algum medicamento?

Teve algum traumatismo na cabeça ou pescoço?

Aperta ou range os dentes?

Passou por alguma cirurgia?

Teve algum processo infeccioso?
\end{abstract}

ANAMNESE 2

Sente que está diferente depois que iniciou o tratamento? Consegue descrever essa diferença? 


\begin{abstract}
ANEXO D:
Instruções para a Escala Analógica Visual para a percepção de dor:

Avalie como você se sente, nesse momento (ou na última semana), com relação a dor. Considere a linha abaixo como representando a gama completa das diversas intensidades de dor que você possa sentir. As extremidades esquerda e direita indicam o mínimo e o máximo de dor respectivamente. Marque, claramente, essa linha com um traço vertical representativo da quantidade de dor que você sente agora.
\end{abstract}

Ausência de Dor

Máximo de Dor 


\section{ANEXO E:}

\section{Instruções para Escala CR10 de Borg (modificada):}

Tente se lembrar da dor mais intensa que você já experimentou.. Qual foi essa dor? Vamos supor que essa dor represente a intensidade "10, Extremamente forte". Contudo, pode ser possível experimentar ou imaginar algo ainda mais forte. Portanto, o "Máximo Absoluto" está posicionado um pouco mais abaixo na escala, sem receber um número fixo; esse nível está marcado por um ponto "•". Se você perceber uma intensidade maior do que 10, poderá usar um número mais elevado.

Comece com uma expressão verbal e, em seguida, escolha um número. Fique à vontade para utilizar meios valores (como 1,5 ou 3,5) ou decimais (como por exemplo, 0,3; 0,8 ou 2,3). É muito importante que você responda o que percebeu, e não o que acredita que deveria responder. Seja o mais honesto possível, e tente não exagerar e nem diminuir as intensidades de dor. 


\section{ANEXO E.1:}

\section{Escala CR10 de Borg (modificada)}

( ) Absolutamente Nada

( ) Extremamente Fraco

( ) Muito Fraco

( ) Fraco

( ) Moderado

( ) Forte

( ) Muito Forte

( ) Extremamente Forte

( ) Maior que Extremamente Forte

0 Absolutamente Nada

0,3

0,5

0,7

1

1,5

2

2,5

3

4

5

6

7

8

9

10 Extremamente Forte

11

- Máximo Absoluto (O mais Intenso Possível) 


\section{ANEXO F:}

Assinalar nas figuras as áreas com sintomatologia dolorosa
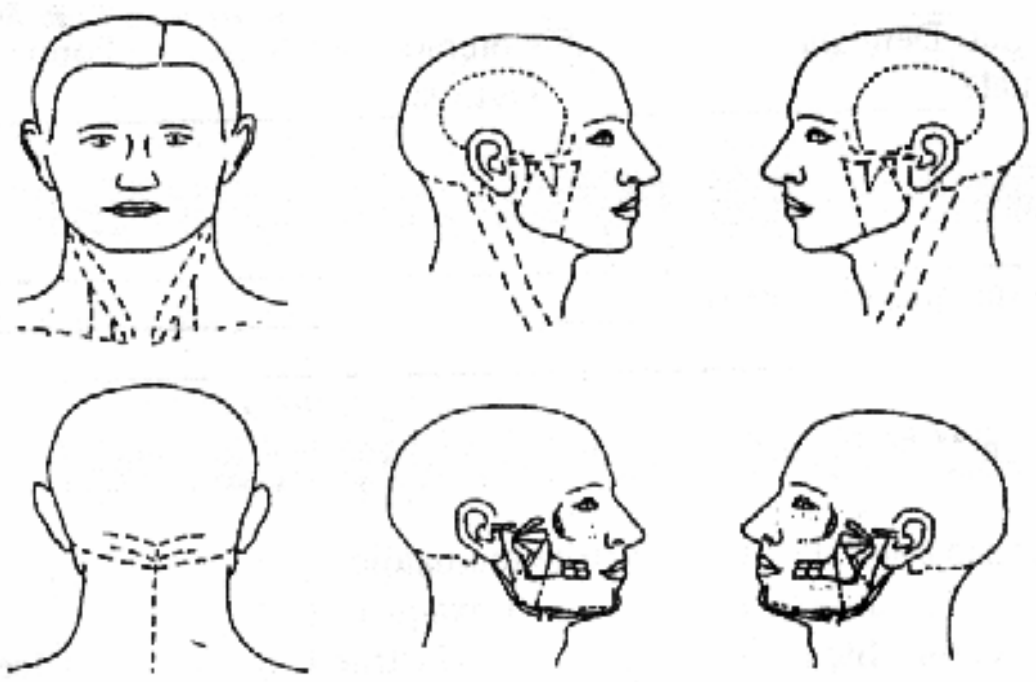
ANEXO G: Regiões de face e pescoço para avaliação de dor à palpação

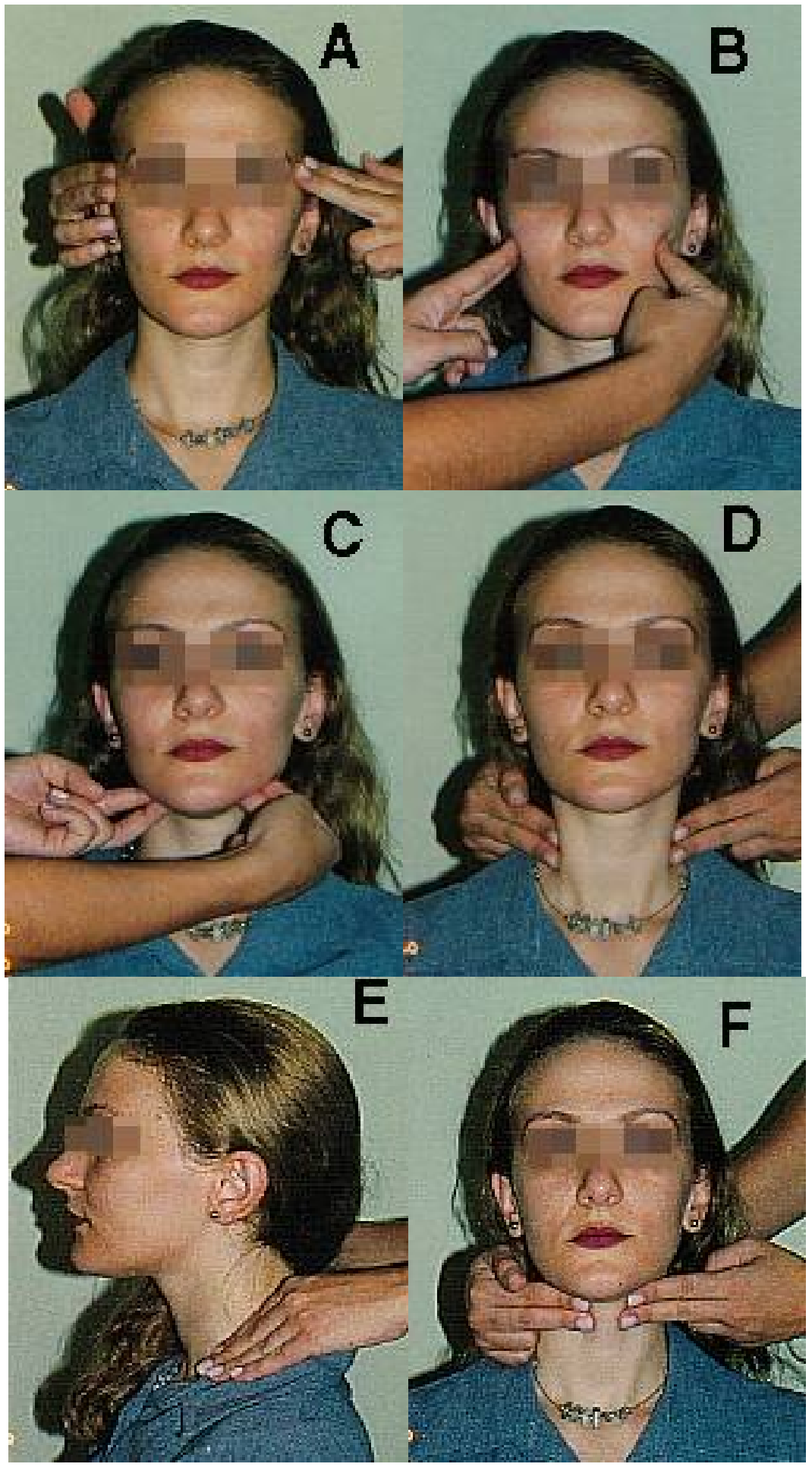




\section{ANEXO G. 1:}

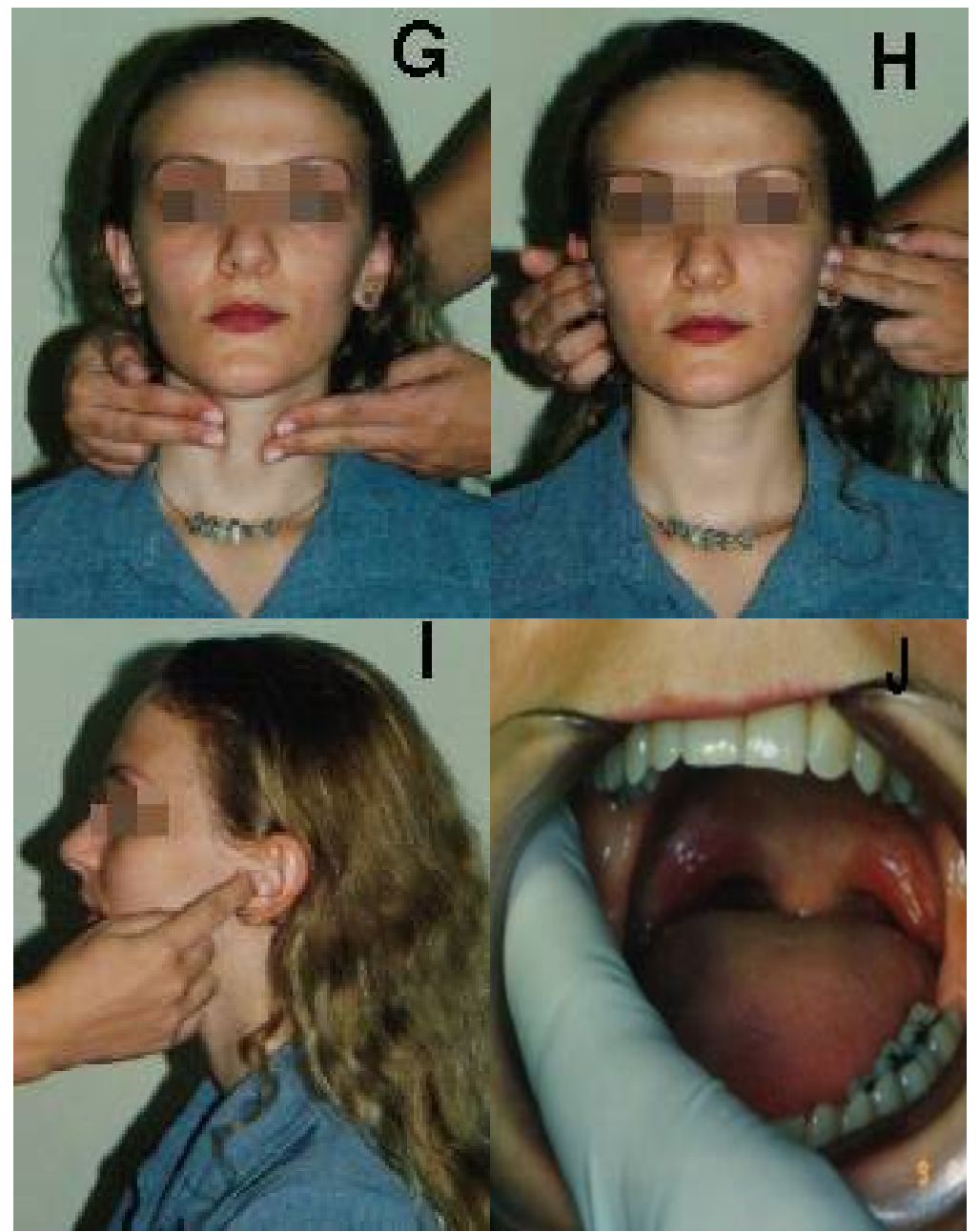

Legenda: A: Temporal, B: Masseter, C: Pterigóideo Medial, D: Esternocleidomastoideo, E: Trapézio, F: Suprahiodeos, G: Infrahiodeos, H: ATM pólo lateral, I: ATM pólo posterior, J: Pterigóideo Lateral 


\section{Anexo H:}

\section{Instruções para Escala CR10 de Borg (modificada II):}

Tente se lembrar da dor mais intensa que você já experimentou.. Qual foi essa dor? Vamos supor que essa dor represente a intensidade "10, Extremamente forte". Contudo, pode ser possível experimentar ou imaginar algo ainda mais forte. Portanto, o "Máximo Absoluto" está posicionado um pouco mais abaixo na escala, sem receber um número fixo; esse nível está marcado por um ponto “•”. Se você perceber uma intensidade maior do que 10, poderá usar um número mais elevado.

Comece com um número e, em seguida, escolha uma expressão verbal. Fique à vontade para utilizar meios valores (como 1,5 ou 3,5) ou decimais (como por exemplo, 0,3; 0,8 ou 2,3). É muito importante que você responda o que percebeu, e não o que acredita que deveria responder. Seja o mais honesto possível, e tente não exagerar e nem diminuir as intensidades de dor. 


\section{ANEXO H.1}

\section{Escala CR10 de Borg (modificada II)}

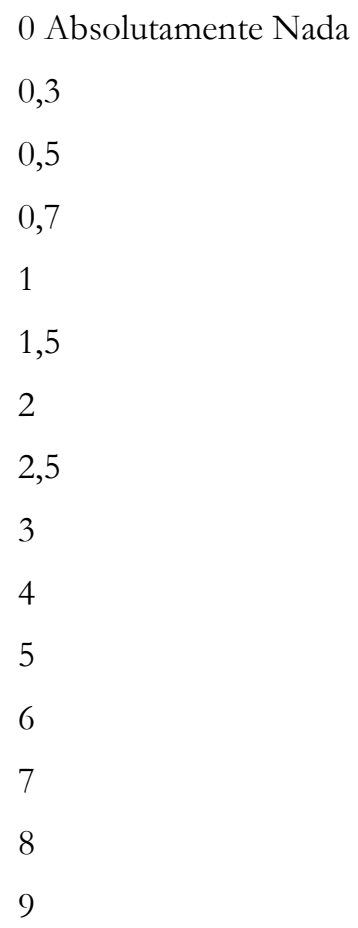

- Máximo Absoluto (O mais Intenso Possível)
( ) Absolutamente Nada
( )Fraco
( ) Muito Forte
( ) Extremamente Fraco
( ) Moderado
( ) Extremamente Forte
( ) Muito Fraco
( ) Forte
( ) Maior que Extremamente Forte 


\section{ANEXO I:}

Instruções para Escala CR10 de Borg (๑ Gunnar Borg, 1981, 1982, 1998):

Tente se lembrar da dor mais intensa que você já experimentou.. Qual foi essa dor? Vamos supor que essa dor represente a intensidade "10, Extremamente forte". Contudo, pode ser possível experimentar ou imaginar algo ainda mais forte. Portanto, o "Máximo Absoluto" está posicionado um pouco mais abaixo na escala, sem receber um número fixo; esse nível está marcado por um ponto "•". Se você perceber uma intensidade maior do que 10 , poderá usar um número mais elevado.

Comece com uma expressão verbal e, em seguida, escolha um número. Se a sua percepção é "Muito Fraca", escolha 1; se "Moderada, escolha 3, etc. Fique à vontade para utilizar meios valores (como 1,5 ou 3,5) ou decimais (como por exemplo, 0,$3 ; 0,8$ ou 2,3). É muito importante que você responda o que percebeu, e não o que acredita que deveria responder. Seja o mais honesto possível, e tente não exagerar e nem diminuir as intensidades de dor.

$\begin{array}{ll}0 \text { Absolutamente Nada } & \text { "Sem D" } \\ 0,3 & \\ 0,5 \text { Extremamente Fraco } & \text { Apenas Perceptível } \\ 1 \text { Muito Fraco } & \\ 1,5 & \text { Leve } \\ 2 \text { Fraco } & \\ 2,5 & \\ 3 \text { Moderado } & \text { Intenso } \\ 4 & \\ 5 \text { Forte } & \\ 6 & \\ 7 \text { Muito Forte } & \\ 8 & \\ 9 & \text { "D Máx.” } \\ \text { 10 Extremamente Forte } & \\ 11 & \\ \ldots & \text { O mais Intenso Possível }\end{array}$


ANEXO J- Tabelas com dados obtidos nas Anamneses do Grupo I

Tabela 1 - Queixas principais de uma amostra de 35 pacientes atendidos na clínica de oclusão da FORP-USP

Tabela 2 - Tempo médio de sinais e sintomas (em anos) apresentados por uma amostra de 35 pacientes da clínica de oclusão da FORP - USP

Tabela 3 - Situações relacionadas às DTMs segundo o relato de 35 pacientes atendidos na clínica de oclusão da FORP - USP

Tabela 4 - Causas das queixas principais relatadas pela amostra de 35 pacientes da clínica de oclusão da FORP - USP

Tabela 5 - Profissionais consultados (com respectivos tratamentos) pela amostra de 35 pacientes atendidos na clínica de oclusão da FORP-USP

Tabela 6 - Queixas secundárias apresentadas por uma amostra de 35 pacientes atendidos na clínica de oclusão da FORP - USP

Tabela 7 - Relato de doença (Atual/Recente), uso de medicação, história de traumatismo, cirurgia, infecção (Atual /Recente) e Bruxismo e/ou Briquismo em uma amostra de 35 pacientes atendidos na clínica de oclusão da FORP- USP

Tabela 8 - Relato de dificuldade para mastigar e mudança de alimentação em uma amostra de 35 pacientes atendidos na clínica de oclusão da FORP- USP

Tabela 9 - Influência da DTM e reação das pessoas segundo o relato de 35 pacientes atendidos na clínica de oclusão da FORP - USP

Tabela 10 - Relato de doença (Atual/Recente), uso de medicação, história de traumatismo, cirurgia, infecção (Atual /Recente) e Bruxismo e/ou Briquismo em uma amostra de 32 pacientes (segunda fase da pesquisa) atendidos na clínica de oclusão da FORP- USP 


\section{ANEXO J.1}

Tabela 1 - Queixas principais de uma amostra de 35 pacientes atendidos na clínica de oclusão da FORP-USP.

\begin{tabular}{|c|c|}
\hline Paciente & Queixa Principal \\
\hline 1 & Bruxismo. Sente dor quando come. \\
\hline 2 & Range os dentes que já estão desgastados. \\
\hline 3 & Dor na região da ATM, ambos os lados, quando mastiga. \\
\hline 4 & $\begin{array}{l}\text { Range os dentes, sente cansaço muscular durante a mastigação, dor nos dentes } \\
\text { quando acorda. }\end{array}$ \\
\hline 5 & Dor nas ATMs, mais intenso no lado esquerdo e pela manhã. \\
\hline 6 & Dor nas ATMs que piora quando come. \\
\hline 7 & Travava os maxilares, dor nos músculos da face e nas ATMs \\
\hline 8 & Dor na face no lado direito. \\
\hline 9 & Dificuldade para abrir a boca, dor no maxilar quando come. \\
\hline 10 & $\begin{array}{l}\text { Dor nas ATMs, na maxila, no pescoço principalmente no lado esquerdo. A dor é } \\
\text { mais intensa pela manhã. Dificuldade para abrir a boca. }\end{array}$ \\
\hline 11 & Range os dentes, sente que estão desgastados, dor nos dentes posteriores. \\
\hline 12 & $\begin{array}{l}\text { Dor de cabeça e na face (masseter) e no fundo do ouvido. A dor é mais freqüente } \\
\text { quando está nervosa. }\end{array}$ \\
\hline 13 & Estalos na ATM direita. \\
\hline 14 & Muita dor no ouvido. Procurou um otorrino que encaminhou para o dentista. \\
\hline 15 & $\begin{array}{l}\text { Dor no rosto, na cabeça, nos olhos, no ouvido e nos ombros. Aperta os dentes e } \\
\text { sente dificuldade para mastigar. }\end{array}$ \\
\hline 16 & Dor de cabeça. Foi ao neuro que apontou problema nos dentes. \\
\hline 17 & $\begin{array}{l}\text { Muita dor. Fazia tratamento com um médico por causa de dor de garganta ele } \\
\text { encaminhou para um dentista quando percebeu que havia problema dentário. }\end{array}$ \\
\hline 18 & Má oclusão. Dor na ATM esquerda e travava os maxilares. \\
\hline 19 & $\begin{array}{l}\text { Estava com muita dor de ouvido e labirintite. O otorrino concluiu que era problema } \\
\text { dentário. }\end{array}$ \\
\hline 20 & $\begin{array}{l}\text { Muita dor no maxilar e na fronte. Não podia abrir muito a boca que travava. O } \\
\text { médico do Posto de Saúde encaminhou para o dentista. }\end{array}$ \\
\hline 21 & Muita dor de ouvido e no rosto. \\
\hline 22 & Não conseguia dormir. Muita tensão, apertava os dentes que ficavam doloridos. \\
\hline 23 & Dor e dificuldade para mastigar \\
\hline 24 & $\begin{array}{l}\text { Desde criança range os dentes. Agora sente também contratura muscular na região } \\
\text { dos ombros e da cabeça. }\end{array}$ \\
\hline 25 & $\begin{array}{l}\text { Estala muito os maxilares e não possui alguns dentes. Foi encaminhamento do } \\
\text { dentista Posto de Saúde }\end{array}$ \\
\hline 26 & Dor de cabeça diária \\
\hline 27 & Encaminhamento do neuro. \\
\hline 28 & diária na cabeça, no osso \\
\hline
\end{tabular}




\section{Conclusão}

Tabela 1 - Queixas principais de uma amostra de 35 pacientes atendidos na clínica de oclusão da FORP-USP

\begin{tabular}{|l|l|}
29 & Dor nas ATMs ao acordar. \\
\hline 30 & Muita dor no ouvido direito. \\
\hline 31 & Dor no ouvido, na cabeça e na boca. \\
\hline 32 & Dor ao mastigar. \\
\hline 33 & Dor ao acordar. Sente que aperta os dentes quando dorme. \\
\hline 34 & Estalos e dor na ATM esquerda. \\
\hline 35 & Dor e estalos nas ATMs. \\
\hline
\end{tabular}




\section{ANEXO J.2}

Tabela 2 - Tempo médio de sinais e sintomas (em anos) apresentados por uma amostra de 35 pacientes da clínica de oclusão da FORP - USP

\begin{tabular}{|c|c|}
\hline Paciente & Tempo Médio dos Sinais e Sintomas (anos) \\
\hline 1 & 5 \\
\hline 2 & 28 \\
\hline 3 & 4 \\
\hline 4 & 20 \\
\hline 5 & 1,5 \\
\hline 6 & 3 \\
\hline 7 & 2 \\
\hline 8 & 2 \\
\hline 9 & 1 \\
\hline 10 & 4 \\
\hline 11 & 2 \\
\hline 12 & 1 \\
\hline 13 & 0,5 \\
\hline 14 & 4,5 \\
\hline 15 & 5 \\
\hline 16 & 13 \\
\hline 17 & 3 \\
\hline 18 & 1 \\
\hline 19 & 20 \\
\hline 20 & 2,5 \\
\hline 21 & 20 \\
\hline 22 & 3,5 \\
\hline 23 & 7,5 \\
\hline 24 & 7 \\
\hline 25 & 6 \\
\hline 26 & 1,5 \\
\hline 27 & 4,5 \\
\hline 28 & 2 \\
\hline 29 & 6 \\
\hline 30 & 4,5 \\
\hline 31 & 2 \\
\hline 32 & 1 \\
\hline 33 & 5 \\
\hline 34 & 2 \\
\hline 35 & 3 \\
\hline
\end{tabular}




\section{ANEXO J.3}

Tabela 3 - Situações relacionadas às DTMs segundo o relato de 35 pacientes atendidos na clínica de oclusão da FORP - USP

\begin{tabular}{|c|c|}
\hline Paciente & $\begin{array}{l}\text { Situações relacionadas à problemática segundo a percepção do } \\
\text { paciente }\end{array}$ \\
\hline 1 & Alimento e/ou líquido gelado e atrito dos dentes \\
\hline 2 & Estresse \\
\hline 3 & Mastigação \\
\hline 4 & Mastigação e estresse \\
\hline 5 & Ao acordar \\
\hline 6 & Mastigação e no final do dia \\
\hline 7 & Mastigação \\
\hline 8 & Mastigação e abertura de boca \\
\hline 9 & Alimento e/ou líquido frio \\
\hline 10 & Mastigação \\
\hline 11 & Alimento e/ou líquido frio \\
\hline 12 & Período menstrual, mastigação e abertura de boca \\
\hline 13 & Ao acordar \\
\hline 14 & Fala e no final do dia \\
\hline 15 & Ao acordar e mastigação \\
\hline 16 & Estresse \\
\hline 17 & Mastigação, abertura de boca e final do dia \\
\hline 18 & Ao acordar \\
\hline 19 & Período menstrual \\
\hline 20 & Ao acordar e estresse \\
\hline 21 & Ao acordar \\
\hline 22 & Estresse e final do dia \\
\hline 23 & Rotina diária \\
\hline 24 & Final do dia e estresse \\
\hline 25 & Rotina diária \\
\hline 26 & Estresse \\
\hline 27 & Estresse e na presença de barulho \\
\hline 28 & Rotina diária \\
\hline 29 & Estresse \\
\hline 30 & Alimento e/ou líquido frio \\
\hline 31 & Ao acordar \\
\hline 32 & Final do dia \\
\hline 33 & Final do dia, mastigação e ausência do cônjuge \\
\hline 34 & Não sabe \\
\hline 35 & Não sabe \\
\hline
\end{tabular}




\section{ANEXO J.4}

Tabela 4: - Causas das queixas principais relatadas pela amostra de 35 pacientes da clínica de oclusão da FORP - USP

\begin{tabular}{|c|l|}
\hline Paciente & Causas da queixa principal segundo a percepção do paciente \\
\hline 1 & Estresse \\
2 & Estresse \\
3 & Não sabe \\
4 & Estresse e mastigação \\
5 & Má oclusão e estresse \\
6 & Não sabe \\
7 & Má oclusão e estresse \\
8 & Estresse e má oclusão \\
9 & Respiração bucal \\
10 & Estresse \\
11 & Infecção na gengiva e desgaste do dentes \\
12 & Ausência de alguns dentes e estresse \\
13 & Ausência de alguns dentes \\
14 & Ausência de alguns dentes e má formação da mandíbula \\
15 & Atrito dos dentes \\
16 & Estresse \\
17 & Má oclusão e sinusite \\
18 & Estresse \\
19 & Mastigação e abertura de boca \\
20 & Ausência de alguns dentes \\
21 & Ausência de alguns dentes \\
22 & Má oclusão e estresse \\
& Ausência de alguns dentes, presença de adenóide e má \\
23 & Oclusão. \\
24 & Estresse \\
25 & Mastigação \\
26 & Estresse \\
27 & Não sabe \\
28 & Estresse \\
29 & Má oclusão e estresse \\
30 & Ausência de alguns dentes \\
31 & Má postura e mastigação unilateral \\
32 & Não sabe \\
33 & Estresse \\
34 & Estresse \\
35 & Não sabe \\
\hline
\end{tabular}




\section{ANEXO J.5}

Tabela 5 - Profissionais consultados (com respectivos tratamentos) pela amostra de 35 pacientes atendidos na clínica de oclusão da FORP-USP

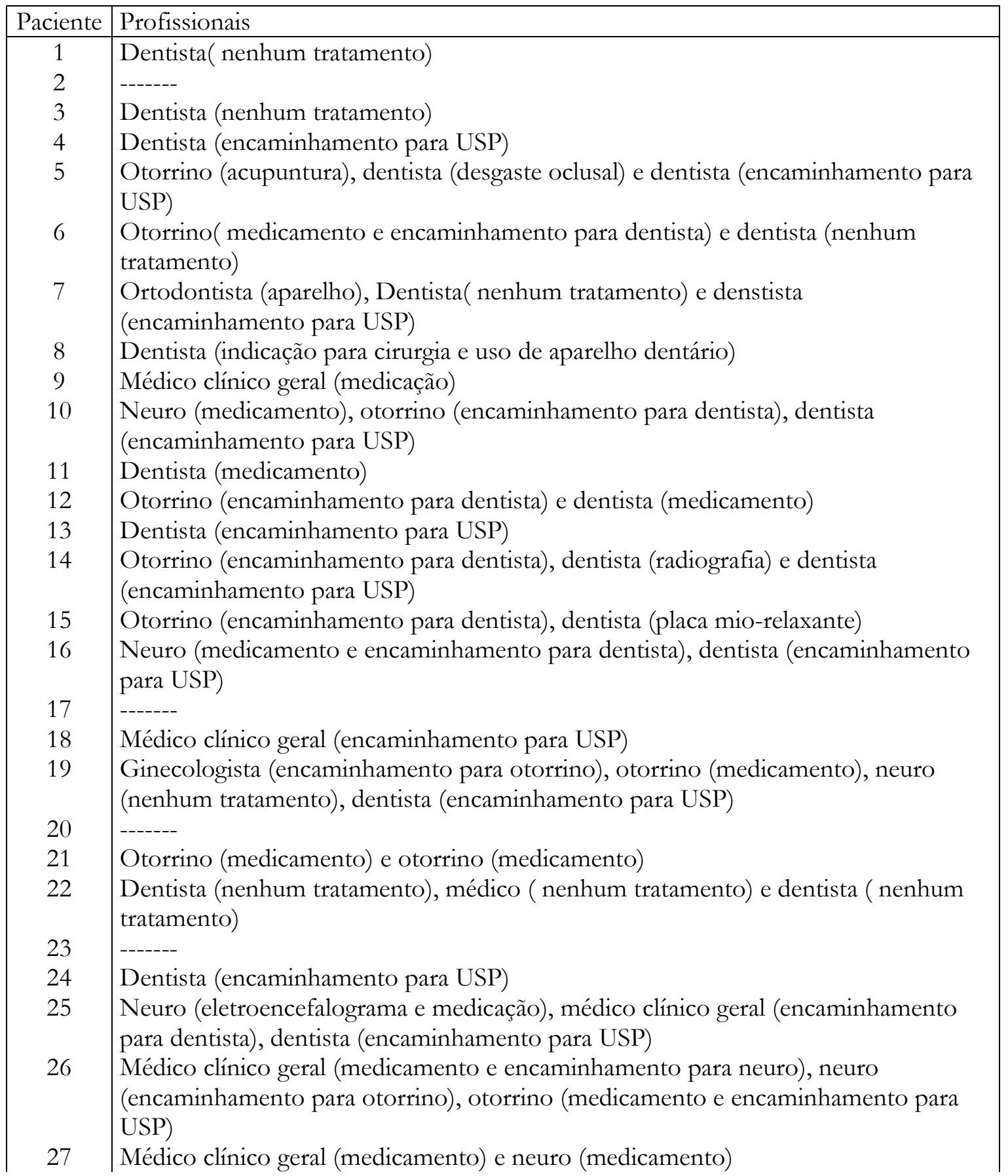

Continua 


\section{Conclusão}

Tabela 5 - Profissionais consultados (com respectivos tratamentos) pela amostra de 35 pacientes atendidos na clínica de oclusão da FORP-USP

\begin{tabular}{|l|l|}
\hline 28 & Médico clínico geral (encaminhamento para USP) \\
29 & - --ó \\
30 & Médico clínico geral ((medicamento), otorrino (encaminhamento para USP) \\
31 & Médico clínico geral (encaminhamento para dentista), dentista( encaminhamento \\
& para USP) \\
32 & ----- \\
33 & Dentista (encaminhamento para USP) \\
35 & Dentista (encaminhamento para USP) \\
\hline
\end{tabular}




\section{ANEXO J.6}

Tabela 6 - Queixas secundárias apresentadas por uma amostra de 35 pacientes atendidos na clínica de oclusão da FORP - USP

\begin{tabular}{|c|c|}
\hline Paciente & Outras Queixas \\
\hline 1 & Contratura muscular \\
\hline 2 & Não \\
\hline 3 & Mãos Suadas \\
\hline 4 & Não \\
\hline 5 & Não \\
\hline 6 & Não \\
\hline 7 & Não \\
\hline 8 & Sistema Nervoso Abalado \\
\hline 9 & Não \\
\hline 10 & Dor nas Pernas \\
\hline 11 & Síndrome do Pânico \\
\hline 12 & TPM \\
\hline 13 & Não \\
\hline 14 & Desvio e Desgaste na Coluna \\
\hline 15 & TPM \\
\hline 16 & Rinite Alérgica \\
\hline 17 & Obesidade \\
\hline 18 & Dor nas Pernas \\
\hline 19 & Não \\
\hline 20 & Tensão, dor nas articulações, ingüa \\
\hline 21 & Prótese de Quadril \\
\hline 22 & Não \\
\hline 23 & Não \\
\hline 24 & Labirintite \\
\hline 25 & Dor de cabeça \\
\hline 26 & L.E.R. e Disritmia Cardíaca \\
\hline 27 & Não \\
\hline 28 & Não \\
\hline 29 & Não \\
\hline 30 & Asma e Esporão no Pé \\
\hline 31 & Não \\
\hline 32 & Não \\
\hline 33 & Não \\
\hline 34 & Não \\
\hline 35 & Não \\
\hline
\end{tabular}




\section{ANEXO J.7}

Tabela 7 - Porcentagens de relatos de doença (Atual/Recente), uso de medicação, história de traumatismo, cirurgia, infecção (Atual /Recente) e Bruxismo e/ou Briquismo em uma amostra de 35 pacientes atendidos na clínica de oclusão da FORP- USP

\begin{tabular}{|c|c|}
\hline DOENÇA & $\begin{array}{c}42,8 \% \\
(17,14 \% \text { recentes e } 25,71 \% \text { atuais })\end{array}$ \\
& $45,7 \%$ \\
MEDICAÇÃO & $\begin{array}{c}(17,14 \% \text { hormônio, } 14,28 \% \text { analgésico, } 2,85 \% \text { antialérgico, } \\
2,85 \% \text { hormônio e anti-ácido, } 2,85 \% \text { analgésico/antiflamatório } \\
\text { e anti-alérgico, } 2,85 \% \text { analgésico e anti-alérgico e } 2,85 \% \\
\text { antiflamatório e antibiótico })\end{array}$ \\
\hline TRAUMATISMO & $28,6 \%$ \\
\hline CIRURGIA & $51,4 \%$ \\
\hline INFECĈ̃O & $54,3 \%$ \\
& $(28,57 \%$ recentes, $25,71 \%$ atuais e $5,71 \%$ não lembram $)$ \\
\hline BRUXISMO/BRIQUISMO & $85,7 \%$ \\
& $(37,14 \%$ BRU e BRI; $28,57 \%$ BRI e $20 \%$ BRU $)$ \\
\hline
\end{tabular}

Tabela 8 - Porcentagens de relatos de dificuldade para mastigar e mudança de alimentação em uma amostra de 35 pacientes atendidos na clínica de oclusão da FORP- USP

\begin{tabular}{|c|c|}
\hline DIFICULDADE DE MASTIGAÇÃO & $71,4 \%$ \\
\hline MUDANÇA DE ALIMENTAÇÃO & $60 \%$ \\
\hline
\end{tabular}




\section{ANEXO J.8}

Tabela 9 - Influência da DTM e reação das pessoas segundo o relato de 35 pacientes atendidos na clínica de oclusão da FORP - USP

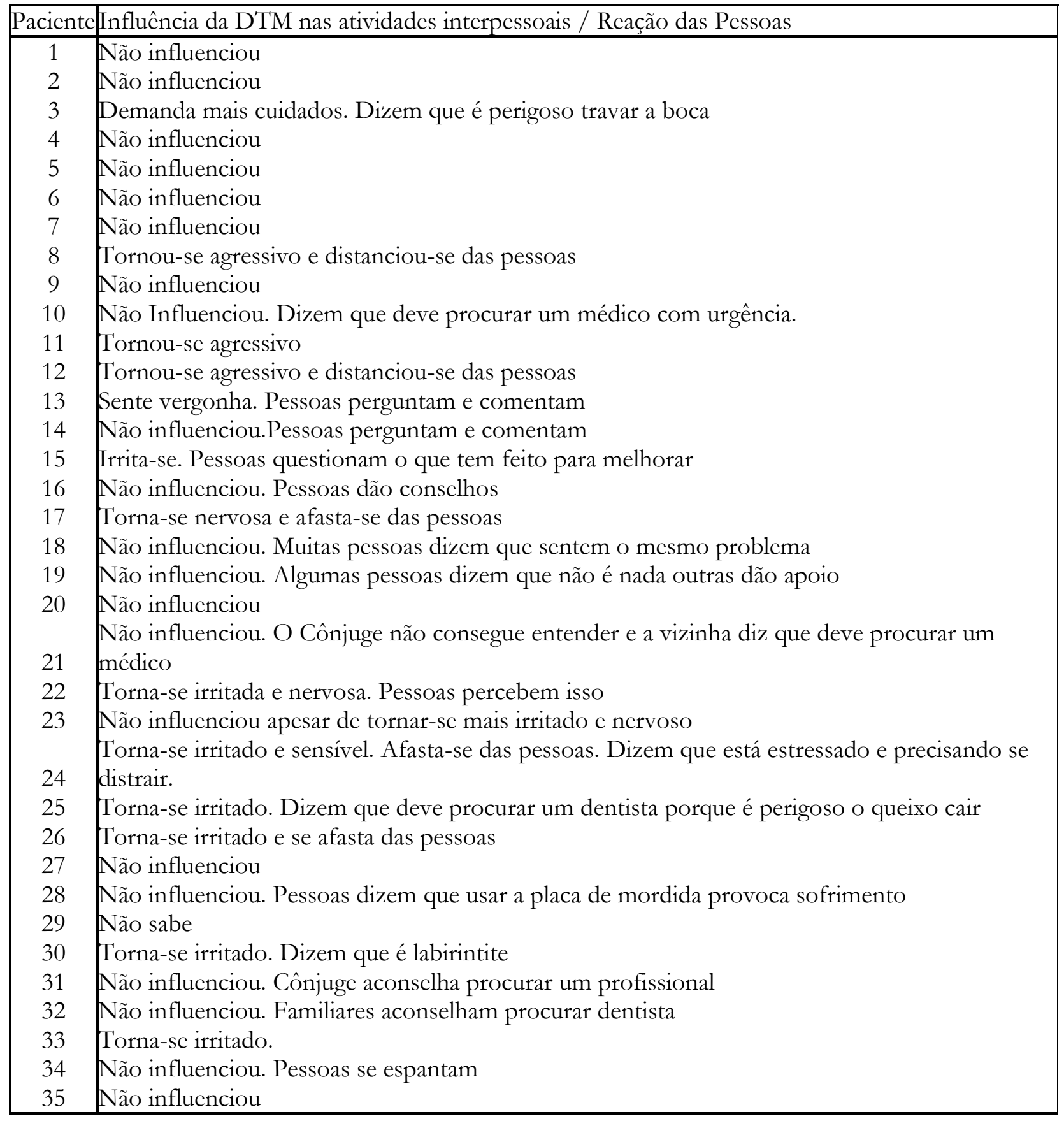




\section{ANEXO J.9}

Tabela 10 - Porcentagens de relatos de doença (Atual/Recente), uso de medicação, história de traumatismo, cirurgia, infecção (Atual /Recente) e Bruxismo e/ou Briquismo em uma amostra de 32 pacientes (segunda fase da pesquisa) atendidos na clínica de oclusão da FORP- USP

\begin{tabular}{|c|c|}
\hline DOENÇA & $\begin{array}{c}37,5 \% \\
(21,87 \% \text { recentes e } 15,62 \% \text { atuais })\end{array}$ \\
\hline MEDICAÇÃO & $\begin{array}{c}37,5 \% \\
\text { (9,37\% hormônios, } 6,25 \% \text { analgésicos, } 3,12 \% \text { anti-depressivo, } \\
3,12 \% \text { hormônio e analgésico, 3,12\% hormônio e anti-ácido, } \\
\text { 3,12\% anti-depressivo e anti-alérgico, 3,12\% ansiolítico, 3,12\% } \\
\text { descongestionante e anti-asmático e 3,12\% vasodilatador) }\end{array}$ \\
\hline TRAUMATISMO & 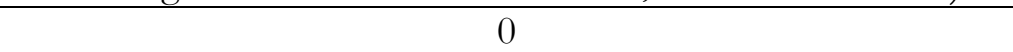 \\
\hline CIRURGIA & 0 \\
\hline INFECÇÃO & $\begin{array}{c}18,75 \% \\
(18,75 \% \text { recentes })\end{array}$ \\
\hline BRUXISMO/BRIQUISMO & $\begin{array}{c}65,6 \% \\
(40,62 \% \text { BRI; } 12,5 \% \text { BRU e } 12,5 \% \text { BRU e BRI) }\end{array}$ \\
\hline
\end{tabular}


ANEXO L-Tabelas com dados obtidos nas Anamneses dos Grupos II e III:

Tabela 1 - Queixas principais de uma amostra de 40 pacientes atendidos na clínica de oclusão da FORP-USP

Tabela 2 - Tempo médio de sinais e sintomas (em anos) apresentados por uma amostra de 40 pacientes da clínica de oclusão da FORP - USP

Tabela 3 - Situações relacionadas às DTMs segundo o relato de 40 pacientes atendidos na clínica de oclusão da FORP - USP

Tabela 4 - Causas das queixas principais relatadas pela amostra de 40 pacientes da clínica de oclusão da FORP - USP

Tabela 5 - Profissionais consultados (com respectivos tratamentos) pela amostra de 40 pacientes atendidos na clínica de oclusão da FORP-USP

Tabela 6 - Queixas secundárias apresentadas por uma amostra de 40 pacientes atendidos na clínica de oclusão da FORP - USP

Tabela 7 - Relato de doença (Atual/Recente), uso de medicação, história de traumatismo, cirurgia, infecção (Atual /Recente) e Bruxismo e/ou Briquismo em uma amostra de 40 pacientes atendidos na clínica de oclusão da FORP- USP

Tabela 8 - Relato de dificuldade para mastigar e mudança de alimentação em uma amostra de 40 pacientes atendidos na clínica de oclusão da FORP- USP

Tabela 9 - Influência da DTM e reação das pessoas segundo o relato de 40 pacientes atendidos na clínica de oclusão da FORP - USP 


\section{ANEXO L.1}

Tabela 1 - Queixa principal apresentada pela amostra de 40 pacientes atendidos na clínica de oclusão da FORP-USP com diagnóstico de DTM

\begin{tabular}{|l|l|}
\hline Paciente & Queixa principal \\
\hline 1 & Problema de oclusão e dor \\
2 & Travava a boca e estalos nas ATMs \\
3 & Dor estalos \\
4 & Dor de cabeça e na coluna \\
5 & Dor no maxilar \\
6 & Dor no maxilar \\
7 & Dor de dente e no ouvido \\
8 & Dor forte na boca \\
9 & Dor nos dentes \\
10 & Deslocamento anterior de queixo \\
11 & Estalos e dor nas ATMs \\
12 & Dor nos maxilares e na cabeça \\
14 & Dor no lado direito do rosto \\
15 & Dor no rosto e falta de dentes \\
16 & Dor e estalos na ATM direita \\
17 & Bruxismo, briquismo e encaminhamento \\
18 & Dor de ouvido, estalos e dentes tortos \\
19 & Dor de cabeça \\
20 & Dor de cabeça \\
21 & Estalos \\
22 & Dor nos músculos da face \\
23 & Dor na costas e ATM esquerda \\
24 & Dor de cabeça e zumbidos no ouvido \\
25 & Dor nas ATMs \\
26 & Dor de ouvido \\
27 & Dor de cabeça e encaminhamento \\
28 & Dor no maxilar \\
29 & Dor de cabeça \\
30 & Dor nas ATMs e maxilares \\
31 & Dor de cabeça, na nuca e nas costas \\
32 & Muita dor de cabeça \\
33 & Muita dor nas ATMs e na cabeça \\
34 & Dor no lado direito do maxilar, garganta e ouvido \\
36 & Encaminhamento de neuro \\
37 & Dor no lado esquerdo da cabeça \\
38 & Muita dor de cabeça, pescoço e estalos nas ATMs \\
39 & Muita dor na cabeça e cãibras no pescoço \\
40 & Dor na face e estalos nas ATMs \\
41 & Dor nas ATMs \\
42 & Dor nos maxilares, dificuldade de abrir a boca e mastigar \\
\hline
\end{tabular}


ANEXO L.2

Tabela 2 - Tempo médio de apresentação de sinais e sintomas de uma amostra de 40 pacientes atendidos na clínica de oclusão da FORP-USP com diagnóstico de DTM

\begin{tabular}{|l|l|}
\hline Paciente & Tempo médio de apresentação dos sinais e sintomas (anos) \\
\hline 1 & 2 \\
2 & 10 \\
3 & 30 \\
4 & 4,5 \\
5 & 1,5 \\
6 & 9 \\
7 & 8 \\
8 & 0,7 \\
9 & 1 \\
10 & 1 \\
11 & 2 \\
12 & 6 \\
14 & 4 \\
15 & 15 \\
16 & 2 \\
17 & 4 \\
18 & 2 \\
19 & 2 \\
20 & 25 \\
21 & 1 \\
22 & 4,5 \\
23 & 1,5 \\
24 & 9 \\
25 & 3,5 \\
26 & 2,5 \\
27 & 10 \\
28 & 10 \\
29 & 14 \\
30 & 5 \\
31 & 10 \\
32 & 15 \\
33 & 6 \\
34 & 3 \\
36 & 9 \\
37 & 2 \\
38 & 4 \\
39 & 13 \\
40 & 7 \\
41 & 2 \\
42 & 16 \\
Média & 6,9 \\
\hline
\end{tabular}


ANEXO L.3

Tabela 3 - Situações relacionadas às DTMs segundo a opinião da amostra de 40 pacientes atendidos na clínica de oclusão da FORP - USP

\begin{tabular}{|c|l|}
\hline Paciente & Situações relacionadas às DTMs \\
\hline 1 & Tensão \\
2 & Qualquer situação \\
3 & Tensão \\
4 & Final da tarde e ambiente doméstico \\
5 & Despertar e mastigação de alimentos duros \\
7 & Qualquer situação \\
8 & Estresse \\
9 & Qualquer situação \\
10 & Qualquer situação \\
11 & Mastigação \\
12 & Tensãão e grande abertura de boca \\
14 & Despertar, mastigação e ato de bocejar \\
15 & Qualquer situação porém agrava-se com a mastigação \\
16 & Qualquer situação \\
17 & Tensão, sono e barulho \\
18 & Mudança de tempo e mastigação de alguns alimentos \\
19 & Tensão, ambiente de trabalho e escolar. Ao assistir TV \\
20 & Tensão, sono e despertar \\
21 & Abertura de boca \\
22 & Final da tarde \\
23 & Agrava-se ao despertar porém, aparece em qualquer situação \\
24 & Qualquer situação \\
25 & Qualquer situação \\
26 & Mudança de temperatura \\
27 & Qualquer situação \\
28 & Qualquer situação porém, agrava-se ao abrir a boca \\
29 & Barulho e ao sair de casa \\
30 & Tensão, grande abertura de boca, mastigação de alimentos duros \\
31 & Ansiedade e despertar \\
32 & Qualquer situação \\
33 & Agrava-se com tensão e quando conversa \\
34 & Despertar, mudança de tempo e concentração \\
36 & Período menstrual \\
37 & Qualquer situação \\
38 & Nervosismo \\
39 & Qualquer situação \\
40 & A dor aparece em qualquer situação. Os estalos somente quando \\
41 & abre muito a boca. \\
42 & Qualquer situação \\
& Em qualquer situação, porém, quando fica nervosa a dor é maior \\
& porque aperta mais os dentes \\
\hline
\end{tabular}


ANEXO L.4

Tabela 4 - Causas do problema segundo a amostra de 40 pacientes atendidos na clínica de oclusão da FORP-USP com diagnóstico de DTM

\begin{tabular}{|l|l|}
\hline Paciente & Causas do problema \\
\hline 1 & Perda de dente \\
2 & Má oclusão \\
3 & Tensão, traumatismo na cabeça e má oclusão \\
4 & Não sabe \\
5 & Briquismo, alimentos duros e dificuldade de relacionamento social \\
6 & Genética e uso prolongado de chupeta \\
7 & Falta de dentes \\
8 & Não sabe \\
9 & Estresse \\
10 & Abertura grande de boca em tratamento odontológico \\
11 & Mastigação unilateral \\
12 & Tensão \\
14 & Perda de dentes \\
15 & Enfraquecimento de dentes devido à falta de informações e de recursos \\
16 & Falta de dentes e má formação óssea \\
17 & Tensão e espongilite anquilosante na coluna \\
18 & Não sabe \\
19 & Não sabe porque cada profissional que procurou apontou uma causa. \\
20 & Tensão \\
21 & Não sabe \\
22 & Ansiedade e tensão \\
23 & Não sabe \\
24 & Problema nas ATMs \\
25 & Falta de dentes \\
26 & Estresse \\
27 & Perda de dentes \\
28 & Não sabe \\
29 & Tensão e traumatismos constantes na cabeça quando pequena \\
30 & Não sabe \\
31 & Falta de dentes, traumatismos na cabeça e ansiedade \\
32 & Tensão \\
33 & Tensão e preocupação \\
34 & Falha de dente \\
36 & Tensão pré menstrual e pancada no pescoço há 12 anos \\
37 & Não sabe \\
38 & Nervosismo \\
39 & Não sabe \\
40 & Falta de dentes \\
41 & Má oclusão \\
42 & Falta de dentes \\
\hline
\end{tabular}




\section{ANEXO L.5}

Tabela 5 - Profissionais consultados (com respectivos tratamentos) pela amostra de 40 pacientes atendidos na clínica de oclusão da FORP-USP

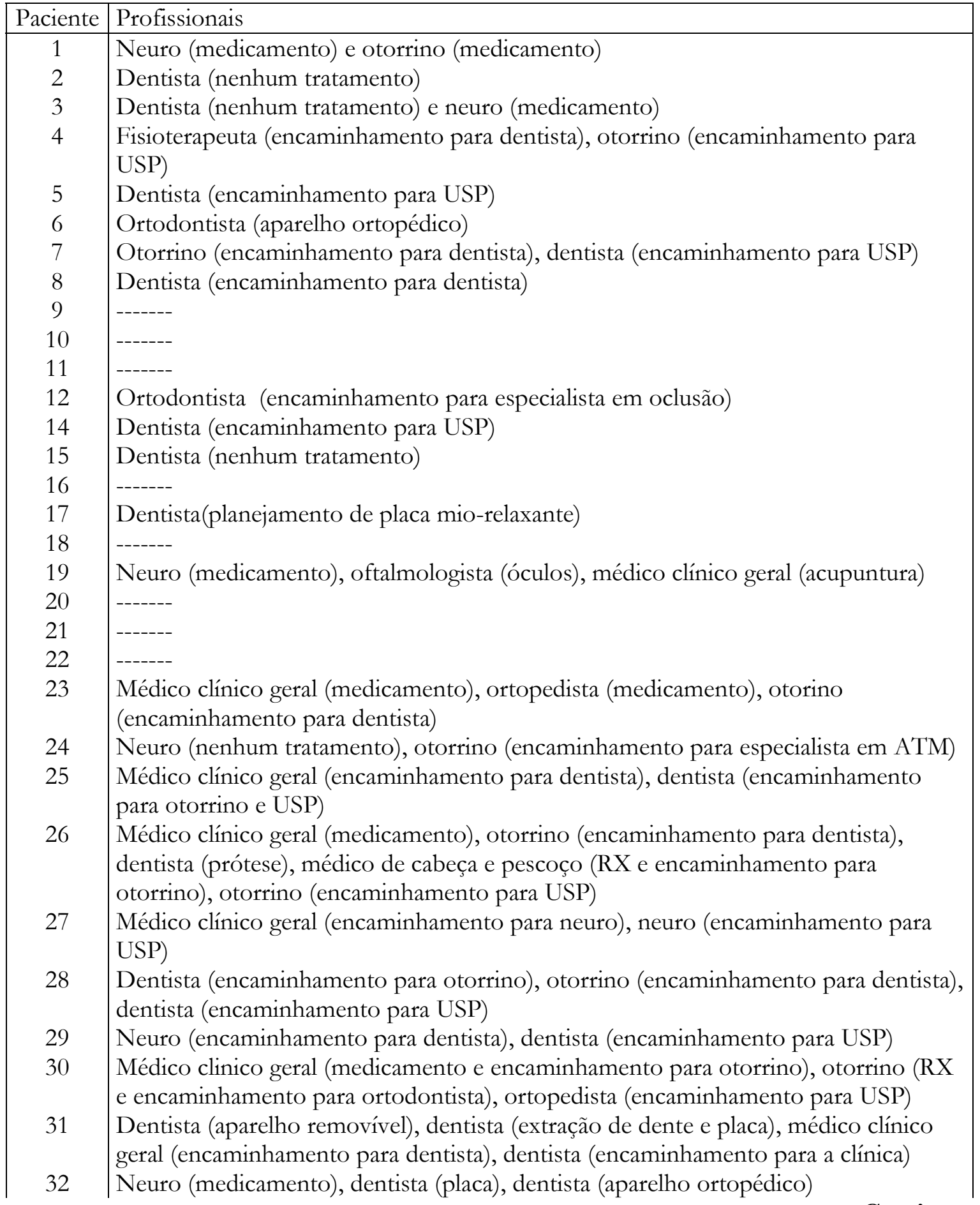




\section{Conclusão}

Tabela 5 - Profissionais consultados (com respectivos tratamentos) pela amostra de 40 pacientes atendidos na clínica de oclusão da FORP-USP

\begin{tabular}{|c|c|}
\hline 33 & Médico clínico geral (encaminhamento par otorrino), otorrino (medicamento e \\
\hline 34 & $\begin{array}{l}\text { Otorrino (medicamento e encaminhamento dentista), Neuro (medicamento), } \\
\text { Dentista (encaminhamento USP) }\end{array}$ \\
\hline 36 & Neuro (medicamento e encaminhamento USP) \\
\hline 37 & Neuro (medicamento e encaminhamento dentista), Dentista (encaminhamento USP) \\
\hline 38 & $\begin{array}{l}\text { Neuro (medicamento e encaminhamento otorrino), Otorrino (medicamento e } \\
\text { encaminhamento dentista), Dentista (encaminhamento USP) }\end{array}$ \\
\hline 39 & $\begin{array}{l}\text { Clínico geral (medicamento e encaminhamento otorrino), Otorrino (medicamento e } \\
\text { encaminhamento psiquiatra), Psiquiatra (medicamento e terapia e encaminhamento } \\
\text { otorrino), Otorrino (medicamento e encaminhamento USP) }\end{array}$ \\
\hline 40 & $----_{-1}^{-1}$ \\
\hline 41 & ------ \\
\hline 42 & $\begin{array}{l}\text { Dentista (encaminhamento USP), otorrino (RX, medicamento e novo } \\
\text { encaminhamento USP) }\end{array}$ \\
\hline
\end{tabular}


ANEXO L.6

Tabela 6 -Queixas secundárias da amostra de 40 pacientes atendidos na clínica de oclusão da FORP-USP

\begin{tabular}{|c|l|}
\hline Paciente & Queixas secundárias \\
\hline 1 & Labirintite \\
2 & Obesidade \\
3 & Solidão e pessimismo \\
4 & ------- \\
5 & Ausência de sobrancelha \\
6 & -------- \\
7 & ------ \\
8 & ------- \\
9 & ------- \\
10 & Enxaqueca \\
11 & -------- \\
12 & Síndrome do Túnel de Carpo \\
14 & ------- \\
15 & Inibição \\
16 & Tensão no pescoço e dor no peito \\
17 & ------- \\
18 & Dor no lado direito da cabeça \\
19 & ------- \\
20 & Aversão a medicamentos \\
21 & Dor na perna \\
22 & Obesidade \\
23 & -------- \\
24 & -------- \\
25 & ------ \\
26 & Disritmia cardíaca \\
27 & ------- \\
28 & ------- \\
29 & Tensão Pré Menstrual \\
30 & --------- \\
31 & ----- \\
32 & Estresse \\
33 & Descontrole emocional \\
34 & ------- \\
36 & Situação financeira ruim \\
37 & Tensão emocional \\
38 & ----- \\
39 & Dor na perna \\
40 & Alergia \\
41 & -------- \\
42 & -------- \\
\hline
\end{tabular}




\section{ANEXO L.7}

Tabela 7 - Porcentagens de relatos de doença (Atual/Recente), uso de medicação, história de traumatismo, cirurgia, infecção (Atual /Recente) e Bruxismo e/ou Briquismo em uma amostra de 40 pacientes atendidos na clínica de oclusão da FORP- USP

\begin{tabular}{|c|c|}
\hline DOENÇA & $37,5 \%$ \\
& $(12,5 \%$ recentes e $25 \%$ atuais $)$ \\
\hline & $52,5 \%$ \\
MEDICAÇÃO & $(15 \%$ analgésico $)$ \\
\hline TRAUMATISMO & $35 \%$ \\
\hline CIRURGIA & $70 \%$ \\
\hline INFECÇ̃̃O & $24 \%$ \\
& $(\%$ recentes, $\%$ atuais e $\%$ não lembram $)$ \\
\hline BRUXISMO/BRIQUISMO & $87,5 \%$ \\
& $(40 \%$ BRU e BRI; $42,5 \%$ BRI e $5 \%$ BRU $)$ \\
\hline
\end{tabular}

Tabela 8 - Porcentagens de relatos de dificuldade para mastigar e mudança de alimentação em uma amostra de 40 pacientes atendidos na clínica de oclusão da FORP- USP

\begin{tabular}{|c|c|}
\hline DIFICULDADE DE MASTIGAÇÃO & $67,5 \%$ \\
\hline MUDANÇA DE ALIMENTAÇÃO & $37,5 \%$ \\
\hline
\end{tabular}




\section{ANEXO L.8}

Tabela 9 - Influência da DTM nas atividades interpessoais e reação das pessoas segundo o relato de uma amostra de 40 pacientes atendidos na clínica de oclusão da FORP- USP

\begin{tabular}{|c|c|c|}
\hline Paciente & Influência da DTM nas atividades & Reação das pessoas \\
\hline 1 & Fica nervosa e agitada & Comentam \\
\hline 2 & $\begin{array}{l}\text { Não influenciou porque é uma pessoa } \\
\text { preservada }\end{array}$ & Espantam-se \\
\hline 3 & Fica sem paciência & Ficam agitadas \\
\hline 4 & Não influenciou & Aconselham a procurar um médico \\
\hline 5 & Não influenciou & Não sabe dizer \\
\hline 6 & Não influenciou & Aconselham a procurar tratamento \\
\hline 7 & Fica irritada & Dão conselhos \\
\hline 8 & Fica mais calada & Comentam \\
\hline 9 & Fica nervosa com os filhos & Ficam bravos \\
\hline 10 & Não influenciou & Ficam irritados \\
\hline 11 & $\begin{array}{l}\text { Afastou-se das pessoas porque tem medo } \\
\text { de que ouçam os estalos }\end{array}$ & Não sabe \\
\hline 12 & Não influenciou & Não percebem \\
\hline 14 & Não influenciou & Não percebem \\
\hline 15 & $\begin{array}{l}\text { Fica com vergonha de sorrir e de falar } \\
\text { muito }\end{array}$ & Reparam e fazem perguntas \\
\hline 16 & Não influenciou & Esposa aconselha a ir ao dentista \\
\hline 17 & Não influenciou & $\begin{array}{l}\text { Ficam com pena e aconselham a tomar } \\
\text { cuidado }\end{array}$ \\
\hline 18 & Fica nervosa & Esposo compreende e fica quieto \\
\hline 19 & Não influenciou & Não percebem \\
\hline 20 & Fica impaciente com os filhos & Os filhos se distanciam \\
\hline 21 & Não influenciou & Namorada aconselha a procurar ajuda \\
\hline 22 & Procura se isolar & Família respeita \\
\hline 23 & Fica mais nervosa & Não entendem e chegam a duvidar \\
\hline 24 & Fica mais irritado e sente um vazio. & A mãe não entende \\
\hline 25 & Não conta para os outros o que sentem & Não percebem \\
\hline 26 & Afastou-se da sociedade & Namorado fica nervoso \\
\hline 27 & Fica mal humorada e irritada & Não falam nada \\
\hline 28 & Não influenciou & Aconselham a procurar um dentista \\
\hline 29 & Fica chateada e não fala com as pessoas & $\begin{array}{l}\text { Não entendem e falam que não têm } \\
\text { nada a ver com o problema }\end{array}$ \\
\hline 30 & Afastou-se dos outros & Não percebem \\
\hline 31 & Não influenciou & Duvidam \\
\hline 32 & Não influenciou & Aconselham a procurar um médico \\
\hline 33 & Fica irritada & As pessoas se afastam \\
\hline
\end{tabular}

Continua 


\section{Conclusão}

Tabela 9 - Influência da DTM nas atividades interpessoais e reação das pessoas segundo o relato de uma amostra de 40 pacientes atendidos na clínica de oclusão da FORP- USP

\begin{tabular}{|l|ll|}
\hline 34 & Fica muito nervosa & A filha não compreende \\
36 & Afasta-se dos outros, quer se isolar & Criticam \\
37 & Não influenciou & Aconselham a procurar um médico \\
38 & Fica nervosa e estressada com todos & Respeitam \\
39 & Fica nervosa e agressiva & A maioria não entende e acham que é \\
& & chatice \\
40 & Não influenciou & Não percebem \\
41 & Não influenciou & Não percebem \\
42 & Fica irritada & Dizem que é estresse \\
\hline
\end{tabular}


REFERÊNCIAS

BIBLIOGRÁFICAS 
Arima, T. \& Svensson, P. Experimental Grinding in Healthy Subjects: A Model for Postexercise Jaw Muscle Soreness? J Orofacial Pain, v. 13, n.2, p. 104-114, 1999.

Borg, G. Borg's Perceived Exertion and Pain Scales. United States: Human Kinetics, 1998 .

Borg, G. \& Borg, E. Principles and Experiments in Category Ratio Scaling. Reports from the Department of Psychology, Stockholm University, v. 789, p. 1 - 30, 1994.

A New Generation of Scaling Methods: Level-Anchored Ratio Scaling. Psychologica, v. 28, p. 15 - 45, 2001.

Borg, G. \& Lindblad, I.. The Determination of Subjective Intensities in Verbal Descriptions of Symptoms. Reports from the Institue of Applied Psycholoy. The University of Stockholm, v.75, 1976.

Bueno, F. S. Minidicionário da Língua Portuguesa. Ed. revista e atualizada. São Paulo: FTD: LISA, 1996.

Caldana, R.H.L. \& Silva, A.M.B.R. As Disfunções Temporomandibulares sob o Enfoque Psicológico: Da Etiologia à Terapêutica. In: Nunes, L.J. Alterações fonaudiológicas, fisioterapêuticas e psicológicas nos distúrbios da ATM. SP: Pancast. (no prelo).

Camparis, C.M. \& Cardoso Júnior, C. A psicologia da dor - aspectos de interesse do cirurgiãodentista. Disponível em: www.odontologia.com.br. Acesso em 22/09/2002.

Carlson, A.M.. Assessment of Chronic Pain. Aspects of the Reliability and Validity of the Visual Analogue Scale. Pain 2 v. 16, p. 87-101, 1983.

Carniel, I.C.. Determinantes Psicossociais das Disfunções Temporomandibulares: Um Estudo Sobre Atitudes Para Posterior Atendimento a Pacientes. Dissertação (Mestrado) Psicologia, Faculdade de Filosofia, Ciências e Letras de Ribeirão Preto - USP, 1997. 
O Acompanhamento Psicológico no Tratamento das Disfunções Temporomandibulares: Uma Proposta de Grupos Operativos com Pacientes. Ribeirão Preto, Tese (Doutorado) Psicologia, Faculdade de Filosofia, Ciências e Letras de Ribeirão Preto USP, 2001.

Carvalho, E.K.; Pavão, R.F.; Zuccolotto, M.C.C.; Bataglion, C. \& Coronatto, E.A.S. Perfil dos Pacientes Portadores de Disfunção Temporomandibulares que Foram Encaminhados ao NODAU (Núcleo de Oclusão, Disfunções Temporomandibulares e Algias Faciais da UNAERP) no período de agosto de 1999 a junho de 2000. Revista de Odontologia. Universidade de Ribeirão Preto (UNAERP), v. 3, n. 2, p. 92-98, 2000.

Chapman, C.R. \& Syrjala, K.L. Measurement of pain. In: The Measurement of Pain. Philadephia: Lea and Febiger, p. 580, 1991.

Conti, P.C.R.; Azevedo, L.R., Souza, N.V.W. \& Ferreira, F.V. Pain assessment in TMD patients: evaluation of precision and sensitivity of different scales. Journal of Oral Rehabilitation, v.28, p. $534-539,2001$.

Cunha, AG. Dicionário Etimológico Nova Fronteira da Língua Portuguesa. RJ: Nova Fronteira, 1982.

Damante, J.H. Curso de Diagnóstico da Dor Facial. Revista Gaúcha de Odontologia, v.38, p. 4, p. 316-318, 1990.

Egermark, I., Carlsson, G.E. \& Magnusson, T. A 20-year longitudinal study of subjective symptoms of temporomandibular disorders from childhood to adulthood.. Acta Odontologica Scandinavia., v. 59, p. 40-48, 2001.

Felicio, C.M. \& Mazzetto, M.O.O Significado da Dor nas Disfunções Crâniomandibulares. Semina: Revista Cultural e Cientifica da Universidade Estadual de Londrina , v. 15, n. 2, p.193 - 195, 1994. 
Gaudet, E.L.Jr \& Brown, D.T. Temporomandibular Disorder Treatment Outcomes: First Report of a Large-Scale Prospective Clinical Study. Cranio, v. 18, n. 1, p. 9-22, 2000.

Gescheider, G.A Psychophysics. The Fundamentals. Third Edition. New Jersey: Mahwah, 1997.

Gracely, R.H.; Dubner, R.; McGrath, P. and Heft, M. New methods of pain measurement and their application to pain control. Pain Measurement and Pain Control, v. 28, n. 1, p. 52 - 65, 1980.

Gracely, R.H. \& Naliboff, B.D. Measurement of Pain Sensation. IN: Kruger, L. Pain and Touch. Ed. Handbook of Perception and Cognition Second Edition, p. 243 - 313, 1996.

Gracely, R.H. \& Wolskee, P.J. Semantic Functional Measurement of Pain: Integrating Perception and Language. Pain, v. 15, p. 389-398, 1983.

Gil, I.A.; Barbosa, C.M.R.; Pedro, V.M.; Silveiro, K.C.A.; Goldfarb, D.P.; Fusco, V. \& Navarro, C.M. Multidisciplinary Approach to Chronic Pain from Myofascial Pain Dysfunction Syndrome: A Four Year Experience at a Brazilian Center. The Journal of Craniomandibular Practice, v.16, n. 1, p. 17-25, 1998.

Harms-Ringdahl, K.; Carlsson, A.M.; Ekholm, J.; Raustorp, A.; Svensson, T. \& Toresson H. Pain Assessment with Different Intensity Scales in Response to Loading of Joint Structures. Pain, v. 27, p. 401-411, 1986.

Henrikson, T. \& Nilner, M. Temporomandibular Disorders and the Need for Stomatognathic Treatment in Orthodontically treated and Untreated Girls. Eur. Journal Orthodontic, v. 22, n. 3, p. 283-292, 2000.

Huskisson, E.C. Visual Analogue Scales. In: Melzack, R. Pain Measurement and Assessment, New York: Raven Press, p. 33-37, 1983.

Int. Association For The Study of Pain, Subcommittee on Taxonomy, Classification of Chronic Pain: descriptions of chronic pain syndromes and definitions of pain terms. Pain, Suppl. 3, 1986. 
Jensen, M.P.; Karoly, P. \& Braver, S. The Measurement of Clinical Pain Intensity: A Comparison of Six Methods. Pain, v. 27, p. 117-126, 1986.

Kopp, S. Constancy of Clinical Signs in Patients with Mandibular Dysfunction. Community Dent. Oral Epidemiol., v. 5, p. 94-98, 1977.

Krogstad, B.S., Jokstad, A., Dahl, B.L. \& Vassend, O. The Reporting of Pain, Somatic Complaints and Anxiety in a Group of Patients with TMD Before and 2 Years After Treatment: Sex Differences. Journal of Orofacial Pain, v. 10, n. 3, p. 263-269, 1996.

Krogstad, B.S., Jokstad, A. \& Dahl, B.L. Somatic Complaints, Psychologic Distress and Treatment Outcome in 2 Groups of TMD Patients, One Previously Subjected to Whiplash Injury. Journal of Orofacial Pain, v. 12, n. 2, p. 136-143, 1998.

Le Resche, L.; Burgess, J. \& Dworkin, S.F. Reliability of Visual Analog and Verbal Descriptor Scales for “Objective” Measurement of Temporomandibular Disorder Pain. J. Dent Res, v. 67, n. 1, p. 33-36, 1988.

Le Resche, L.; Dworkin, S.F.; Wilson, L. \& Ehrlich, K.J. Effect of Temporomandibular Disorder Pain Duration on Facial Expressions and Verbal Report of Pain. Pain, v. 51, p. 289-295, 1992.

Le Resche, L. Epidemiology of temporomandibular disorders: implications for the investigation for etiologic factors. Critical Reviews in Oral Biology and Medicine, v. 8, p. 291-305, 1997.

Linton, S.J. \& Götestam, K.G. A Clinical Comparison of two Pain Scales: Correlation, Remembering Chronic Pain, and a Measure of Compliance. Pain, v. 17, p. 57-65, 1983.

Linton, S.J. \& Melin, L. The Accuracy of Remembering Chronic Pain. Pain, v. 13, n. 3, p. 281-285, 1982. 
Magnusson, T.; List, T. \& Helkimo, M.. Self-assessment of pain and discomfort in patients with temporomandibular disorders: a comparison of five different scales with respect to their precision and sensitivity as well as their capacity to register memory of pain and discomfort. Journal of Oral Rehabilitation, v. 22, p. 549-556, 1995.

Molina, O.F. (1999) O Problema da dor na ATM. In: Interlandi, S. Ortodontia, bases para a iniciação. SP: Artes Médicas, p. 393-434.

Neely, G. W. Category-ratio scaling of sensory magnitude in comparison with other methods. Doctoral Dissertation. Department of Psychology, Stockholm University, Sweden, 1995.

Okeson, J.P. Dor orofacial, guia de avaliação, diagnóstico e tratamento de Bell. São Paulo: Quintessence editora, 1998

Pereira, L.V. \& Sousa, F.AE.F. Estimação em Categorias dos Descritores da Dor Pós-operatória. Revista latino-americana de enfermagem, v. 6, n.4, p. 41-48, 1998.

Pimenta, C.A M. \& Teixeira, M.J. Avaliação da Dor. Revista Médica, v. 76, n. 1, p. 27-35, 1997.

Price, D.D.; McGrath, P.A.; Rafii, A. \& Buckingham, B. The Validation of Visual Analogue Scales as Ratio Scale Measures for Chronic and Experimental Pain. Pain, v. 17, p. 45-56, 1983.

Rauhala, K.; Oikarinen, K.S. \& Raustia, A.M.. Role of Temporomandibular Disorders (TMD) in Facial Pain: Occlusion, Muscle and TMJ Pain. The Journal of Craniomandibular Practice, v. 17, n. 4, p. 254-261, 1999.

Reading, A. \& Raw, M.. The Treatment of Mandibular Dysfunction Pain. Possible Application of Psychological Methods. Brit. Dent. J., v. 16, p. 201-205, 1976.

Seymour, R. A.; Simpson, J.M.; Charlton, J.E. \& Philips, M.E. An Evaluation of Length and Endphrase of Visual Analogue Scales in Dental Pain. Pain, v.21, p. 177-185, 1985. 
Sipilä, S. Facial pain and temporomandibular disorders. Academic Dissertation. Department of Prosthetic Dentistry and Stomatognathic Physiology, Institute of dentistry, University of Oulu, Finland, 2002.

Siqueira, J.T.T. \& Teixeira, M. J. Dor Orofacial, diagnóstico, terapêutica e qualidade de vida. Curitiba: Ed. Maio, 2001.

Souza, J.A. Síndrome da Articulação Temporomandibular. Revista Gaúcha de Odontologia, v. 38, n. 4, p. 295-298, 1990.

Svensson, P.; List T. \& Hector, G. Analysis of stimulus-evoked pain in patients with myofascial temporomandibular pain disorders. Pain, v. 92, p. 399-409, 2001.

Waddie, N.A Language and pain expression. Journal Advanced Nursing, v. 23, p. 868-872, 1996.

Wilson, L.; Dworkin, S.F.; Whitney, C. \& Le Resche, L. Somatization and Pain Dispersion in Chronic Temporomandibular Disorder Pain. Pain, v. 57, p. 55-61, 1994.

Wilson, R.C. \& Jones, P.W. A Comparison of the Visual Analogue Scale and Modified Borg Scale for the Measurement of Dyspnoea During Exercise. Clinical Science, v. 76, p. 277-282, 1989. 